Argonne

ANL/NE-16/18

\title{
Status Report on Ex-Vessel Coolability and Water Management
}

NE Division 


\section{About Argonne National Laboratory}

Argonne is a U.S. Department of Energy laboratory managed by UChicago Argonne, LLC under contract DE-AC02-06CH11357. The Laboratory's main facility is outside Chicago, at 9700 South Cass Avenue, Argonne, Illinois 60439. For information about Argonne and its pioneering science and technology programs, see www.anl.gov.

\section{DOCUMENT AVAILABILITY}

Online Access: U.S. Department of Energy (DOE) reports produced after 1991 and a growing number of pre-1991 documents are available free via DOE's SciTech Connect (http://www.osti.gov/scitech/)

Reports not in digital format may be purchased by the public from the National Technical Information Service (NTIS):

U.S. Department of Commerce

National Technical Information Service

5301 Shawnee Rd

Alexandria, VA22312

www.ntis.gov

Phone: (800) 553-NTIS (6847) or (703) 605-6000

Fax: (703) 605-6900

Email:orders@ntis.gov

Reports not in digital format are available to DOE and DOE contractors from the Office of Scientific and Technical Information (OSTI):

U.S. Department of Energy

Office of Scientific and Technical Information

P.O. Box 62

Oak Ridge, TN 37831-0062

www.osti.gov

Phone: (865) 576-8401

Fax: (865) 576-5728

Email: reports@osti.gov

\section{Disclaimer}

This report was prepared as an account of work sponsored by an agency of the United States Government. Neither the United States Government nor any agency thereof, nor UChicago Argonne, LLC, nor any of their employees or officers, makes any warranty, express or implied, or assumes any legal liability or responsibility for the accuracy, completeness, or usefulness of any information, apparatus, product, or process disclosed, or represents that its use would not infringe privately owned rights. Reference herein to any specific commercial product, process, or service by trade name, trademark, manufacturer, or otherwise, does not necessarily constitute or imply its endorsement, recommendation, or favoring by the United States Government or any agency thereof. The views and opinions of document authors expressed herein do not necessarily state or reflect those of the United States Government or any agency thereof, Argonne National Laboratory, or UChicago Argonne, LLC. 


\section{Status Report on Ex-Vessel Coolability and Water Management}

prepared by

M.T. Farmer

Division, Argonne National Laboratory

K.R. Robb

Oak Ridge National Laboratory

September 15, 2016 


\section{ACKNOWLEDGEMENTS}

Successful preparation of this report required input and support from several individuals and organizations. Mr. Jeff Gabor and Mr. David Luxat from Jensen Hughes and Mr. Richard Wachowiak from Electric Power Research Institute provided input and advice on modelling needs and approaches that have been implemented as part of this work. Model development activities were funded by the U.S. Department of Energy's Office of Nuclear Energy Light Water Reactor Sustainability Program and the Electric Power Research Institute. This support is greatly appreciated. 
ACKNOWLEDGEMENTS. .. $\mathrm{i}$

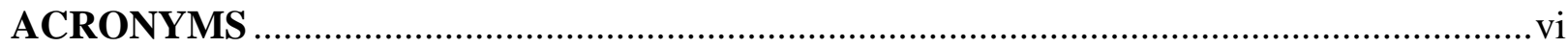

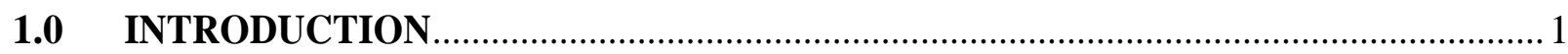

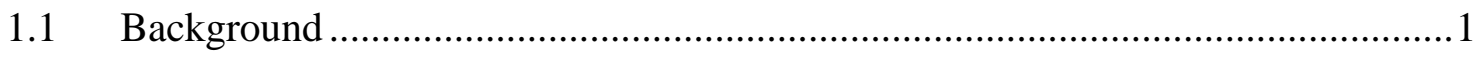

1.2 Technical Objectives ................................................................................2

2.0 STATUS OF MELTSPREAD MODELING IMPROVEMENTS ……….................

2.1 Melt Jet Breakup Model in Water................................................................

2.2 Melt Interaction Model with Below Vessel Structure...........................................7

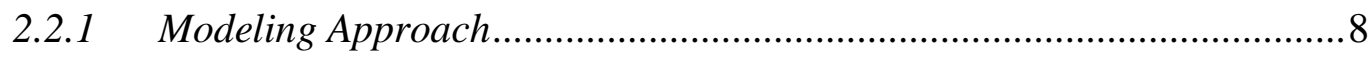

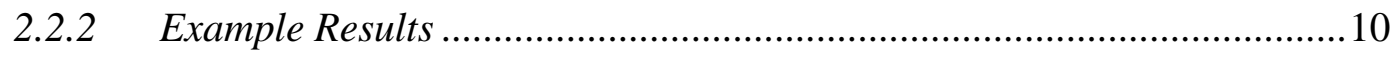

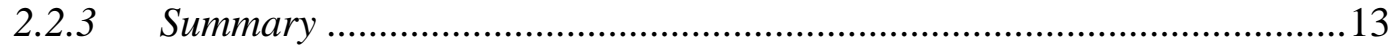

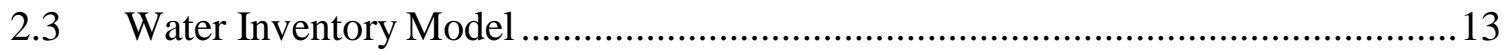

3.0 STATUS OF CORQUENCH MODELING IMPROVEMENTS …….......................15

3.1 Automated Multi-Nodal Analysis Capability .......................................................... 15

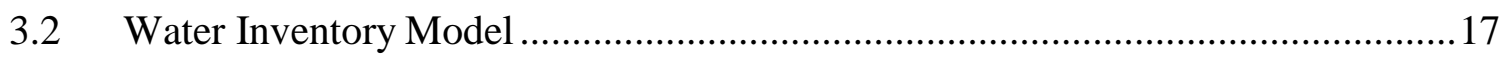

4.0 STATUS OF ANALYSIS TO SUPPORT INDUSTRY IN DEVELOPING AN ALTERNATE WATER ADDITION STRATEGY ………....................................18

5.0 STATUS OF DEBRIS COOLABILITY TESTING ……………...........................19

5.1 Test Specifications and Facility Design ................................................................19

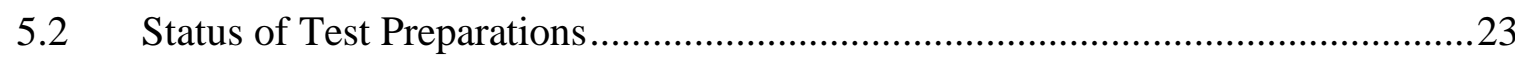

6.0 UPGRADED MODEL APPLICATIONS TO 1F1 ACCIDENT SEQUENCE...........25

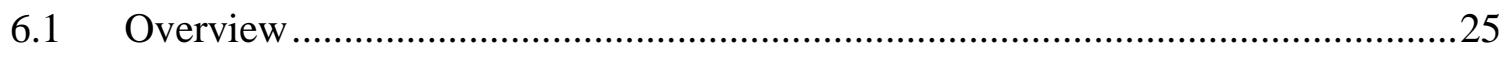

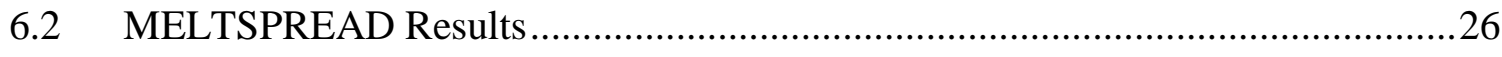

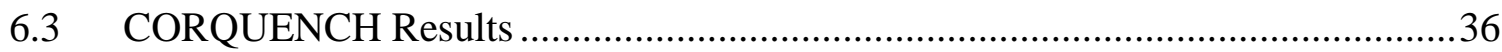

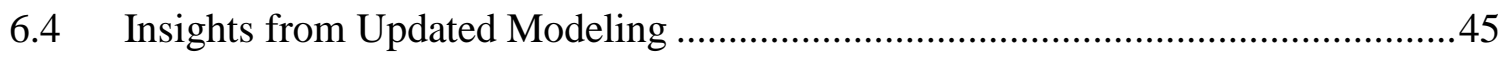

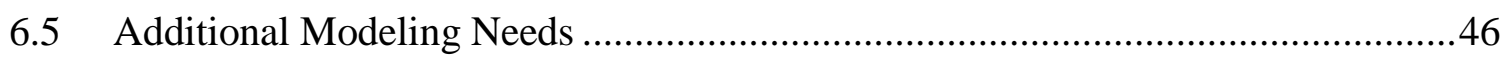

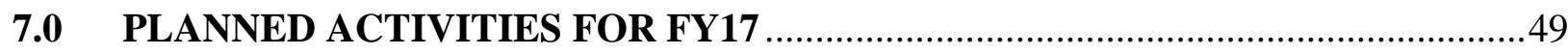

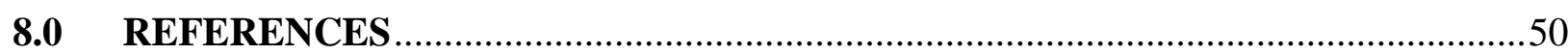




\section{List of Figures}

2-1 Illustration of Unit Cells at Various Axial Elevations

2-2 Local and Cumulative Splashed (left) and Frozen (right) Corium Masses

During Relocation for Scenario III

3-1 Illustration of Simplified Single-Node MCCI Modeling Approach Utilized in CORQUENCH 3.03 [13] 16

3-2 Illustration of BWR Mark I Containment..................................................................16

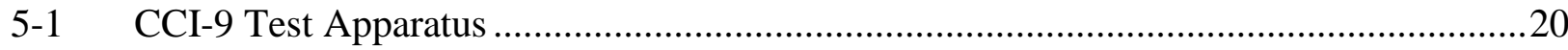

5-2 Top View of Lower Test Section.............................................................................. 21

5-3 Side View of Lower Test Section Showing Electrode Sidewalls.....................................21

5-4 Side Views Showing Non-Electrode Sidewalls and Electrode Clamp Configuration .......22

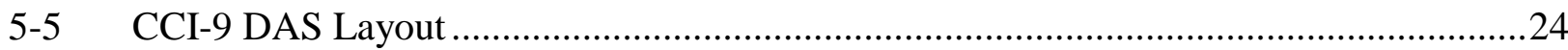

6-1 Piece-Wise Linear Approximations to MAAP (top) and MELCOR (bottom) Melt Pours Used in MELTSPREAD Calculations ..............................................................26

6-2 Predicted Water Depth in Sump and Fraction of Jet Fragmented for MAAP (top) and MELCOR (bottom) Pour Conditions 28

6-3 Predicted Melt Stream Breakup Due to Fragmentation in Sump Water Volume for MAAP (top) and MELCOR (bottom) Pour Conditions

6-4 Steam Production Rate (top) and Water Inventories (bottom) During Melt Relocation for MAAP Pour Conditions 30

6-5 Steam Production Rate (top) and Water Inventories (bottom) During Melt Relocation for MELCOR Pour Conditions

6-6 Melt Temperature-Depth and Water profiles at Sequential Times for MAAP Scenario ..32

6-7 Fukushima Unit 1 Containment Nodalization Scheme.......................................................34

6-8 Post-Spreading Melt Distributions for MAAP (top) and MELCOR (bottom) Pour

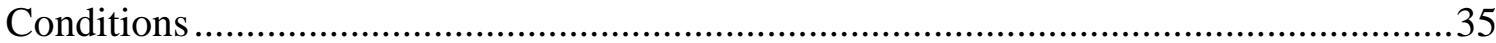

6-9 Best-Estimate of 1F1 RPV Flooding Rate (Courtesy of TEPCO [22, 23]) …...................38

6-10 Best-Estimate of Containment Pressure Variation (Courtesy of TEPCO [21,23])............38

6-11 Principal Integral Results from MAAP Simulation: (a) Water-Steam Flowrates and (b) Masses; (c) Power Distribution, and (d) Core Debris Mass Distribution......................39

6-12 Cumulative Noncondensable Gas Production for MAAP Simulation ................................40

6-13 1F1 Final Ex-Vessel Debris Configuration Based on MAAP Simulation: Quenched and Stabilized After 107 hours. 
6-14 Principal Integral Results from MELCOR Simulation: (a) Water-Steam Flowrates and (b) Masses; (c) Power Distribution, and (d) Core Debris Mass Distribution ..............42

6-15 Cumulative Noncondensable Gas Production for MELCOR Simulation............................43

6-16 1F1 Final Ex-Vessel Debris Configuration Based on MELCOR Simulation: Quenched and Stabilized after 108 hours.........................................................................43

6-17 1F1 Ex-Vessel Debris Configuration and Water Level at 38 Hours into the Accident Sequence Based on MELCOR Input .................................................................4 



\section{List of Tables}

Table

Page

1-1 Summary of FY16 Technical Objectives for Water Management Task........................2

2-1 Assumed Pour Conditions for the Four Pour Scenarios ................................................ 10

2-2 Assumed Dimensions of the Lower Structures...................................................... 11

2-3 Assumed Vertical Dimensions of the Space below the RPV ........................................11

2-4 Analysis Results for the Example Pour Scenarios ................................................11

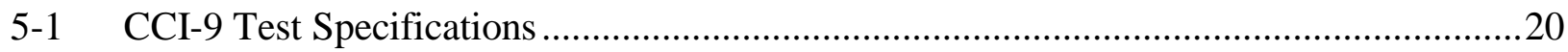

6-1 Melt Spreading Input Data from MELCOR and MAAP Accident Analyses.................25 


\section{ACRONYMS}

AC

ANL

BWR

CCI

CEA

CRD

DEH

DOE

EdF

EPRI

FY

INL

IRSN

MCCI

NRC

OECD

ORNL

PC

$\mathrm{R} \& \mathrm{D}$

RPV

RST

SAG

SAMG

SAWA
Alternating Current

Argonne National Laboratory

Boiling Water Reactor

Core Concrete Interactions

Commissariat à l'énergie Atomique et Aux énergies Alternatives

Control Rod Drive

Direct Electrical Heating

Department of Energy

Electricité de France

Electric Power Research Institute

Fiscal Year

Idaho National Laboratory

Institut de Radioprotection et de Sûreté Nucléaire

Molten Corium Concrete Interaction

Nuclear Regulatory Commission

Organization for Economic Cooperation and Development

Oak Ridge National Laboratory

Personal Computer

Research and Development

Reactor Pressure Vessel

Reactor Safety Technologies

Severe Accident Guidance

Severe Accident Management Guideline

Severe Accident Water Addition 


\section{ACRONYMS (Contd.)}

SAWM Severe Accident Water Management

SNL Sandia National Laboratories

SSWICS Small Scale Water Ingression and Crust Strength

TEPCO Tokyo Electric Power Company, Incorporated

US United States 



\section{STATUS REPORT ON EX-VESSEL COOLABILITY AND WATER MANAGEMENT}

\subsection{INTRODUCTION}

\subsection{Background}

Specific to BWR plants, current accident management guidance calls for flooding the drywell to a level of approximately $1.2 \mathrm{~m}$ (4 feet) above the drywell floor once vessel breach has been determined. While this action can help to submerge ex-vessel core debris, it can also result in flooding the wetwell and thereby rendering the wetwell vent path unavailable. An alternate strategy is being developed in the industry guidance [1] for responding to the severe accident capable vent Order, EA-13-109 [2]. The alternate strategy being proposed would throttle the flooding rate to achieve a stable wetwell water level while preserving the wetwell vent path.

The overall objective of this work is to upgrade existing analytical tools (i.e. MELTSPREAD and CORQUENCH - which have been used as part of the DOE-sponsored Fukushima accident analyses [3] ) in order to provide flexible, analytically capable, and validated models to support the development of water throttling strategies for BWRs that are aimed at keeping ex-vessel core debris covered with water while preserving the wetwell vent path. In particular, there are currently gaps in analysis capability for evaluating core melt relocation and cooling behavior that accounts for several important factors that include:

i) the influence of below vessel structure and pre-existing water on the containment floor on melt stream breakup and subsequent spreading behavior, and

ii) the effect of water throttling on spreading and long term debris coolability.

These gaps have been identified by the RST industry-lab advisory group as high priority items to address [4].

A related factor that can impact flooding strategy is the spatial distribution of core melt in containment following vessel failure and melt spreading. For instance, a localized accumulation of melt in the pedestal region may require a more specific flooding approach in comparison to the situation in which core melt is spread uniformly over the pedestal and drywell floor areas. In the former case, the localized core melt accumulation could form a dam preventing adequate debris flooding and cooling if the water is not injected directly on top the core debris, whereas in the latter case, effective debris flooding is expected regardless of injection point(s) as long as the injection flowrate is high enough to remove both sensible energy and decay heat. These spatial distribution questions, coupled with the overall effectiveness of the debris cooling process, impact the water injection requirements for achieving a balance between injection flowrate versus water boil-off, thereby minimizing extraneous spillover into the wetwell. 
In order to adequately address questions that arise due to the above considerations, there is also a need to develop a multi-nodal modeling capability to address localized core-concrete interaction behavior given actual containment features (e.g. sumps and compartments) that is coupled with a realistic water inventory model that can be used to evaluate water injection strategies. Note that this multi-nodal core-concrete interaction analysis capability was first implemented as part of the earlier Fukushima analyses [3]. However, this work was carried out manually (i.e., the containment was nodalized and individual CORQUENCH cases were run for each node, and then the results were combined using a spread sheet). Furthermore, this early effort did not include a realistic water inventory model. Thus, the current work further aims to automate the multi-nodal CORQUENCH analysis capability, and to interface this capability with a realistic water inventory model to provide an integrated model for assessing long-term water throttling strategies for BWRs.

\subsection{Technical Objectives}

With this background, the specific FY16 technical objectives for this project related to the development of an integrated modeling capability to support optimization of Severe Accident Water Addition (SAWA) and Severe Accident Water Management (SAWM) strategies for BWRs is summarized in Table 1-1. The purpose of this status report is to document progress made towards meeting these FY16 objectives.

Table 1-1. Summary of FY16 Technical Objectives for Water Management Task.

\begin{tabular}{|c|c|c|}
\hline Task & Description & Status \\
\hline \multirow{4}{*}{1} & \multicolumn{2}{|l|}{ Upgrade and Document Melt Spreading Model (MELTSPREAD): } \\
\hline & $1.1 \quad$ Incorporate model for melt jet fragmentation/breakup & Completed \\
\hline & Incorporate model for melt jet interactions with below-vessel structure & $\begin{array}{l}\text { Basic physics } \\
\text { model developed }\end{array}$ \\
\hline & Incorporate detailed water inventory model & Completed \\
\hline \multirow{3}{*}{2} & \multicolumn{2}{|l|}{ Upgrade and Document Core Debris Coolability Model (CORQUENCH): } \\
\hline & 2.1 Upgrade model to include an automated multi-nodal analysis capability & Completed \\
\hline & 2.2 Incorporate detailed water inventory model & Completed \\
\hline \multirow[b]{2}{*}{3} & \multicolumn{2}{|l|}{ Analysis in support of industry to develop an alternate water addition strategy: } \\
\hline & $\begin{array}{l}\text { 3.1 Consult with industry to identify a set of calculations to be performed in } \\
\text { support of the development of SAWA/SAWM strategies. }\end{array}$ & $\begin{array}{l}\text { Initiated; primarily } \\
\text { an FY17 task }\end{array}$ \\
\hline \multirow[b]{2}{*}{4} & \multicolumn{2}{|l|}{ Conduct experiments to validate debris coolability models: } \\
\hline & $\begin{array}{l}\text { 4.1 Conduct test CCI-9 (1-D core-concrete interaction experiment with siliceous } \\
\text { concrete examining water ingression cooling mechanism) }\end{array}$ & $\begin{array}{c}\text { Scheduled for } \\
\text { 24 September } 2016\end{array}$ \\
\hline
\end{tabular}

This report is organized as follows. Section 2 describes the overall approach to, and status of, modeling upgrades to MELTSPREAD (Task 1 in Table 1-1). Similarly, the approach and status of upgrades to CORQUENCH (Task 2) are summarized in Section 3. The status of planned calculations to support industry in the development of a water management strategy 
(Task 3) is described in Section 4. The status of experiments to validate debris coolability models (Task 4) is then summarized in Section 5. In terms of applications, the upgraded MELTSPREAD and CORQUENCH codes are applied to the accident sequence at Fukushima Daiichi Unit 1 (1F1) to illustrate the new predictive capabilities; these results are presented in Section 6. Finally, planned activities for FY17 are summarized in Section 7. 


\subsection{STATUS OF MELTSPREAD MODELING IMPROVEMENTS}

To put the current work in context, it is helpful to first describe the overall approach for applying MELTSPREAD and CORQUENCH to a typical ex-vessel plant accident sequence, which is as follows. Given the time-dependent melt pour conditions from the RPV (i.e., melt composition, pour rate, temperature, RPV hole size, and elevation above the containment basemat) predicted by system-level codes such as MAAP or MELCOR, MELTSPREAD is used to calculate the overall melt spreading distance and mass distribution in containment during the relocation phase from the RPV. These results are then used to develop input for CORQUENCH (with automated software) which then analyzes long-term core-concrete interaction including localized ablation phenomena, water flooding behavior, and finally the extent that the core debris is quenched and rendered permanently coolable.

This section outlines upgrades to MELTPSREAD that are being made to improve the ability of the code to predict melt spreading under realistic plant accident conditions. Specifically, models are being implemented for key phenomena that were not addressed in earlier versions of the code. Appropriate modeling improvements to better support SAWA/SAWM strategy development were defined in a meeting held with industry representatives on 10 October 2015. In this meeting, upgrades to both MELTSPREAD and CORQUENCH were discussed; the CORQUENCH upgrades are summarized in Section 3.

Through this industry consultation, appropriate upgrades to MELTSPREAD were defined as follows (see Table 1-1):

i) incorporate a model for melt jet fragmentation in water during relocation from the RPV,

ii) incorporate a model for melt jet interactions with below-vessel structure, and

iii) incorporate a detailed water inventory model.

Analysis of melt stream breakup in water can impact the extent of spreading by fragmenting and cooling material, thereby reducing the ability of the core melt to spread. The extent of spreading is important as the accumulated debris depth increases as the spreading distance decreases, and deeper melt accumulations are harder to cool and more difficult to cover with water. BWRs have a tremendous amount of below-vessel structure in the form of CRDs and instrument tube penetrations; this structure can act as heat sink that holds up core debris, and also cause the jet to fragment by virtue of interaction with this structure. Both of these occurrences will reduce the extent of spreading. Finally, a critical modeling need for SAWA/SAWM is a physically realistic water inventory model that can account for local elevation differences due to core debris accumulations and/or cavity geometry details, diverse water injection points, spillover into downcomers, and finally heatup and boiloff of water.

A summary of modeling upgrades made to MELTSPREAD in the above defined three areas are summarized in sequence below. 


\subsection{Melt Jet Breakup Model in Water}

A melt jet breakup model was implemented to evaluate the effect of fragmentation in a water pool beneath the RPV on subsequent spreading behavior. The model requires melt pour rate and RPV hole diameter vs. time as inputs, as well as the RPV elevation distance above the pedestal floor. With that information, the code calculates melt jet thinning and acceleration as it falls towards the water pool beneath the RPV under the force of gravity. In particular, given the time-dependent melt fall height $\mathrm{z}$, the melt jet radius and velocity at impact with the top of the water are given through the following equations:

$$
\begin{aligned}
& R(z)=R_{o}\left(1+\frac{2 g z}{U_{o}^{2}}\right)^{-1 / 4} \\
& U(z)=U_{o}\left(1+\frac{2 g z}{U_{o}^{2}}\right)^{1 / 2}
\end{aligned}
$$

In the above, $U$ denotes velocity, $g$ is gravitational acceleration and subscript $o$ denotes conditions at the RPV exit. The code treats $R_{o}(t)$ as user input, and is typically calculated as part of a MAAP analysis, but not for MELCOR. The other main parameter output by these codes is the time-dependent melt pour rate. With that information, the exit velocity from the $\mathrm{RPV}$ is evaluated from the simple expression:

$$
U_{o}=\dot{Q} / \pi R_{0}^{2}
$$

Once the jet impacts the water, the extent of jet fragmentation is calculated using correlations available in the literature. The approach utilized here is the same as that recommended in an OECD/NEA Technical Note on ex-vessel debris coolability [5]; i.e., the potential for coarse jet breakup is calculated based on the Saito correlation [6], while the potential for fine jet breakup is calculated using the Epstein correlation [7] that is based on Kelvin-Helmholtz instability theory. The theoretical jet penetration distance is then set equal to the lesser of these predictions. The Saito correlation is based on jet breakup due to gravity and inertial effects; the expression for maximum jet penetration distance $\mathrm{L}$ is given by [6]:

$$
L / D)_{\text {Saito }}=2.1\left(\frac{\rho_{m}}{\rho_{w}} F r\right)^{1 / 2}
$$

where $\rho$ denotes density, subscripts $m$ and $w$ denote melt and water phases, respectively, and $\mathrm{Fr}$ is the Froude number that is defined as: 


$$
F r=\frac{U^{2}}{2 R g}
$$

In contrast to the Saito correlation, the Epstein model assumes that jet fragmentation occurs due to Kelvin-Helmholtz instability at the interface between the penetrating jet and blanketing steam layer. The correlation for breakup length is of the form [7]:

$$
L / D)_{\text {Epstein }}=\frac{\sqrt{3}}{2}\left(1+\frac{\rho_{s}}{\rho_{m}}\right)\left(\frac{\rho_{m}}{\rho_{s}}\right)^{1 / 2}
$$

where subscript $s$ denotes steam. This model is applicable to high Weber number ( $W e=\rho_{s} U^{2} D / \sigma_{m} ; \sigma_{m}$ is melt surface tension) flow conditions.

As noted earlier, the extent of melt stream breakup is determined by calculating the Saito and Epstein limits through Eqs. 2-4 and 2-6, and then taking the lesser of these two values. Thus, at low entry velocities, breakup is controlled by inertia and gravitational effects, whereas at high flowrates, inertia and surface tension effects control the jet breakup process.

With the theoretical penetration distance $L$ known through the above methodology, the jet is assumed to be completely fragmented and cooled if the theoretical penetration distance is less than the water depth. Conversely, if the water depth is too shallow to completely fragment the melt jet, then the fraction of the jet fragmented is calculated on the basis of the ratio of the actual water depth to the depth required for complete fragmentation. Assuming an idealized geometry in which the coherent jet remains circular and the erosion mass flux from the jet surface remains constant over the penetration distance $L$, then we derive the following equation for the fraction of core debris fragmented when the water pool depth $x_{p}$ is $<L$,

$$
F_{\text {frag }}=\frac{2 x_{p}}{L}\left(1-\frac{x_{p}}{2 L}\right)
$$

Two modeling options are provided for assessing the impact of jet fragmentation on the melt arrival conditions on the pedestal floor. In the first approach, any particulate formed is assumed to re-mix with the melt, which acts to lower (through a thermal equilibration calculation) the effective melt temperature at impact with the floor. This increases viscosity which acts to lower the spreading velocity. In the second approach, the debris fragmented from the jet is assumed to be rendered as a particle bed that resides on top of the remaining coherent melt material that lands and then spreads on the concrete. The assumption is made that the cooling of the remaining coherent jet is minimal, and this material impacts and spreads at the vessel exit temperature. Thus, in this scenario melt temperature is the same, but the melt mass 
available for spreading is reduced. Based on physical observations from reactor material jet fragmentation tests (i.e. Argonne Corium Coolant Mixing (CCM) [8] and FARO tests conducted at ISPRA [10]), the latter scenario is deemed to be most likely.

In the analysis, the time-dependent water depth over the core debris is calculated including the effects of local boil-off of water from the jet fragmentation process, as well as elevation changes due to accumulation of the remaining coherent melt that is not fragmented below the water surface.

The jet fragmentation model has been fully implemented into MELSTPREAD, debugged, checked for numerical accuracy, and has been shown to be numerically stable and reliable over the range of calculations conducted to date. Examples of the impact of jet fragmentation on melt spreading behavior predicted by this model are provided in Section 6.

\subsection{Melt Interaction Model with Below Vessel Structure}

Aside from melt jet fragmentation in water, work progressed on development of analytical methods for evaluating melt stream breakup and holdup in the extensive below vessel structure for BWRs. As shown in Table 1-1, a stand-alone physics-based model has been developed and exercised to predict below vessel melt-structure interactions. The following section briefly describes the modeling scheme and provides example predictions. The stand- alone model will be integrated into the MELTSPREAD architecture in FY17 to provide more realistic predictions of melt arrival conditions on the containment floor for subsequent melt spreading and coolability analyses.

The below vessel structure penetrating a BWR bottom head includes control rod drive (CRD) housings, instrumentation tube penetrations, and a drain line. A network of supports is also located below the bottom head to limit the ejection of a CRD if a failure were to occur. This system includes several support beams that are located near the bottom of the RPV. Connected to these support beams are hangar rods that extend down beyond the ends of the CRD housing. Attached to the hangar rods are support bars. On top of the support bars are grid bars that are located under the CRD housing. These grid bars cradle the CRD and limit movement in the event of CRD ejection. Below the tubes and structural supports there is a maintenance platform used by personnel during component replacement (e.g., CRD replacement). The platform also supports the CRD handling and exchange device used during maintenance.

Core melt would likely interact with the below vessel structures before arriving on the containment floor. The interactions could result in melt being held up and frozen on structures, thereby decreasing the amount of melt arriving on the containment floor. Splashing of melt on the structures could break up the melt pour jet into droplets. These droplets could freeze on the structures, decreasing the amount of melt arriving on the floor. If the droplets do not freeze on the structures, the melt droplets could 'rain' down, changing the characteristic of the melt arriving on the containment floor and subsequent spreading. 
Previously, there has been limited investigation of the impacts of below vessel structure on the melt pour. The possible interaction of a melt pour with the below vessel structures was noted in the Mark I liner vulnerability study [10], but the analysis did not account for any interactions. In the only relevant analysis known to the authors, Chu et al. [11] developed a model that assumed the melt pour interacted with an impeding member until melt-through of that member occurred. The melt-through time accounted for the effects of an intermediate crust and impingement heat transfer. While the impeding member is intact, all the melt pour is splashed onto nearby CRD structures. Based on the line of site, the possible surface area the splashed melt may contact was estimated to be $10 \%$ (i.e. $450 \mathrm{~m}^{2}$ ) of the total available surface area of the lower structures. The amount of melt that freezes onto this contact area versus 'raining out' was based on the conduction-limited crust growth rate equation. In their example simulations that included two long duration pours, a single $2.5 \mathrm{~cm}$ thick impeding member was analyzed. This member was predicted to melt-through in approximately 30 seconds, which limited the amount of melt that was splashed.

\subsubsection{Modeling Approach}

Building on the work of Chu et al. [11], a new model has been developed as part of this study to analyze melt interactions with below vessel structures. The first issue to address is simplifying the complicated geometry of the below vessel structure to provide a basis for a tractable analysis. In the lateral direction, the lower structures were divided into a repeating geometry, defined as a unit cell. The unit cell consists of 1 CRD housing, $1 / 2$ of a hangar rod, and $1 / 4$ of an instrument tube housing. Depending on the axial location, the unit cell can also consist of portions of the support structure and flanges. The unit cells at various locations are illustrated in Figure 2-1.

In terms of modeling flow, ablation, and freezing behavior, the maximum flow rate of melt downwards through a unit cell is based on gravity driven flow. This is determined by equating the forces on the fluid due to gravity and friction (based on melt contact with vertical surfaces in the unit cell). For this calculation, the hydraulic diameter includes all the surface and flow area of the unit cell.

If the pour rate from the RPV is greater than what can be accommodated in one unit cell, then the additional melt is passed to the next unit cell. If the maximum flow rate in the first and second unit cell cannot accommodate the full pour rate from the RPV, the additional melt is passed to the next unit cell. This is repeated until the RPV pour mass flow rate equals the summation of the mass flow rates in all the unit cells. In reality, the melt may spread from one unit cell into four (4) adjacent cells, instead of one. However, with respect to the computational approach, the melt occupying $25 \%$ of four unit cells is equivalent to the melt occupying $100 \%$ of one unit cell.

In each unit cell, two melt-structure interaction phenomena are considered: melt freezing onto vertical surfaces and melt splashing off horizontal surfaces. Melt is modeled to freeze 
onto the vertical surfaces of the CRD housing, instrumentation tube housing, and hangar rods. The crust growth rate is estimated through the modeling of two semi-infinite solids coming into sudden contact (i.e. see Eqs. 5.57 and 5.63 in [12]). The amount of melt that is frozen is then determined based on the crust thickness and surface contact area.

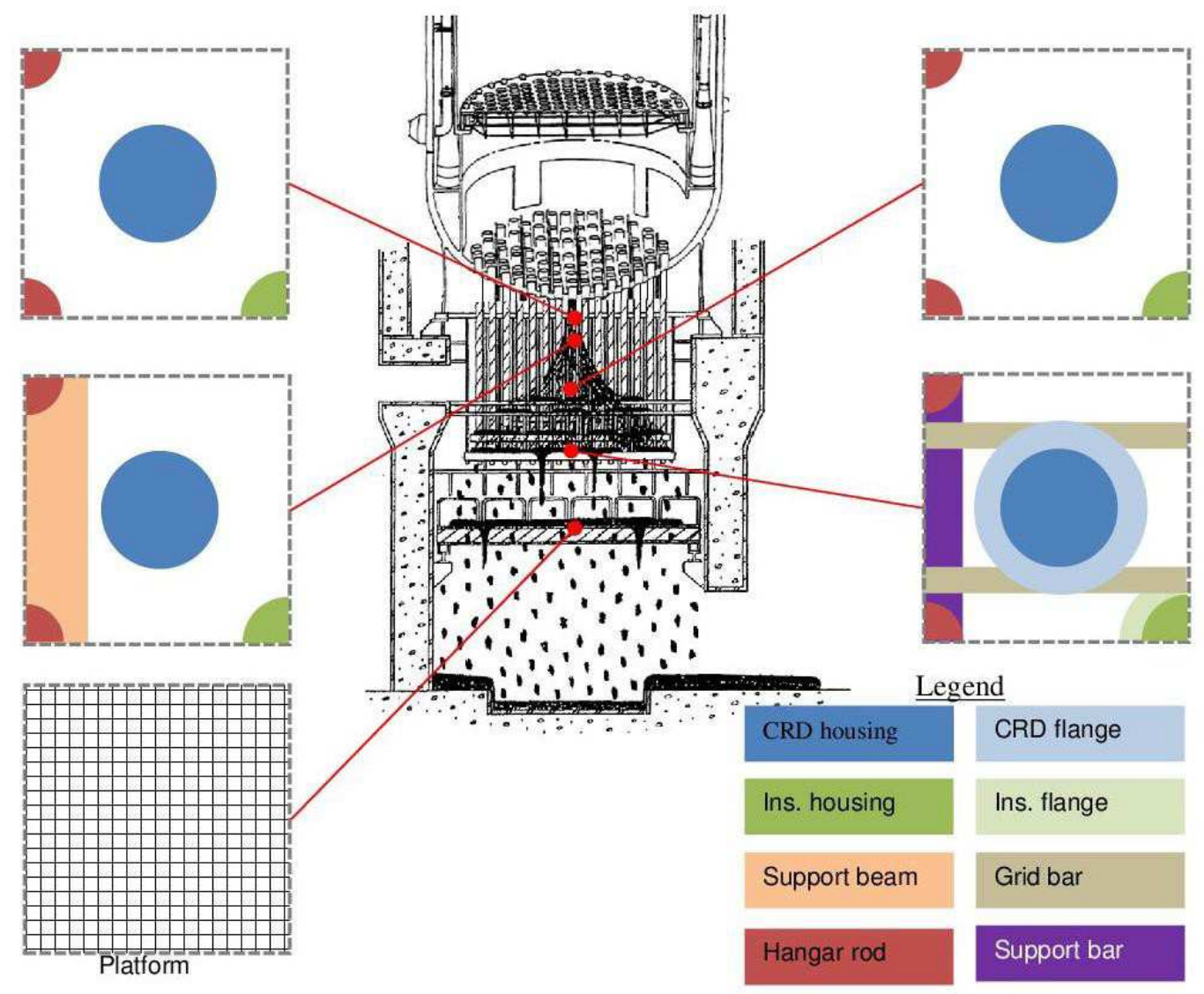

Figure 2-1. Illustration of Unit Cells at Various Axial Elevations.

Melt is modeled to splash of off the horizontal surfaces in three splash zones. The first zone is the support beams. The second zone includes the CRD flanges, instrumentation tube flanges, support bars, and grid bars. The third zone is the maintenance platform. The rate of melt splashing in each zone is estimated by the fraction of the flow area blocked by the horizontal surface area multiplied by the mass flow rate. Over time, the horizontal members erode away. The rate of erosion is modeled by impingement heat transfer and erosion correlations $[13,14]$. After the member has eroded half-way through, the assumed failure point of the member, the splashing ceases in that particular zone of the unit cell. The melt splashed in zone 1 would likely impact nearby structures and freeze. For the melt splashed in zone 2, some would impact and freeze on nearby structures while some portion would fall onto the maintenance platform. For the melt splashed in zone 3, some would freeze on the platform while the rest would pass through and 'rain' onto the containment floor. Currently, the fraction of the splashed melt that freezes on structures versus 'rains out' is not estimated. 


\subsubsection{Example Results}

Four example scenarios were simulated for shakedown testing of the modeling methodology and to provide example results to guide future refinement. The first two scenarios, summarized in Table 2-1, are based on those analyzed as part of the Mark I linear vulnerability study [10]. The pour conditions and thermophysical properties were taken from the paper of Chu et al. [11]. The latter two scenarios, also summarized in Table 2-1, are based on the MELCOR and MAAP predicted pours from the Fukushima Daiichi Unit 1 reactor vessel [3]. These four scenarios cover a wide range of pour conditions to exercise the melt-structure interaction model. Tables 2-2 and 2-3 summarize the assumed dimensions for the various components below the RPV.

Table 2-4 provides the key results from the simulations, while plots illustrating the time- dependent melt splashing and freezing rates for Scenario III are provided in Figure 22. For Scenario I, a long protracted pour of melt near its solidification temperature, a substantial amount of core debris, $28.4 \%$, is predicted to be frozen onto the lower structures. The melt eventually freezes shut 22 unit cells. The grid bars and support bars (zone 2) and maintenance platform floor (zone 3) is eroded through in 22 unit cells. Similar results are predicted for Scenario II, which is a longer pour with more debris at a slightly higher superheat. For Scenario III, a low- temperature pour of medium duration, only four channels are predicted to freeze shut. As such, an order of magnitude less mass is predicted to be frozen on structures compared to Scenarios I and II. Finally, for Scenario IV, a fast pour of high temperature debris, a negligible amount of melt freezes on structures. The hot, fast flowing melt only flows downwards through one unit cell.

Table 2-1. Assumed Pour Conditions for the Four Pour Scenarios

\begin{tabular}{|c|c|c|c|c|}
\hline Density $\left(\mathrm{kg} / \mathrm{m}^{3}\right)$ & $\begin{array}{c}\text { Scenario I } \\
\text { (Scenario I in } \\
[11]) \\
8500\end{array}$ & $\begin{array}{c}\text { Scenario II } \\
\text { (Scenario II in } \\
[11]) \\
*\end{array}$ & $\begin{array}{c}\text { Scenario III } \\
\text { (MELCOR in } \\
[3]) \\
7300\end{array}$ & $\begin{array}{c}\text { Scenario IV } \\
\text { (MAAP-LP in } \\
{[3] \text { ) }} \\
7300\end{array}$ \\
\hline Specific heat $(\mathrm{J} / \mathrm{kg} \mathrm{K})$ & 485 & 622 & 530 & 530 \\
\hline Thermal conductivity (W/m K) & 16.8 & 24.15 & 5.0 & 5.0 \\
\hline Pour temperature $\left({ }^{\circ} \mathrm{C}\right)$ & 2437 & 1594 & 1702 & 2500 \\
\hline Pour freeze temperature $\left({ }^{\circ} \mathrm{C}\right)$ & 2400 & 1507 & 1687 & 1595 \\
\hline Melt viscosity (Pa s) & 0.0048 & 0.005 & 1.5 & 0.005 \\
\hline Total pour duration $(\mathrm{s})$ & 9299 & 23200 & 4030 & 17.5 \\
\hline Total pour mass $(\mathrm{kg})$ & 169800 & 347000 & 140950 & 140328 \\
\hline Pour rate $(\mathrm{kg} / \mathrm{s})$ & $\begin{array}{rr}t<189, & 560 \\
t \geq 189, & 7\end{array}$ & $\begin{array}{lr}\mathrm{t}<12000, & 18.7 \\
\mathrm{t} \geq 12000, & 11\end{array}$ & $34.975^{* *}$ & $8018.7 * *$ \\
\hline
\end{tabular}

* For time < $12000 \mathrm{~s}$, the density is $7480 \mathrm{~kg} / \mathrm{m}^{3}$; for later times, the density is $8210 \mathrm{~kg} / \mathrm{m}^{3}$.

** Time average flow rate is used. 
Table 2-2: Assumed Dimensions of the Lower Structures.

\begin{tabular}{|c|l|c|}
\hline Component & \multicolumn{1}{|c|}{ Parameter } & $\begin{array}{c}\text { Dimension } \\
\text { (cm) }\end{array}$ \\
\hline \multirow{4}{*}{ CRD } & Pitch & 30.5 \\
\cline { 2 - 3 } & Housing OD & 15.2 \\
\cline { 2 - 3 } & Flange OD & 25.4 \\
\cline { 2 - 3 } & Flange height & 15.2 \\
\hline $\begin{array}{c}\text { Instrumentation } \\
\text { Tube }\end{array}$ & Housing OD & 5.1 \\
\cline { 2 - 3 } & Flange OD & 10.2 \\
\hline Hangar Rod & OD & 3.8 \\
\hline Support Beam & Width & 6.4 \\
\hline \multirow{2}{*}{ Grid Bar } & Width & 2.5 \\
\cline { 2 - 3 } & Height & 15.2 \\
\hline \multirow{2}{*}{ Support Bar } & Width & 2.5 \\
\cline { 2 - 3 } & Height & 15.2 \\
\hline \multirow{3}{*}{ Platform Floor } & Web thickness & 0.6 \\
\cline { 2 - 3 } & Pitch & 3.2 \\
\cline { 2 - 3 } & Floor thickness & 3.8 \\
\hline
\end{tabular}

Table 2-3. Assumed Vertical Dimensions of the Space below the RPV.

\begin{tabular}{|l|c|}
\hline \multicolumn{1}{|c|}{ Description } & $\begin{array}{c}\text { Vertical Distance } \\
(\mathbf{m})\end{array}$ \\
\hline Bottom of vessel to support beams & 0.3 \\
\hline Support beams height & 0.3 \\
\hline Bottom of support beams to top of CRD flange & 2.4 \\
\hline Top of CRD flange to bottom of support bar & 0.3 \\
\hline Bottom of support bar to top of platform & 2.1 \\
\hline Platform thickness & 0.3 \\
\hline Bottom of platform to pedestal floor & 4.9 \\
\hline
\end{tabular}

Table 2-4. Analysis Results for the Example Pour Scenarios.

\begin{tabular}{|l|c|c|c|c|}
\hline \multicolumn{1}{|c|}{ Parameter } & $\begin{array}{c}\text { Scenario I } \\
\text { (Scenario I } \\
\text { in [11]) }\end{array}$ & $\begin{array}{c}\text { Scenario II } \\
\text { (Scenario } \\
\text { II in [11]) }\end{array}$ & $\begin{array}{c}\text { Scenario III } \\
\text { (MELCOR } \\
\text { in [3]) }\end{array}$ & $\begin{array}{c}\text { Scenario IV } \\
\text { (MAAP-LP } \\
\text { in [3] }\end{array}$ \\
\hline Total unit cells with melt & 23 & 36 & 5 & 1 \\
\hline Total unit cells plugged by solidified melt & 22 & 35 & 4 & 0 \\
\hline Total mass of frozen melt (kg) & 48173 & 72361 & 7965 & 61 \\
\hline Total mass splashed in zone 1 (kg) & 21799 & 41187 & 18290 & 6116 \\
\hline Total mass splashed in zone 2 (kg) & 81592 & 161484 & 81105 & 14199 \\
\hline Total mass splashed in zone 3 (kg) & 10217 & 21307 & 12227 & 519 \\
\hline Percent of mass of frozen melt (\%) & 28.4 & 20.9 & 5.7 & 0.04 \\
\hline Percent of mass splashed in zone 1 (\%) & 12.8 & 11.9 & 13.0 & 4.4 \\
\hline Percent of mass splashed in zone 2 (\%) & 48.1 & 46.5 & 57.5 & 10.1 \\
\hline Percent of mass splashed in zone 3 (\%) & 6.0 & 6.1 & 8.7 & 0.4 \\
\hline $\begin{array}{l}\text { Number of unit cells with eroded-though } \\
\text { beams in zone 1 }\end{array}$ & 0 & 35 & 4 & 1 \\
\hline $\begin{array}{l}\text { Number of unit cells with eroded though } \\
\text { beams in zone 2 }\end{array}$ & 22 & 35 & 4 & 1 \\
\hline $\begin{array}{l}\text { Number of unit cells with eroded floor in } \\
\text { zone 3 }\end{array}$ & 22 & 35 & 4 & 1 \\
\hline
\end{tabular}



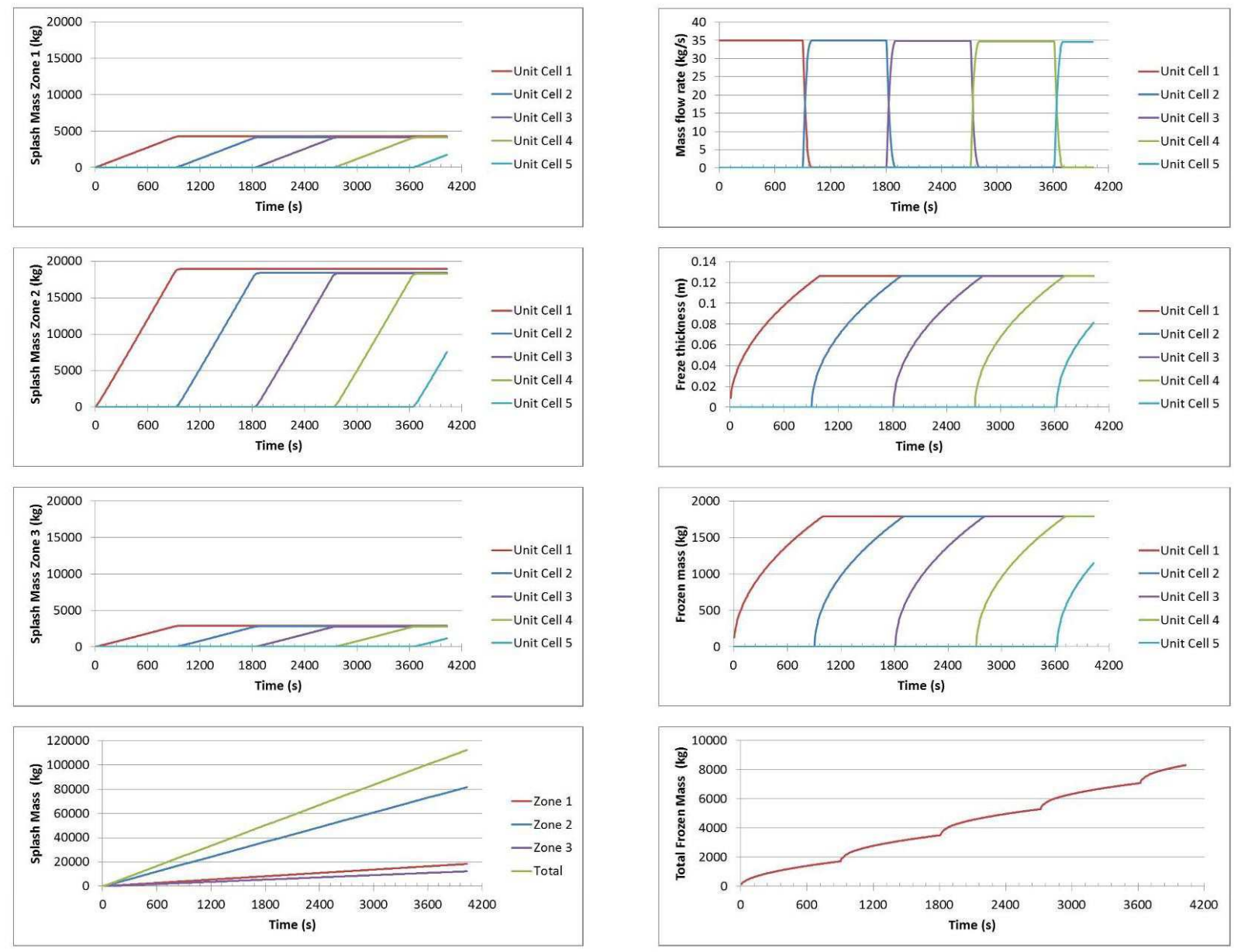

Figure 2-2. Local and Cumulative Splashed (left) and Frozen (right) Corium Masses During Relocation for Scenario III.

For Scenarios I - III, a substantial fraction of the melt is predicted to splash off of the members in the three zones (before they are eroded away or the unit cell freezes shut). Interestingly, in Scenario I the unit cells are predicted to freeze shut before the support beams (zone 1) are eroded half way through. As noted earlier, the melt splashed in zone 1 would likely freeze onto other structures, some of the melt splashed in zone 2 would freeze on other structures while some portion would 'rain' downwards, and most of the melt splashed in zone 3 would 'rain' downwards. For Scenario IV, the rapid high temperature melt pour quickly erodes through horizontal members limiting the amount of melt that is predicted to splash off them.

In Scenarios I and II, a large amount of frozen debris is predicted to be held up and a large number of the supporting structures (beams and bars) are predicted to be eroded through. It is uncertain whether there would be sufficient structural support to hold up this mass including the CRD and other structures. It is possible that frozen debris including the CRDs and other structures could relocate downwards onto the maintenance platform. 
The amount of melt splashed and frozen onto the structures for Scenarios I and II is much greater than that predicted in previous work [11]. This is mainly due to three factors. First, the current methodology calculates melt freezing on vertical surfaces throughout the duration of the pour. This is in contrast to the previous study that only accounted for freezing of splashed melt. Second, the current work uses three splash zones while the previous work only considered one. Finally, the thickness of the impeding members, which cause the splashing, are much greater than that assumed in the previous study $(2.5 \mathrm{~cm})$ which provides for a longer duration of splashing.

\subsubsection{Summary}

A preliminary model of melt pour interactions with the structures below the RPV has been developed. The model estimates the amount of melt that would freeze on vertical structures and the amount of melt that would splash off horizontal members. The freezing model is relatively simple; i.e., it does not account for the following factors:

1) time (depth) dependent properties of the frozen debris

2) internal heat generation in the debris

3) the finite size of structures with respect to heat sink capacity

4) the enhanced heat transfer due to the flowing melt

Addressing the first of these simplifications would provide for a more refined answer in the case of a pour with time dependent melt properties (e.g., an initial metallic pour followed by an oxidic pour). Addressing the second through fourth areas would likely lead to predictions of less melt freezing on structures.

\subsection{Water Inventory Model}

As noted in Table 1-1, implementation of a detailed water inventory model within MELTSPREAD has been completed. This was a substantial developmental effort. The approach was to modify the 1-D transient fluid mechanics model used to calculate local spreading depth and velocities for the core melt in MELTSPREAD [15] for use in evaluating water flow and boiloff behavior atop the core melt. Thus, the water is assumed to spread over the melt, with local boiling that depletes the inventory up to and including complete localized or global dryout. The water spreading model was also set up to analyze water injection at arbitrary, user-specified locations within the spreading mesh that spans the entire pedestal and drywell floor areas (water flowrate and inlet temperature are input as tabular functions). Finally, the water model was also set up with the ability to calculate gravity-driven spillover into downcomers that can be specified at arbitrary points in the spreading mesh. The water inventory model also includes subcooling effects by solving a coupled water conservation of energy equation that was borrowed and modified from the melt spreading model subroutines. Thus, the water inventory model has been set up to embody all key features required to adequately assess water throttling strategies for BWRs. 
As an additional side note, the water inventory model was also integrated with the jet fragmentation model to evaluate localized depletion of the water inventory due to jet fragmentation and associated steam production. Thus, the model can realistically account for local augmentation in steam production due to jet fragmentation that reduces the water depth and, correspondingly, the extent that the jet can be fragmented.

The water inventory model has been fully implemented into MELSTPREAD, debugged, checked for numerical accuracy, and has been shown to be numerically stable and reliable over the range of calculations conducted to date. Examples of the impact of this model on melt spreading behavior are provided in Section 6. 


\subsection{STATUS OF CORQUENCH MODELING IMPROVEMENTS}

The overall computational relationship between MELTSPREAD and CORQUENCH was outlined in Section 2. Effectively, MELTSPREAD is used to calculate melt spreading distance and mass distribution in containment during the melt relocation phase from the RPV. Using automated software, these results are then used to develop input for CORQUENCH which then analyzes the long-term core-concrete interaction.

This section outlines key upgrades to CORQUENCH that have been implemented to improve the ability of the code to predict key phenomenological behavior (i.e., extent of concrete attack, combustible gas production, and core debris coolability) under realistic plant accident conditions.

As noted in Section 2, modeling improvements for both MELTSPREAD and CORQUENCH to better support SAWA/SAWM strategy development were defined in a meeting held with industry representatives on 10 October 2015. Through this industry consultation, appropriate upgrades to CORQUENCH were defined as follows (see Table 1-1):

i) Develop an automated multi-nodal core-concrete analysis capability that allows for global treatment of core-concrete interaction in containment as opposed to localized evaluations as is currently the case for system-level codes, and

ii) Incorporate a detailed water inventory model.

Specifically, in order to adequately support SAWA/SAWM strategy development, there is a need to develop a multi-nodal modeling capability to address localized core-concrete interaction behavior given actual containment features (e.g. sumps and compartments) that is coupled with a realistic water inventory model that can be used to evaluate water injection strategies. The overall intent of the above two modeling upgrades is to provide that type of computational tool.

A summary of upgrades made to CORQUENCH in the above two areas are summarized in sequence below.

\subsection{Automated Multi-Nodal Analysis Capability}

As for all other core-concrete interaction models known to the authors, CORQUENCH was originally developed to be a single node MCCI analysis code [14,17]. In this approach, the core melt is treated as a single pool at a uniform temperature, with heat transfer to radial and axial concrete boundaries driving concrete ablation and cooling to overlying structure or water, depending upon whether or not the cavity is flooded (see Figure 3-1). The primary focus of these types of models is the analysis of heat transfer to the various boundaries of the pool as well as chemical reactions between metallic melt constituents and concrete decomposition gases that produce combustible gases $\left(\mathrm{H}_{2}\right.$ and $\left.\mathrm{CO}\right)$ that are a safety concern during a severe accident. Although these single node models provide detailed treatment of localized physical phenomena, they lack the ability to capture global behavior in actual containment geometries like the Mark I 
(see Figure 3-2) in which structures like sumps and compartments can lead to varying melt accumulations within containment that can impact the cavity flooding strategy as well as the ability to quench and thermally stabilize ex-vessel core debris.

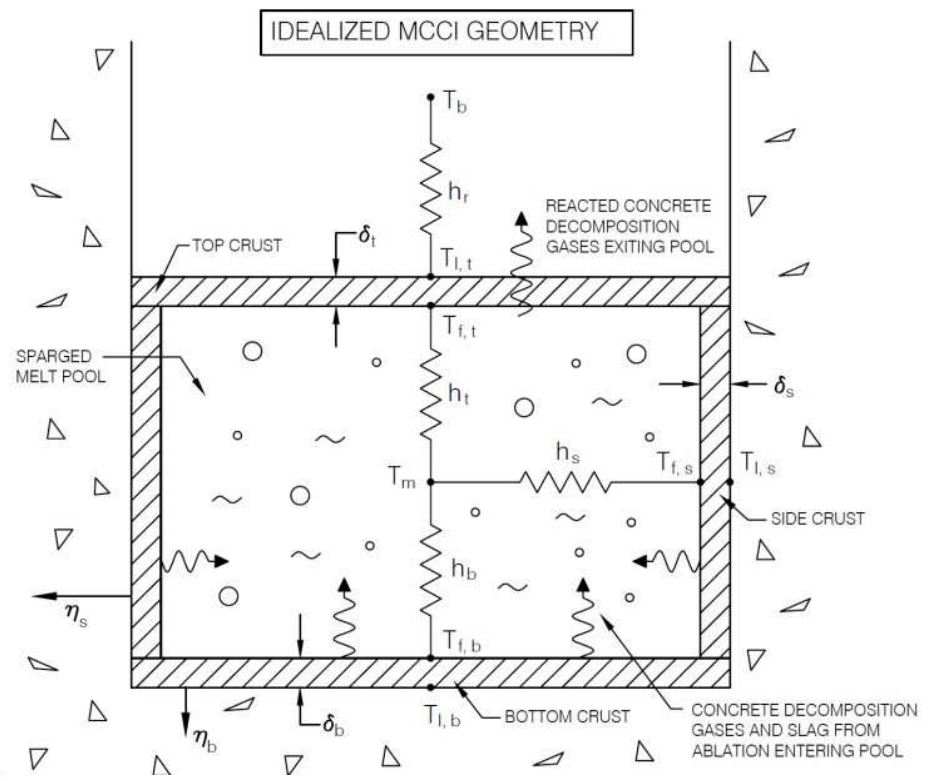

Figure 3-1. Illustration of Simplified Single-Node MCCI Modeling Approach Utilized in CORQUENCH 3.03 [17].

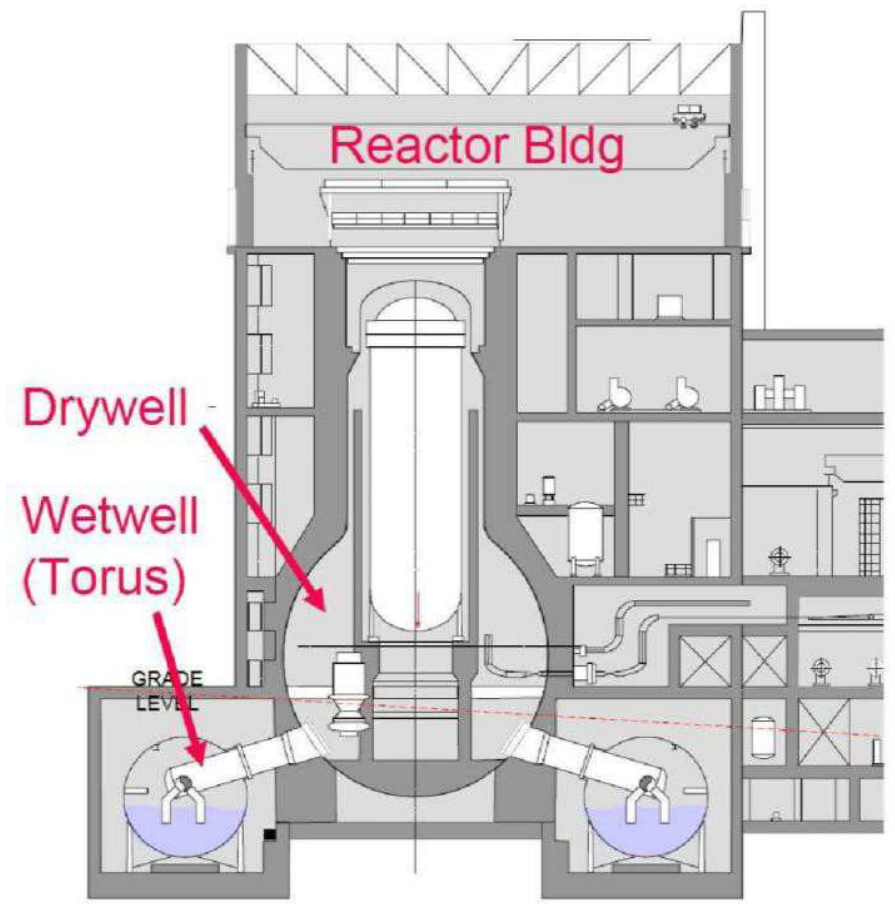

Figure 3-2. Illustration of BWR Mark I Containment. ${ }^{1}$

${ }^{1}$ https://upload.wikimedia.org/wikipedia/commons/a/a0/BWR_Mark_I_Containment\%2C diagram.png 
Based on this background, CORQUENCH has been upgraded to incorporate a multinodal analysis capability. However, the ability to do single node analysis has been retained, as this capability is important and relevant for isolated treatment of structures such as sumps, as well as the fact that validation experiments can be mocked up quite well using the single node approximation. The multi-nodal capability was achieved as follows. All common blocks in the main program were first analyzed to determine what variables were common to any given node, as well as those that were dependent upon local conditions (these include melt depth, composition, specific enthalpy, boundary condition state, and cavity conditions such as area, 1 vs. 2-D erosion characteristics, etc). With the dependent variables identified, additional common blocks were developed that allowed dependent variables to be saved at each timestep. The main program was then vectorized to analyze across an array of nodes, each of which is characterized by user-defined input data. A series of single node core-concrete analyses are thus carried out in parallel, with appropriate bridging software that allows integral quantities across the various nodes to be tallied for output to printing and plotting files. In terms of node geometric characteristics, a variety of user options have been supplied that allow physical features of containments (e.g., sumps, walls, doorways, flow channels, etc.) to be mocked up in an integral fashion. The model can treat dry cavity scenarios, wet cavity scenarios with fixed coolant conditions, or situations in which the cavity is flooded and the water conditions are calculated based on a water inventory model that is summarized in the next subsection.

The multi-nodal modeling capability has been fully implemented in CORQUENCH, debugged, checked for numerical accuracy, and has been shown to be numerically stable and reliable over the range of calculations conducted to date. Examples of the utility of this modeling capability in ex-vessel severe accident plant analyses are provided in Section 6.

\subsection{Water Inventory Model}

As noted in Table 1-1, implementation of a detailed water inventory model within CORQUENCH has also been completed. The modeling approach and overall capabilities are virtually identical to that utilized for MELTSPREAD; see Section 2.3 for details. However, the water inventory routine in CORQUENCH had to be upgraded to include special modeling requirements that are unique to this code, which includes the presence of an overlying particle bed that can develop as a result of melt eruptions. Thus, under certain scenarios, the particle bed might only be partially filled with water, or even dry out.

The water inventory model has been fully implemented into CORQUENCH, debugged, checked for numerical accuracy, and has been shown to be numerically stable and reliable over the range of calculations conducted to date. Examples of the impact of this model on core debris coolability are provided in Section 6. 


\subsection{STATUS OF ANALYSIS TO SUPPORT INDUSTRY IN DEVELOPING AN ALTERNATE WATER ADDITION STRATEGY}

Ultimately, the upgraded MELTSPREAD and CORQUENCH codes developed as part of this work are to be applied to postulated plant-specific accident scenarios to provide initial insights related to SAWA/SAWM to support industry in SAG development in response to the severe accident capable vent Order, EA-13-109 [2]. The initial and boundary conditions for these calculations will be determined through interactions with industry (led by EPRI). The overall objective of the analysis will be to scope out a set of operator actions (e.g., water addition location and flowrate) that will achieve the accident management objective of keeping the debris covered with water and cooled while preserving the wetwell vent path.

The plan for this particular task (i.e. Task 3 in Table 1-1) is to apply MELTSPREAD and CORQUENCH to melt pour conditions predicted by MELCOR and MAAP, as these two systemlevel codes predict quite diverse melt pour conditions [3] which likely span the range of what might be expected during an actual plant accident. As a separate task within the RST pathway, MAAP and MELCOR are being exercised in order to generate severe accident analysis accident signatures to test the SAMG symptom-based approach and confirm that they can address a widerange of accident signatures given model differences and uncertainties and be successful in accident mitigation strategies [18]. This activity was initiated through a meeting held at Argonne on April 13, 2016 that was attended by participants from EPRI, Jensen-Hughes, Exelon, ORNL, SNL, and ANL. As a natural byproduct of this work, melt pour conditions for selected scenarios in which the RPV is predicted to fail are being generated. This data is being provided to ORNL and ANL for additional analysis with MELTSPREAD-CORQUENCH to examine SAWA/SAWM strategies. During the meeting in April, Peach Bottom was selected as the model plant for analysis, and a Station Blackout (SBO) scenario was selected as the accident sequence to be analyzed. To initiate this particular study, Jensen-Hughes supplied melt pour conditions predicted by MAAP in August 2016. We have begun preparing input files for SAWA/SAWM analysis with MELTPREAD-CORQUENCH in FY17. We expect to receive counterpart MELCOR pour results from SNL for analysis in early FY17. 


\subsection{STATUS OF CORE DEBRIS COOLABILITY TESTING}

As part of a co-funded effort between Electricité de France (EdF), Institut de Radioprotection et de Sûreté Nucléaire (IRSN), Commissariat à l'énergie Atomique et Aux énergies Alternatives (CEA), US NRC, and DOE, large-scale reactor material core debris cooling experiments are being conducted with the objective of demonstrating that core melt interacting with concrete can be stabilized with "early" direct top flooding. Test CCI-9 is focusing on providing data on the water ingression cooling mechanism for the case of core melt interacting with low-gas content siliceous concrete in a one-dimensional (1-D) cavity. The 1-D design is specified since it minimizes the chances of lateral water ingression and, thereby, optimizes the extent that the test results can be extrapolated to plant conditions. In essence, CCI9 is a scaled up version of the SSWICS tests $[19,20]$ that focused on measuring water ingression, but without any electrical heating of the melt that would simulate decay heat, as is being done in CCI-9. This section summarizes the test specifications, facility design, and status of test preparations.

\subsection{Test Specifications and Facility Design}

Overall test specifications for CCI-9 are summarized in Table 5-1. The facility utilizes equipment and technology developed as part of the OECD/MCCI program [21], which included long-term experiments with sustained internal heating. The system consists of a test apparatus, a power supply for direct electrical heating (DEH) of the corium, a water supply system, a steam condensation system, a ventilation system to complete filtration and exhausting of the off-gases, and a data acquisition system. A schematic illustration of the facility is provided in Figure 5-1. The apparatus for containment of the core material consists of a test section that is $\sim 3 \mathrm{~m}$ tall with a square internal cross-section that measures $70 \mathrm{~cm} \mathrm{x} 70 \mathrm{~cm}$. The concrete crucible is located at the bottom of the test section. A top view of this component is shown in Figure 5-2, while crosssectional views of the electrode and non-electrode sidewalls are provided in Figures 5-3 and 5-4, respectively.

As shown in Figure 5-2, both the non-electrode and the electrode sidewalls are fabricated from castable $\mathrm{MgO}$ refractory that forms the inner structural barrier for radial containment of the core melt. The $\mathrm{MgO}$ sidewalls are contained within a flanged steel form that is used to secure the lower section to the balance of the existing test section components with an aluminum transition plate. The lower section is fabricated with vertical, flanged casting seams between the $\mathrm{MgO}$ walls so that the lower sidewalls can be disassembled to reveal the solidified corium after the test. The $\mathrm{MgO}$ sections are intended to be reusable. A layer of $\mathrm{U}_{3} \mathrm{O}_{8}$ powder is used to protect the interior surfaces of these components against thermo-chemical attack by the corium. In the event that the $\mathrm{U}_{3} \mathrm{O}_{8}$ layer does not provide adequate protection, molybdenum back-up plates are embedded in the electrode sidewalls that serve as a final barrier to terminate sidewall attack. Multi-junction Type $\mathrm{C}$ thermocouple assemblies are cast within the sidewalls so that the time-dependent heat loss from the melt can be determined using standard inverse heat conduction techniques. 
Table 5-1. CCI-9 Test Specifications.

\begin{tabular}{|c|c|}
\hline Parameter & $\begin{array}{c}\text { Specification } \\
\end{array}$ \\
\hline Corium & $100 \%$ oxidized PWR with 6 wt $\%$ concrete \\
\hline Concrete basemat cross-sectional area & $70 \mathrm{~cm} \times 70 \mathrm{~cm}$ \\
\hline Initial melt mass (depth) & $1000 \mathrm{~kg}(30 \mathrm{~cm})$ \\
\hline Concrete basemat type & Siliceous (EdF specific) \\
\hline Sidewall construction & Inert: castable $\mathrm{MgO}$ lined with $\mathrm{U}_{3} \mathrm{O}_{8}$ powder on inner surface \\
\hline Basemat maximum ablation depth & $47.5 \mathrm{~cm}$ \\
\hline System operating pressure & Atmospheric \\
\hline Melt formation technique & Chemical reaction ( $\sim 30$ second reaction time $)$ \\
\hline Initial melt temperature & $\sim 2300^{\circ} \mathrm{C}$ \\
\hline Melt heating technique & Direct Electrical (Joule) Heating \\
\hline $\begin{array}{l}\text { Melt heating method under dry cavity } \\
\text { conditions }\end{array}$ & Constant power at a level of $151 \mathrm{~kW}$. \\
\hline Melt heating method after cavity flooding & $\begin{array}{l}\text { - Phase 1: Constant power at } 151 \mathrm{~kW} \text { until: i) bulk cooling is } \\
\text { completed, or ii) } 5 \text { minutes has elapsed, whichever is } \\
\text { longer. } \\
\text { - Phase 2: Constant voltage until power level falls to } 50 \mathrm{~kW} \text {. } \\
\text { - Phase 3: Constant power at } 50 \mathrm{~kW} \text { until a test termination } \\
\text { criterion is met. }\end{array}$ \\
\hline Criteria for top cavity flooding & $\begin{array}{l}\text { Axial basemat erosion to a depth of } 1.0 \mathrm{~cm}^{*} \text {, or operator } \\
\text { judgment if a test anomaly occurs. }\end{array}$ \\
\hline Top flooding water inlet conditions & $\begin{array}{l}\text { Inlet water temperature: } 15^{\circ} \mathrm{C} \\
\text { Inlet water flowrate: } \sim 2 \text { liters } / \mathrm{sec} \\
\text { Sustained water depth over melt: } 50 \pm 5 \mathrm{~cm}\end{array}$ \\
\hline Test termination criteria & $\begin{array}{l}\text { 1) melt quenches, or 2) maximum axial ablation depth is } \\
\text { reached. }\end{array}$ \\
\hline
\end{tabular}

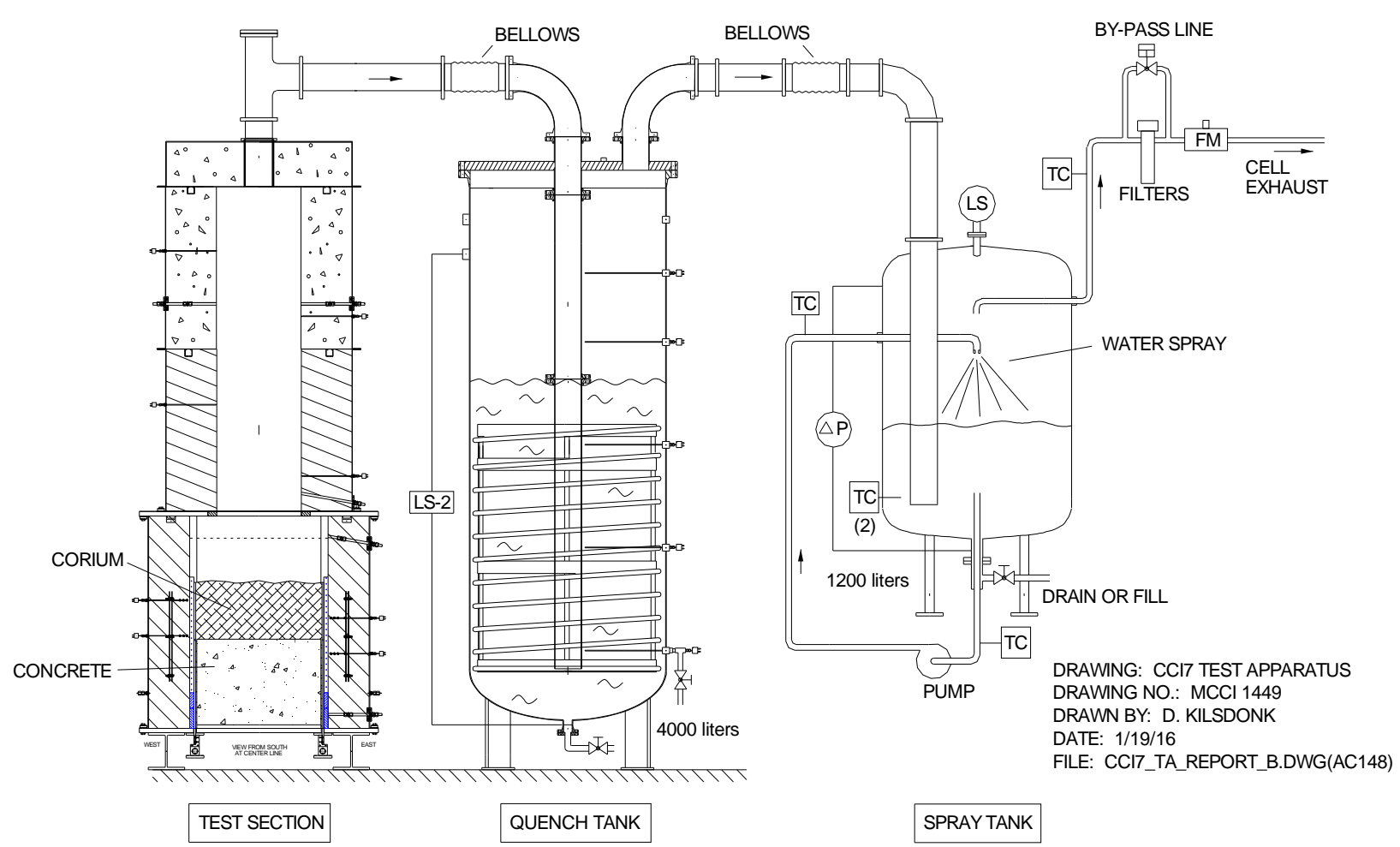

Figure 5-1. CCI-9 Test Apparatus. 


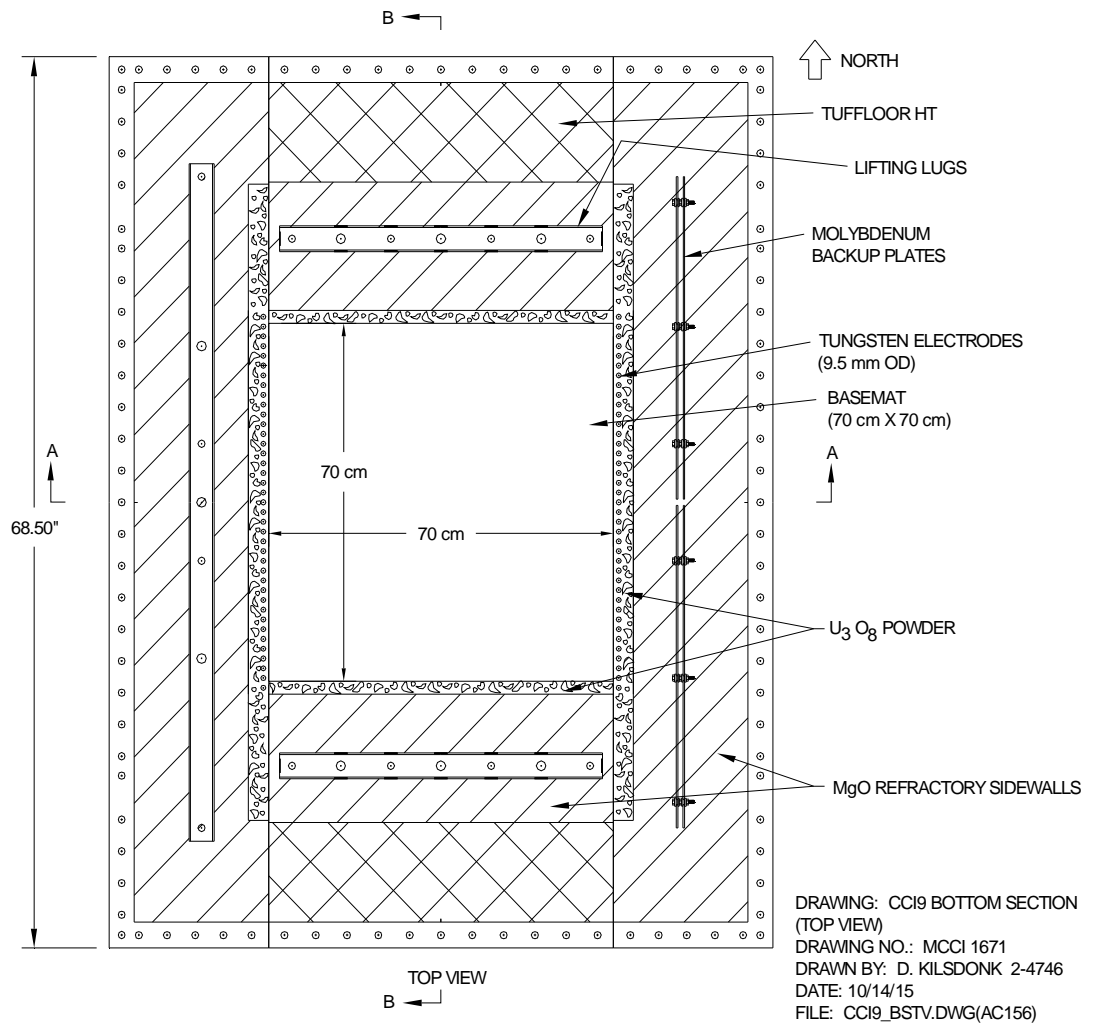

Figure 5-2. Top View of Lower Test Section.

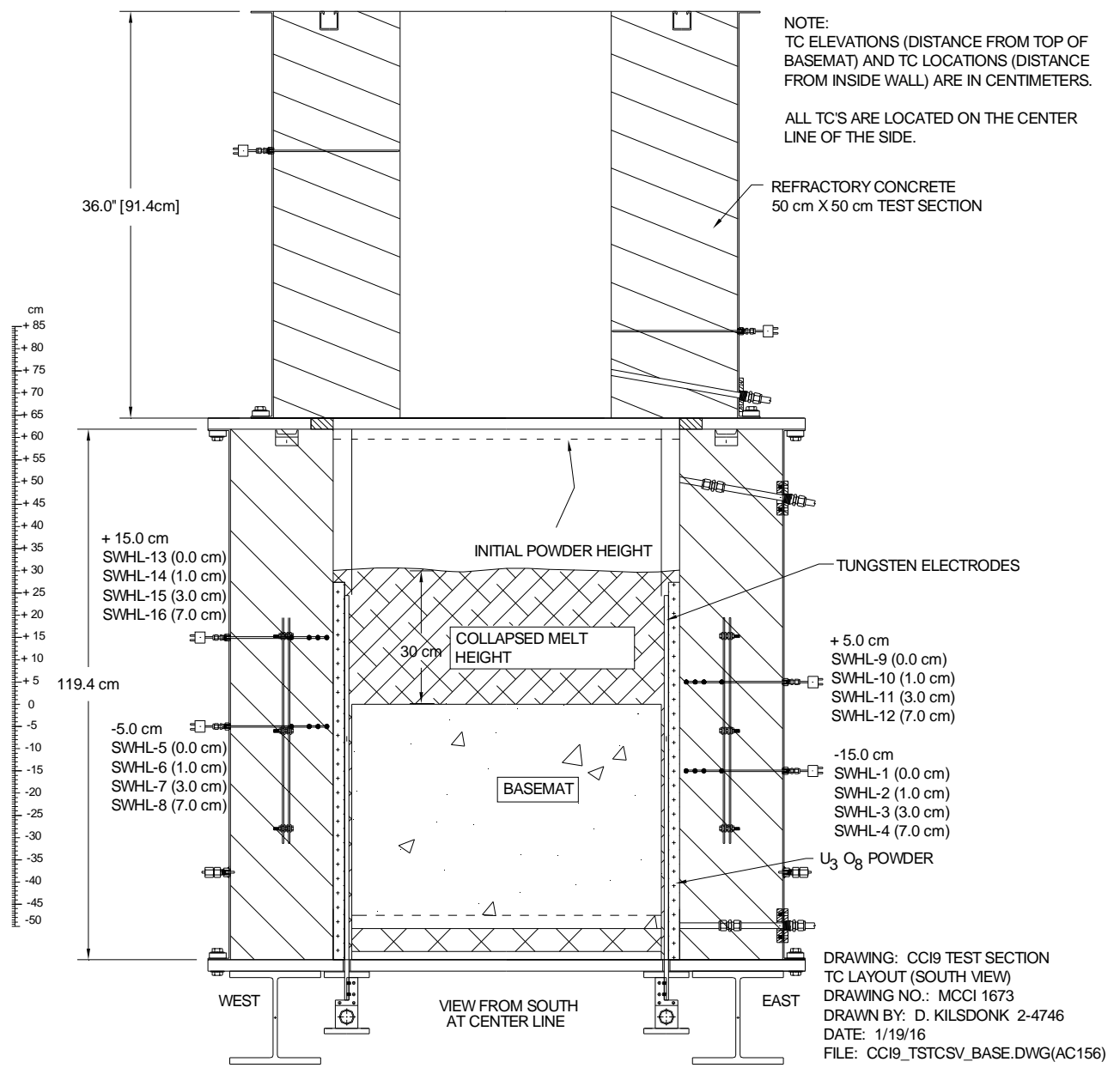

Figure 5-3. Side View of Lower Test Section Showing Electrode Sidewalls. 

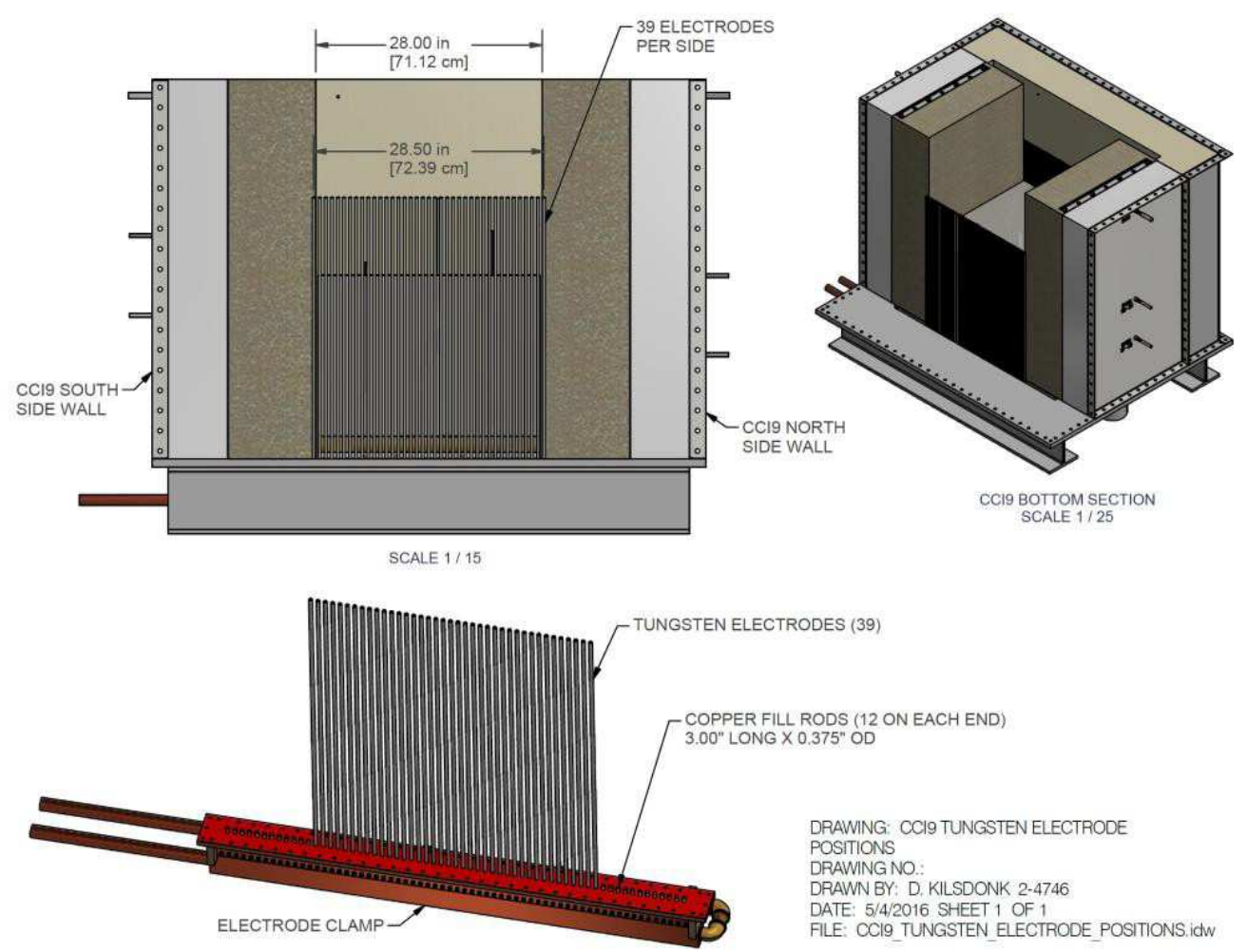

\section{Figure 5-4. Side Views Showing Non-Electrode Sidewalls and Electrode Clamp Configuration.}

Melt generation is achieved through an exothermic chemical reaction yielding the target initial melt mass over a time of $\sim 30$ seconds. After the chemical reaction, DEH is supplied to the melt to simulate decay heat through two banks of tungsten electrodes. As shown in Figures 5-2 and 5-3, the electrodes line the interior surfaces of two opposing $\mathrm{MgO}$ sidewalls. The electrodes are $9.5 \mathrm{~mm}$ in diameter and are pitched at $1.9 \mathrm{~cm}$ intervals. They are attached by copper clamps and water-cooled bus bars to a $560 \mathrm{~kW}$ AC power supply. The tops of the electrodes are at the same elevation as the collapsed melt height, which is the same approach used in previous tests.

A few minutes after the melt is formed, ablation of the concrete basemat and sidewalls will commence. As shown in Figure 5-1, a large (15-cm-diameter) gas line is used to vent the helium cover gas and the various gas species arising from the core-concrete interaction (i.e., $\mathrm{CO}, \mathrm{CO}_{2}, \mathrm{H}_{2} \mathrm{O}$, and $\mathrm{H}_{2}$ ) into two adjacent quench tanks that are partially filled with water (see Figure 5-1). In the early initial phase of the experiment when the cavity is dry, the tanks serve to cool the off-gases and to filter aerosols generated from the core/concrete interaction. After the cavity is flooded, the tanks serve to condense the steam and, based on the measured condensation rate, provide data on the corium cooling rate. In either case, the helium cover gas and non-condensables $\left(\mathrm{CO}, \mathrm{CO}_{2}\right.$, and $\left.\mathrm{H}_{2}\right)$ pass through the tanks and are vented through an off gas system that includes a demister and filters. The gases are eventually exhausted through the containment ventilation system and a series of high-efficiency filters before finally being released from the building stack. 
Soon after concrete erosion begins, the cavity is flooded from an instrumented water supply system. The water enters the test section through two weirs located in the opposing (nonelectrode) sidewalls of the top test section. Makeup water is periodically added to maintain the water level in the test section at nominally $50 \pm 5 \mathrm{~cm}$.

The CCI-9 facility is heavily instrumented to monitor and guide experiment operation and to log data for evaluation of key characteristics such as axial concrete erosion rate, melt temperature, and corium cooling rate. Principal parameters that are monitored during the test include the power supply voltage, current, and gross input power to the melt; melt temperature and temperatures within the concrete basemat and $\mathrm{MgO}$ sidewalls; water volume and temperature within the test apparatus, and water volume and temperature within the quench system tanks. Other key data recorded by the data acquisition system includes pressures at various locations within the system. A lid mounted video camera provides the ability to observe the physical characteristics of the CCI, as well as cell overview cameras that are used to monitor the state of the facility as the experiment proceeds.

As part of this project, the data acquisition system has been completed upgraded under DOE funding. The new system is managed by two PCs with one running LabVIEW to log sensor data and the other to stream video from a series of network cameras. The LabVIEW PC is linked to a collection of National Instruments hardware via a network connection through the cell wall (Figure 5-5). Three cDAQ-9188 chassis house plug-in modules that accommodate thermocouples (NI-9214), pressure transmitters, flow meters, and level (NI-9205 for \pm 10 VDC), and special purpose signals (NI-9229 for \pm 60 VDC). Sensor data will be logged at $\sim 1 \mathrm{~Hz}$. The system is currently configured for $256 \mathrm{~K}$-type thermocouples and $64 \mathrm{C}$-type thermocouples with room for expansion. Several slots have been reserved in the event they are needed to log additional sensor data. All electronics are housed within a climate controlled cabinet for protection in the event of a steam release into the containment.

The second PC records images from network cameras distributed around the cell and near the test section. The melt camera, which looks down onto the corium surface, has been upgraded to a high-resolution model. It will have special wide dynamic range capabilities that should drastically improve image quality for the large intensity variations often seen across the corium surface.

\subsection{Status of Test Preparations}

Accomplishments this fiscal year are summarized as follows. Based on interactions with the sponsors, test specifications were finalized (see Table 5-1). Design drawings for new test section components were completed, submitted to Argonne Central Shops, and fabricated. All necessary equipment (instrumentation, electrodes, thermowells, chemicals for the corium charge, and new data acquisition hardware and software) was procured. The new test section components were prepared, and the data acquisition was completely replaced and wired from the instrument locations into the new data logging equipment. In addition, new steamline 
components were designed and fabricated, and the existing quench system tanks in the test cell were reconfigured to increase the overall heat capacity of the system.

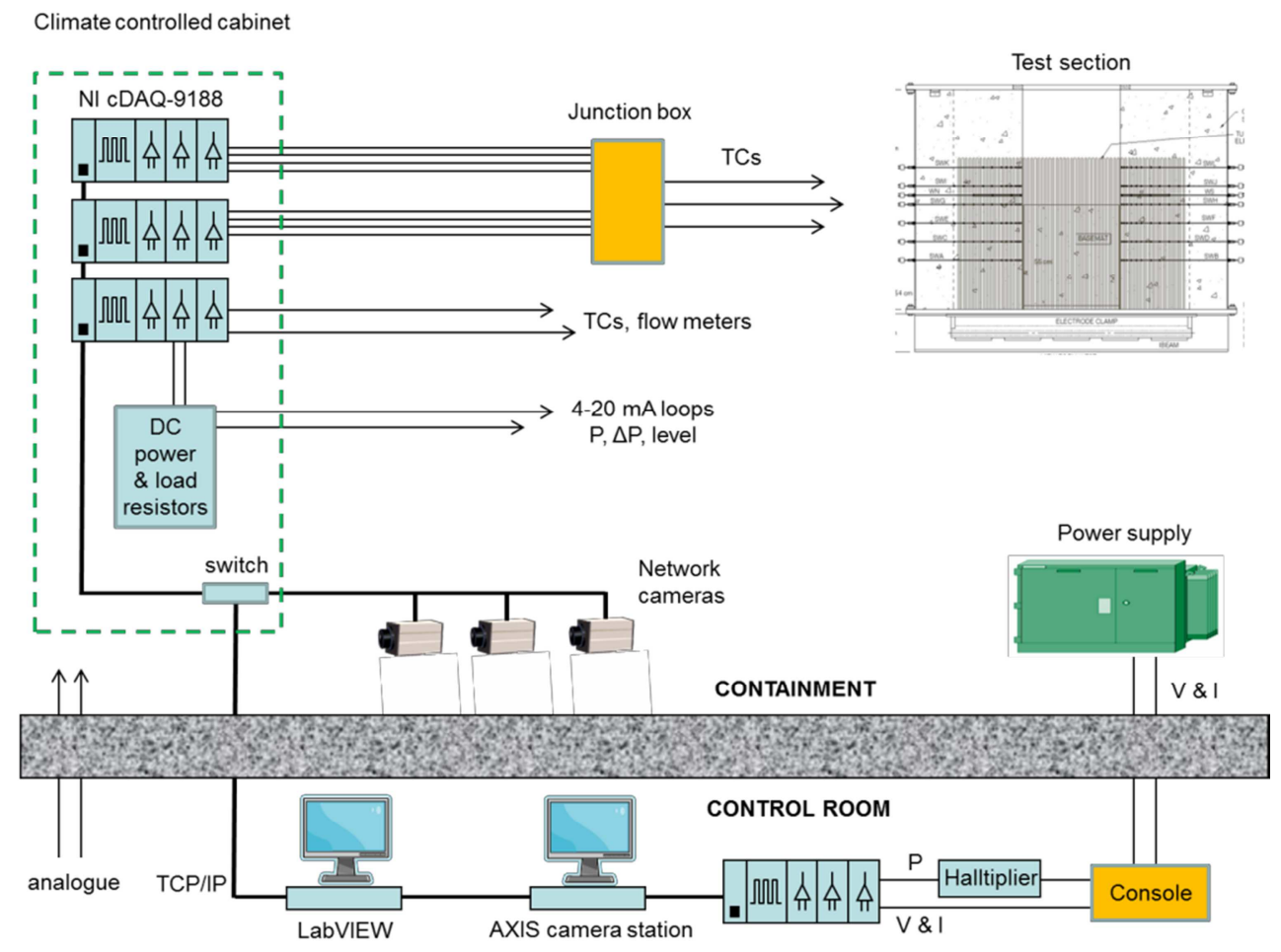

Figure 5-5. CCI-9 DAS Layout.

The chemicals for the corium charge $(1000 \mathrm{~kg})$ were mixed in a ventilated hood and then transferred to the test cell. The lower test section was assembled in preparation for loading of the corium charge, and a radiological control tent was built to limit the spread of contamination during loading. Loading of the $\mathrm{U}_{3} \mathrm{O}_{8}$ liner and corium charge was completed, the tent disassembled, and the test cell decontaminated back to a controlled area for the balance of test preparations. After this step was completed, the balance of the test section was assembled and final instrument hookups were completed. Test checkout procedures have been initiated to ensure that the facility is in proper working order before the test is executed. The test is scheduled to be conducted 24 September, 2016. 


\subsection{UPGRADED MODEL APPLICATIONS TO 1F1 ACCIDENT SEQUENCE}

\subsection{Overview}

This section provides some initial scoping calculations with the upgraded MELTSPREAD and CORQUENCH codes for the $1 \mathrm{~F} 1$ accident sequence to illustrate the nature of the predictions and also to gain additional insights into the accident progression. Both MAAP and MELCOR melt pour scenarios are analyzed. The MELCOR pour conditions are the same as that examined in the previous MELTSPREAD-CORQUENCH study of the accident sequence [3]. However, an updated MAAP pour was provided by Jensen Hughes to support this ongoing effort. ${ }^{2}$ A summary of melt pour conditions predicted by the two codes is provided in Table 6-1, while piece-wise linear curve fits to the time-dependent pour rates used in the current analysis are shown in Figure 6-1. As discussed in [3], there are large differences in pour conditions between MELCOR and MAAP, with MELCOR predicting a lowtemperature gradual pour, and MAAP predicting a high temperature rapid pour. Relative to the previous work [3], the new MAAP pour is slightly less rapid and at lower temperature. With this model input data, the updated MELTSPREAD and CORQUENCH calculations are described in sequence below.

Table 6-1. Melt Spreading Input Data from MELCOR and MAAP Accident Analyses.

\begin{tabular}{|c|c|c|}
\hline Case Designator & MELCOR & MAAP-LP \\
\hline Sequence description & LP vessel failure & LP vessel failure \\
\hline Onset of pour (hours) & 14.3 & 16.1 \\
\hline Pour duration $(\mathrm{sec})$ & 4030 & 28.5 \\
\hline 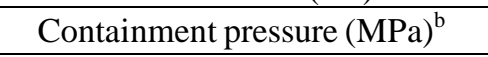 & 0.75 & 0.75 \\
\hline Water level on drywell floor $(\mathrm{cm})$ & 55 & 10 \\
\hline Melt pour temperature $(\mathrm{K})$ & $\begin{array}{c}\text { Range: } 1850-2100 \\
\text { Average: } 1975\end{array}$ & $2403-2414$ \\
\hline Oxide phase solidus-liquidus $(\mathrm{K})^{\mathrm{a}}$ & $2215-2467$ & $2202-2502$ \\
\hline Metal phase solidus-liquidus $(\mathrm{K})^{\mathrm{a}}$ & $1705-1735$ & $1832-1867$ \\
\hline Melt solid fraction $(-)^{\mathrm{a}}$ & 0.56 & 0.42 \\
\hline Decay heat (W/kg fuel) & 86 & 104 \\
\hline \multicolumn{3}{|l|}{ Pour mass of constituent $(\mathrm{kg})$ : } \\
\hline $\mathrm{UO}_{2}$ & 69400 & 78166 \\
\hline $\mathrm{Zr}$ & 25800 & 23962 \\
\hline $\mathrm{ZrO}_{2}$ & 16600 & 11435 \\
\hline $\mathrm{Cr}$ & 5900 & 11424 \\
\hline $\mathrm{Cr}_{2} \mathrm{O}_{3}$ & 30 & 1698 \\
\hline $\mathrm{Fe}$ & 20430 & 25788 \\
\hline $\mathrm{FeO}$ & 230 & 6906 \\
\hline $\mathrm{Ni}$ & 2530 & 983 \\
\hline $\mathrm{NiO}$ & 30 & 734 \\
\hline $\mathrm{B}_{4} \mathrm{C}$ & 0 & 546 \\
\hline Total & 140950 & 161642 \\
\hline
\end{tabular}

${ }^{\mathrm{a} C a l c u l a t e d}$ with MELTSPREAD-CORQUENCH property routines given composition and melt temperature.

${ }^{\mathrm{b}}$ Approximate; based on plant data [22,23].

\footnotetext{
${ }^{2}$ D. Luxat, Jensen Hughes, personal communication to M. T. Farmer, Argonne National Laboratory, April 22, 2016.
} 

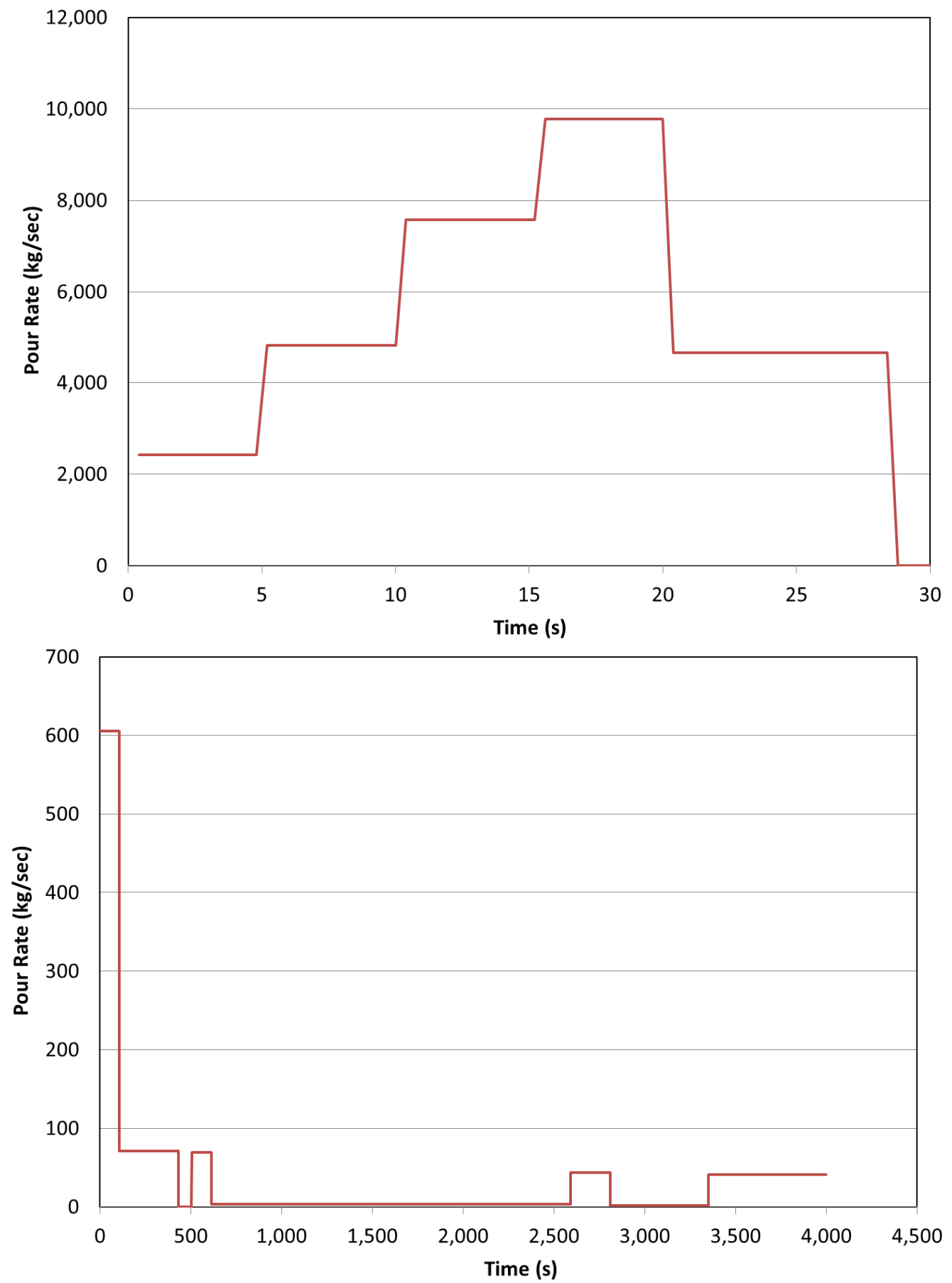

Figure 6-1. Piece-Wise Linear Approximations to MAAP (top) and MELCOR (bottom) Melt Pours Used in MELTSPREAD Calculations.

\subsection{MELTPSREAD Results}

The results presented here are intended to illustrate predicted spreading behavior for the MAAP and MELCOR scenarios, with a focus on the new modeling features that include: i) a detailed water inventory model, and ii) modeling of melt jet fragmentation in water beneath the reactor vessel. Note that a standalone model has been developed for melt interaction with below vessel structure (see Section 2.2), but this model has not yet been deployed in MELTSPREAD to assess the impact on spreading behavior. However, scoping calculations indicate that melt 
retention in the structure may be significant for cool melt pours and slow pour rates like the MELCOR case.

In terms of the jet fragmentation analysis, initial water depths on the drywell floor are shown in Table 6-1. The initial water temperature is taken as $400 \mathrm{~K}$ for both cases, which is $\sim 37$ $\mathrm{K}$ subcooled with respect to saturation temperature at containment pressure. Based on the MAAP output, water is present on the pedestal and drywell floors at a depth of $10 \mathrm{~cm}$, whereas for MELCOR the initial depth is $55 \mathrm{~cm}$, just below the downcomer inlet height of $60 \mathrm{~cm}$. Based on the TEPCO data [22,23], no water was injected over the time interval in which the melt pour occurred for either simulation. The sump cover plates are assumed to fail at the time of impact with melt, and the sumps (1.2 m deep) are further assumed to be filled with water, leading to a total initial water depth of $1.3 \mathrm{~m}$ in the sumps for the MAAP case, and $1.75 \mathrm{~m}$ for the MELCOR case. The RPV is assumed to be at an elevation of $8 \mathrm{~m}$ over the pedestal floor. Core debris is assumed to drain from the RPV into the sump. MAAP calculates the time-dependent hole size in the reactor vessel during the pour. Due to the high temperature and flowrate, the hole is ablated from the initial CRD opening size (or diameter) of $20 \mathrm{~cm}$ to a final size of $\sim 60 \mathrm{~cm}$ at the end of the pour; for the purposes of this study the diameter is assumed to vary linearly with time. MELCOR does not perform a mechanistic analysis of melt pour from the RPV. Thus, for the purposes of this study, a constant hole diameter equal to the initial CRD opening size of $20 \mathrm{~cm}$ is assumed. Hole ablation for the MELCOR case is expected to be much less in comparison to MAAP due to the low flowrate and extremely low core debris temperature.

The remaining water depth in the sump and fraction of the melt stream fragmented into particulate over the course of the MAAP and MELCOR pours are shown in Figures 6-2 and 6-3, respectively. Similarly, steam production rates and overall water mass balances are shown in Figures 6-4 and 6-5. These data indicate that fragmentation for the MAAP case is minor, with only about $5 \%$ of the overall core melt mass rendered in the form of particulate. This is due to several factors that includes a rather shallow water depth at the start of the pour, rapid boiling from debris fragmentation, and finally the rapid rate at which melt pouring into the sump displaces water, all of which act to limit the amount of water available to fragment the melt jet.

In contrast, for the MELCOR case substantial jet fragmentation is predicted. In particular, $\sim 60 \%$ of the relocating core debris is rendered into the form of particulate, with the balance of the melt penetrating through the water to form a coherent melt layer in the sump beneath the overlying particle bed. This physical configuration has been observed in previous reactor material melt stream breakup tests [8,9]. Steam production for this case is limited and is dominated by quenching of particulate as it settles through the water pool. Spreading results are discussed later in this section, but boiling off the balance of the debris is limited due to the initial subcooling in the water pool as well as the fact that the melt is effectively retained in the pedestal region, limiting the extent of contact with the water outside of the pedestal. 
With this new jet fragmentation feature, there are a few shortcomings that have been identified in the current melt spreading model that need to be addressed in future work. This includes an evaluation of long term debris bed cooling for these longer duration pours in which significant fragmentation is predicted. In any event, this scoping calculation indicates the potential for significant debris fragmentation for slow pours that leads to an initial condition for the long-term MCCI analysis that is dominated by particulate as opposed to a coherent melt pool as is currently assumed in most models.
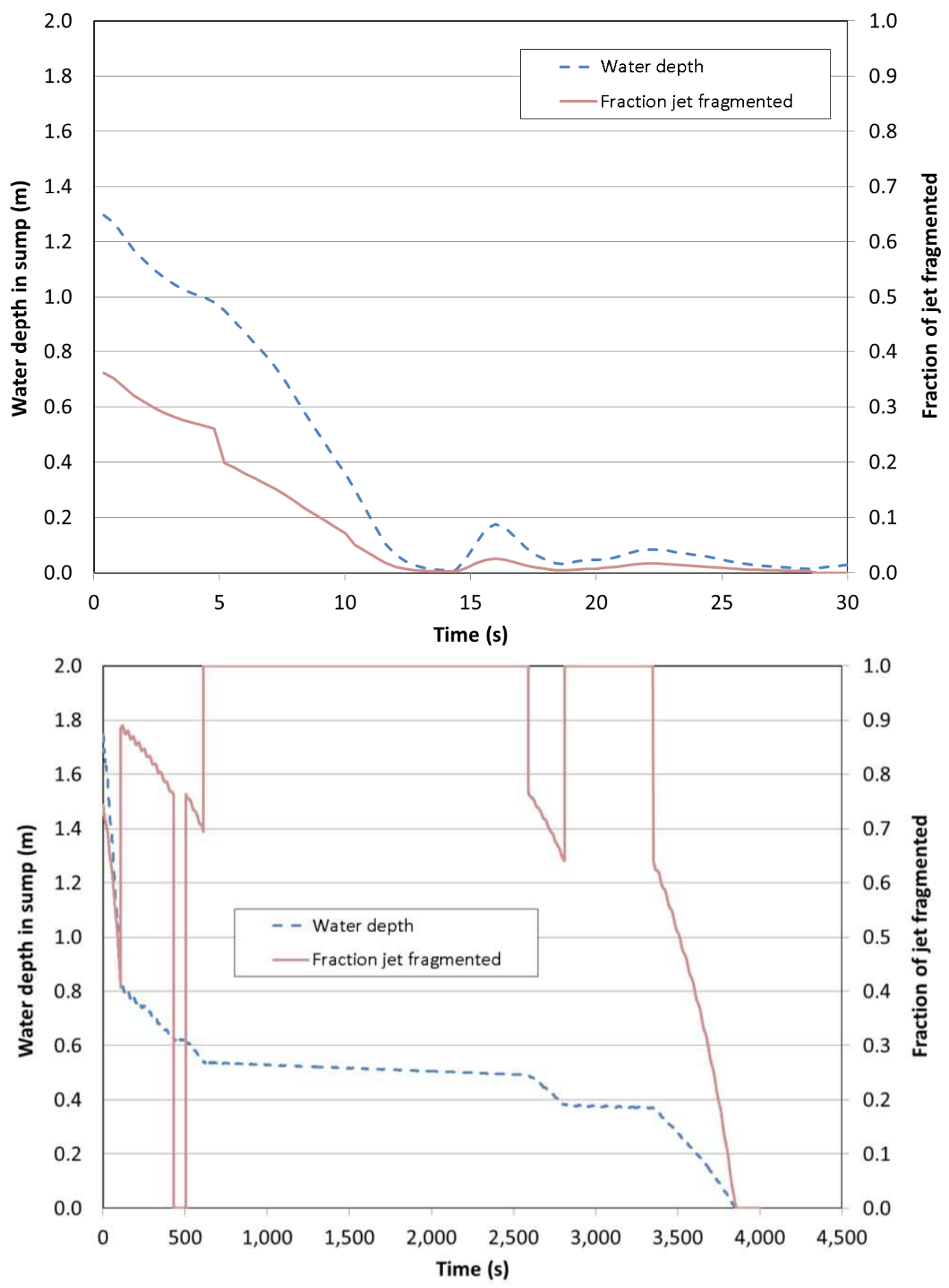

Figure 6-2. Predicted Water Depth in Sump and Fraction of Jet Fragmented for MAAP (top) and MELCOR (bottom) Pour Conditions. 

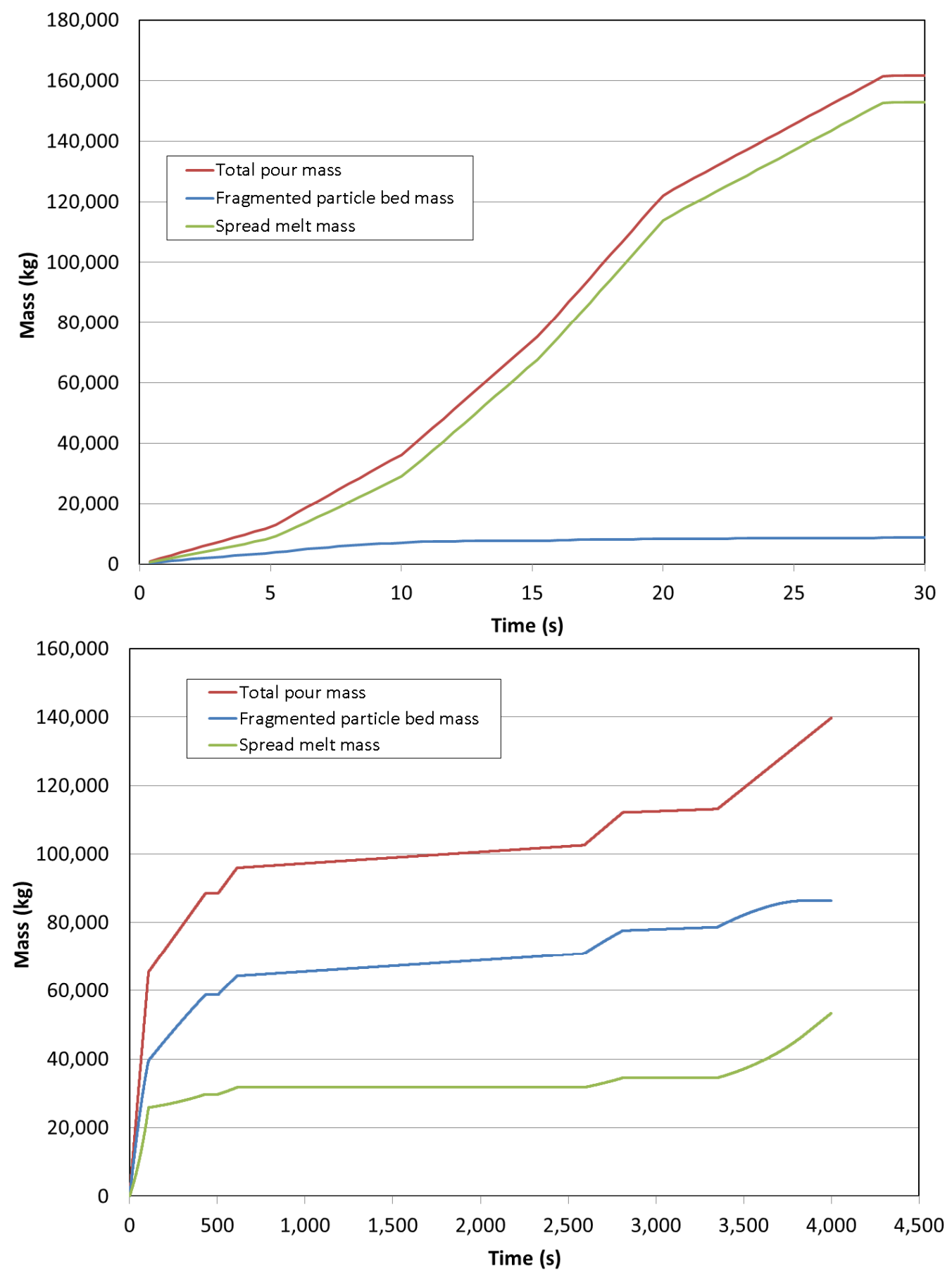

Figure 6-3. Predicted Melt Stream Breakup Due to Fragmentation in Sump Water Volume for MAAP (top) and MELCOR (bottom) Pour Conditions. 

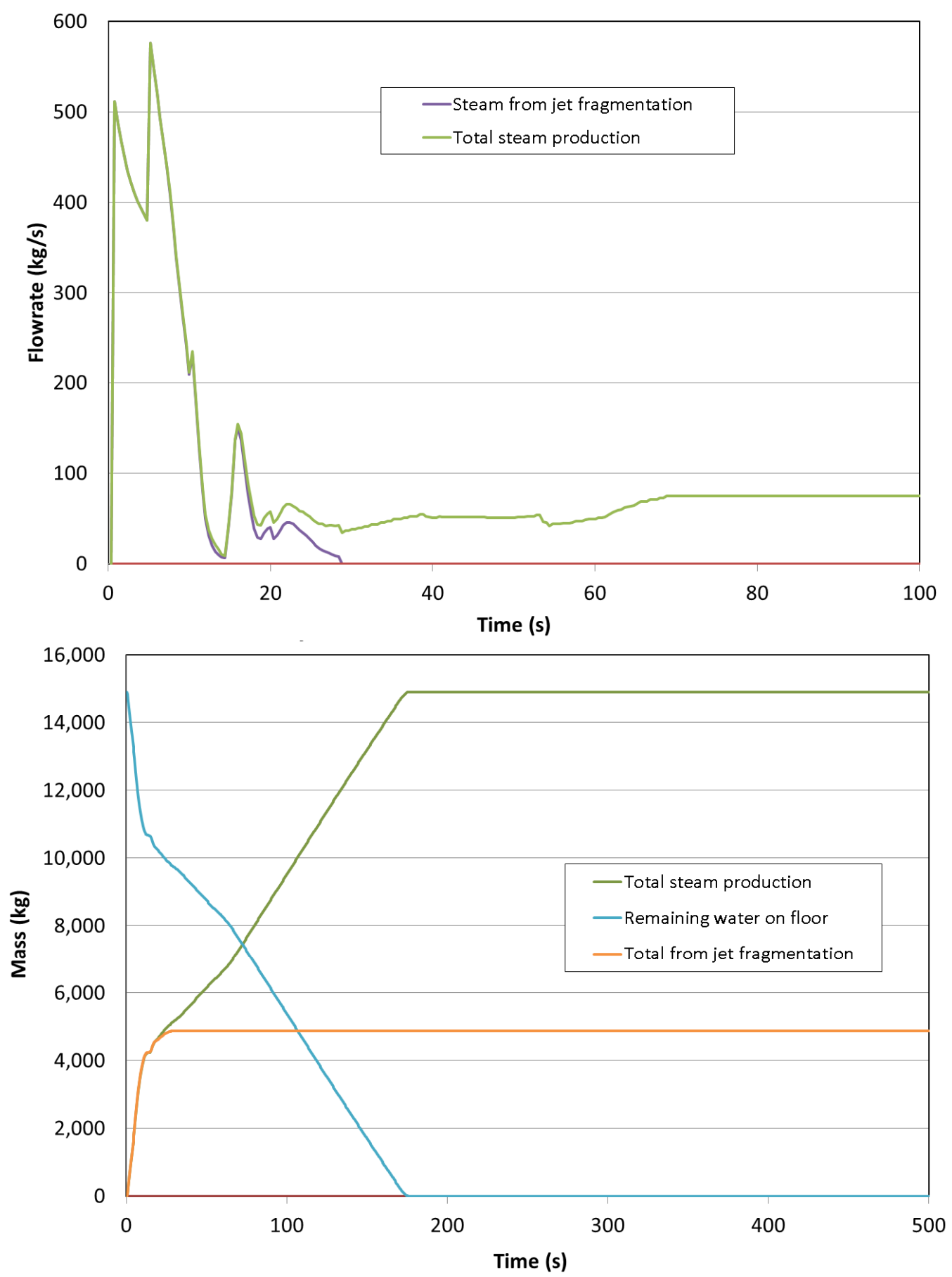

Figure 6-4. Steam Production Rate (top) and Water Inventories (bottom) During Melt Relocation for MAAP Pour Conditions. 

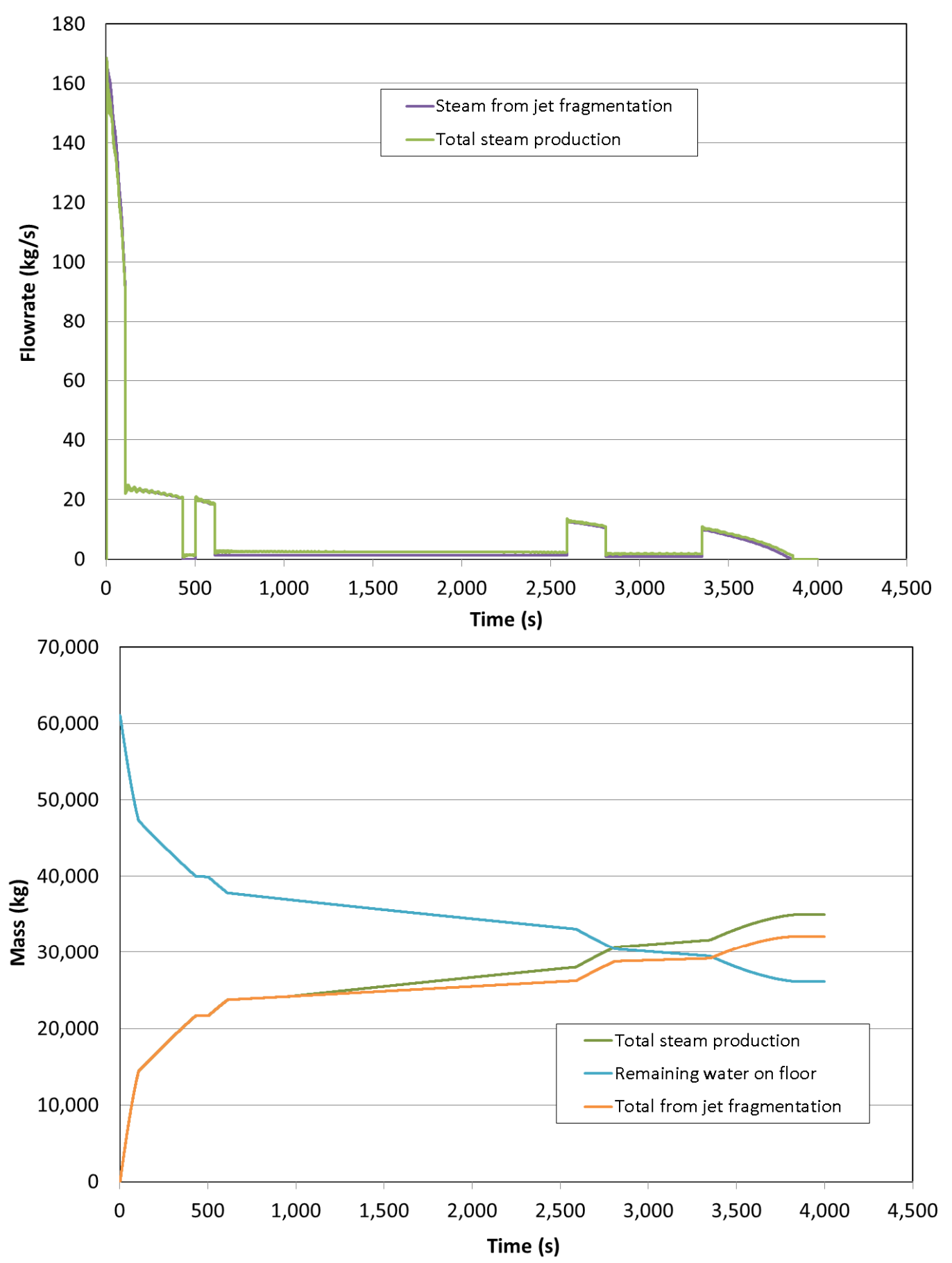

Figure 6-5. Steam Production Rate (top) and Water Inventories (bottom) During Melt Relocation for MELCOR Pour Conditions.

To provide additional perspective on the predictive capabilities of the upgraded code, melt depth/temperature profiles at various times are shown in Figure 6-6 for the MAAP case. Water level over the core debris during the spreading transient is also shown. As background, the containment nodalization used in this calculation is illustrated in Figure 6-7. 
5 seconds

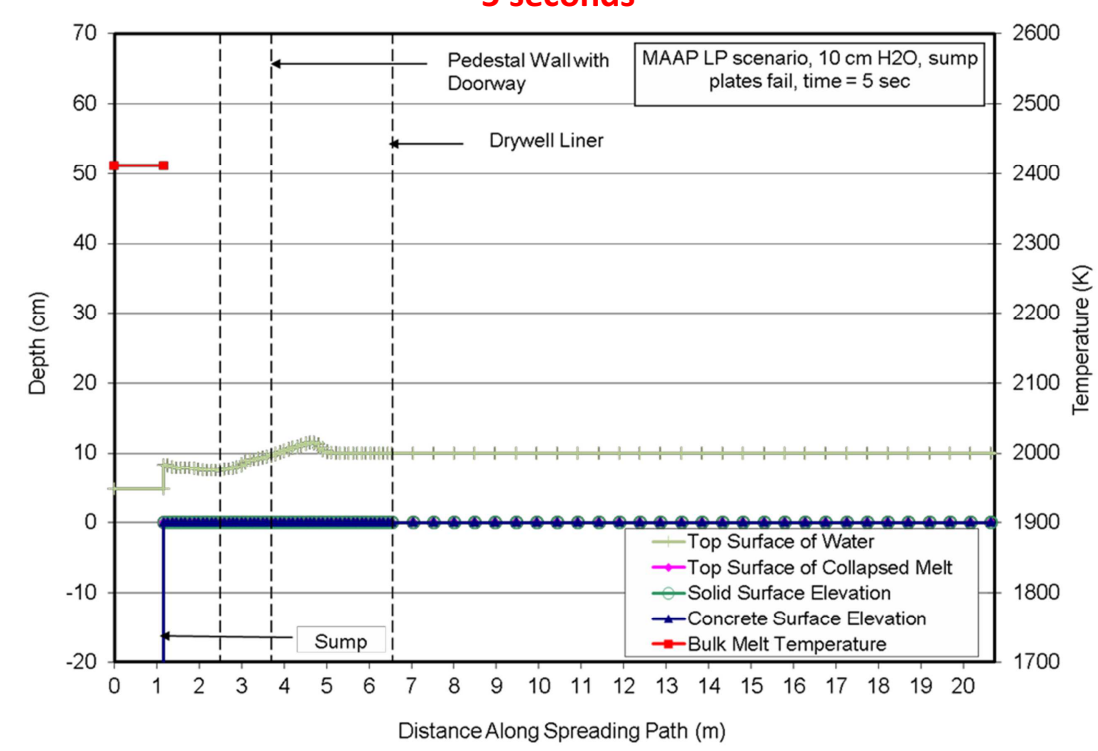

15 seconds

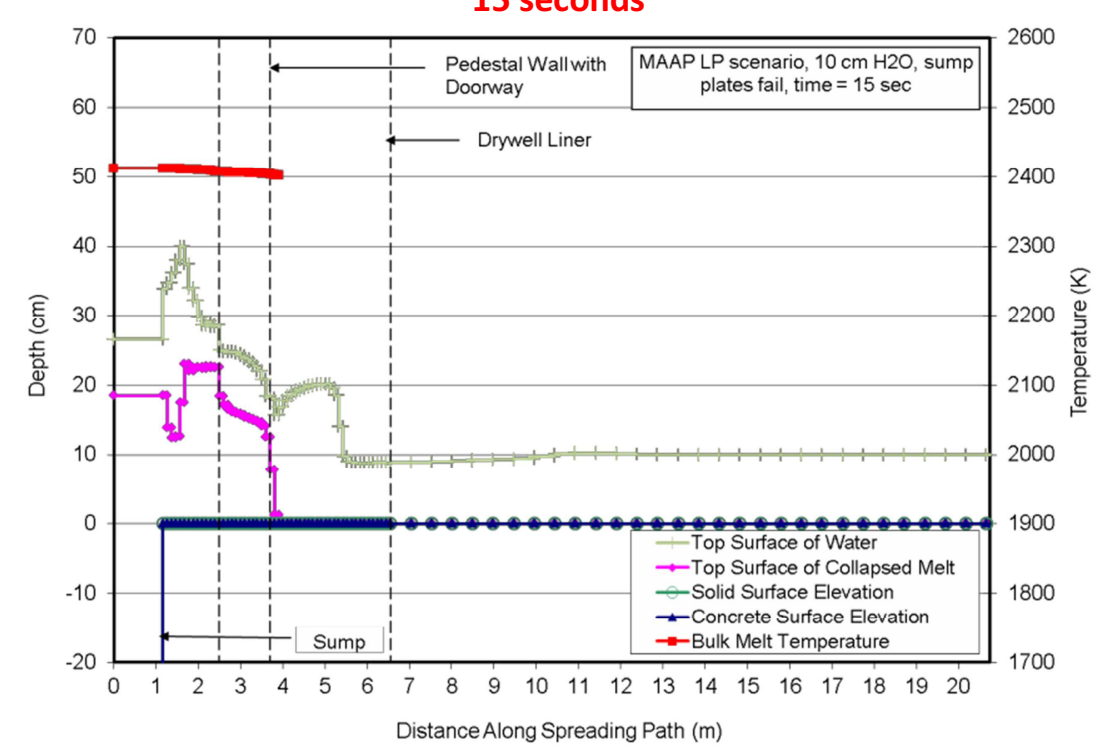

10 seconds

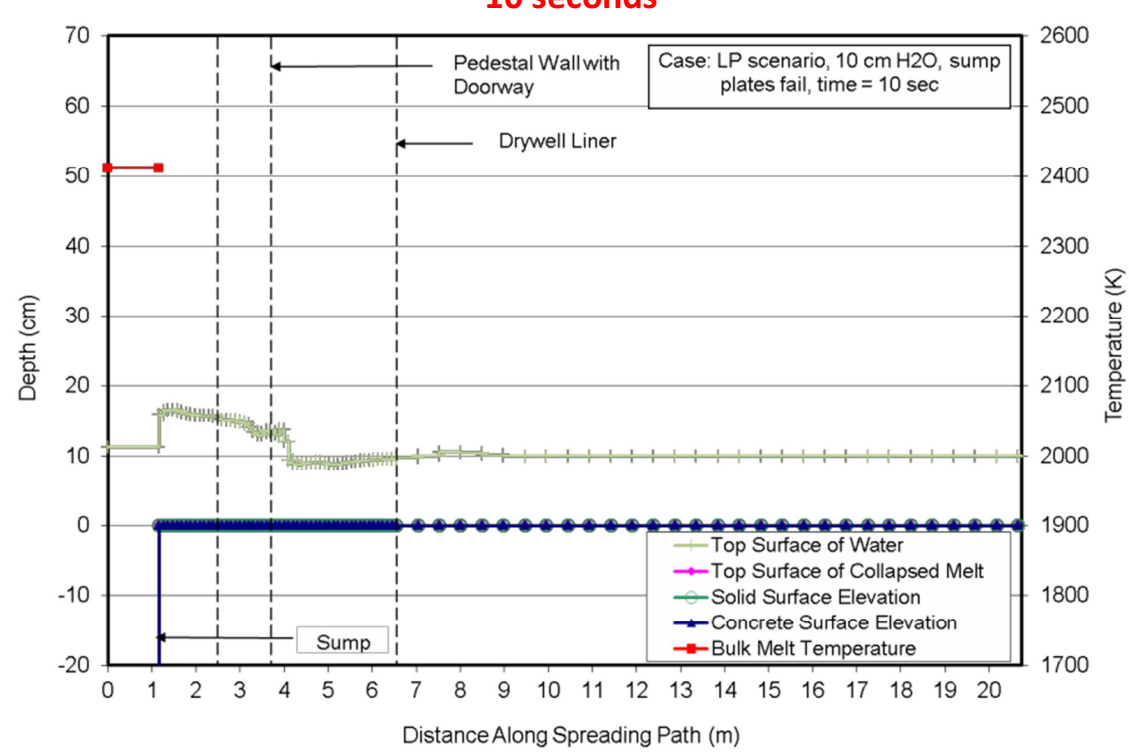

20 seconds

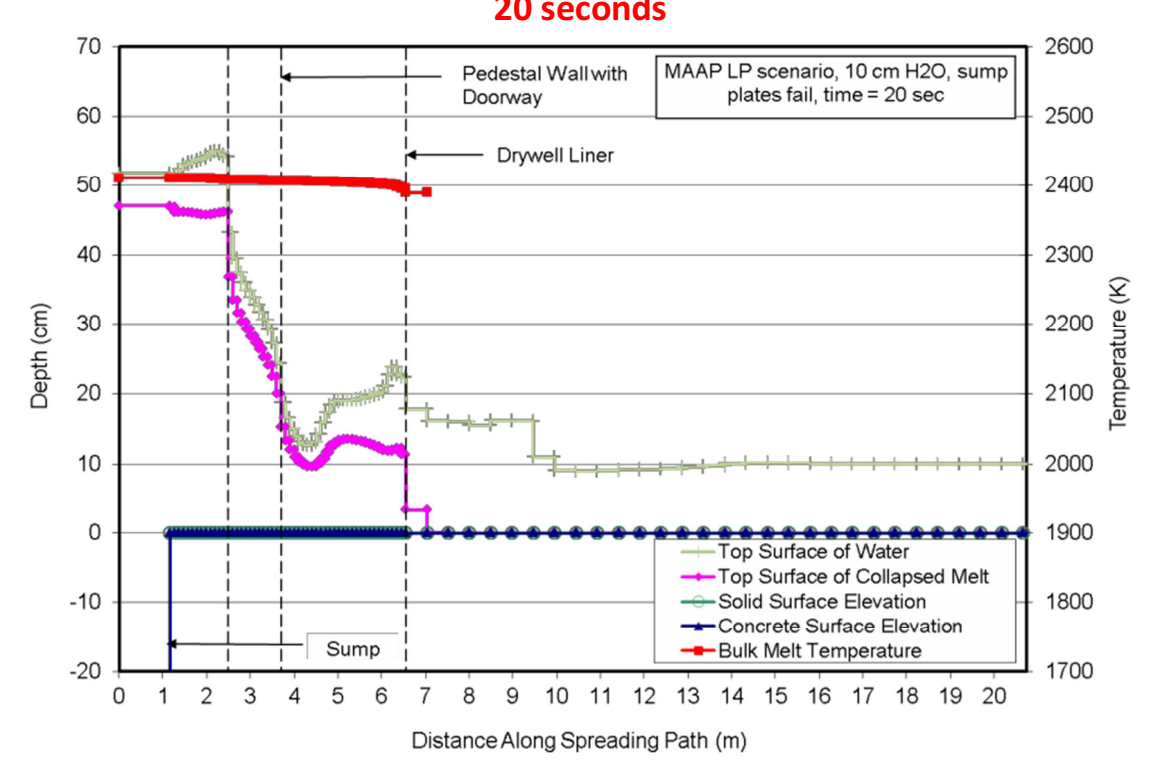

Figure 6-6. Melt Temperature-Depth and Water profiles at Sequential Times for MAAP Scenario. 


\section{5 seconds}

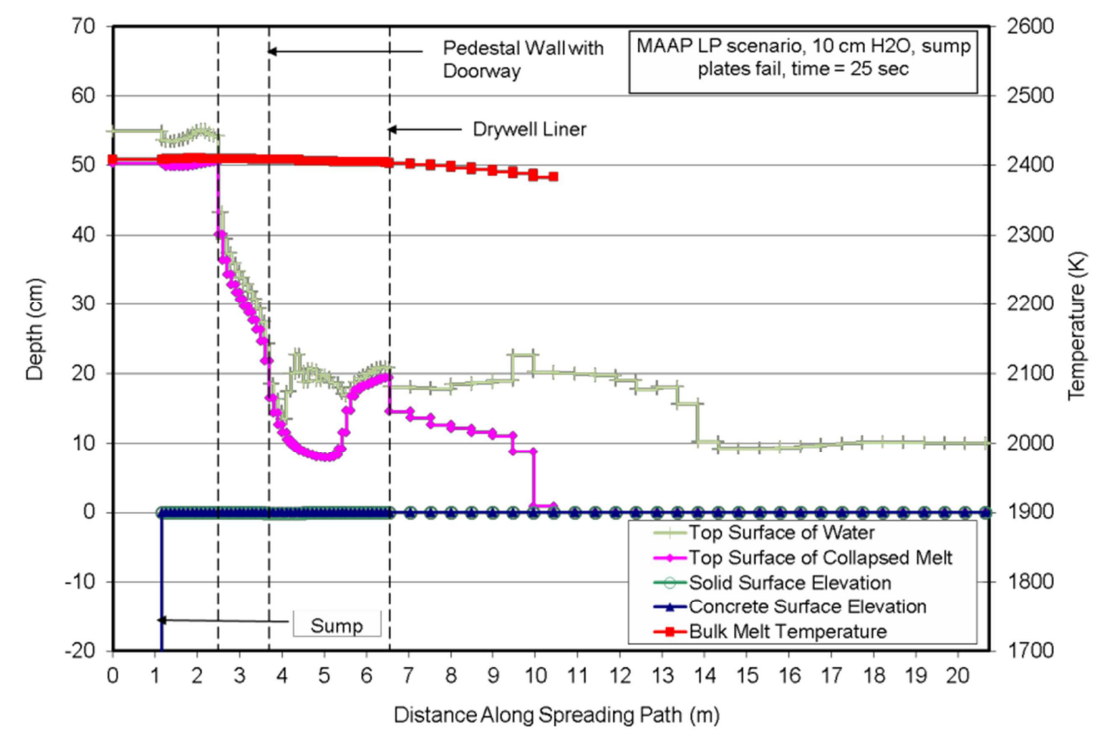

60 seconds

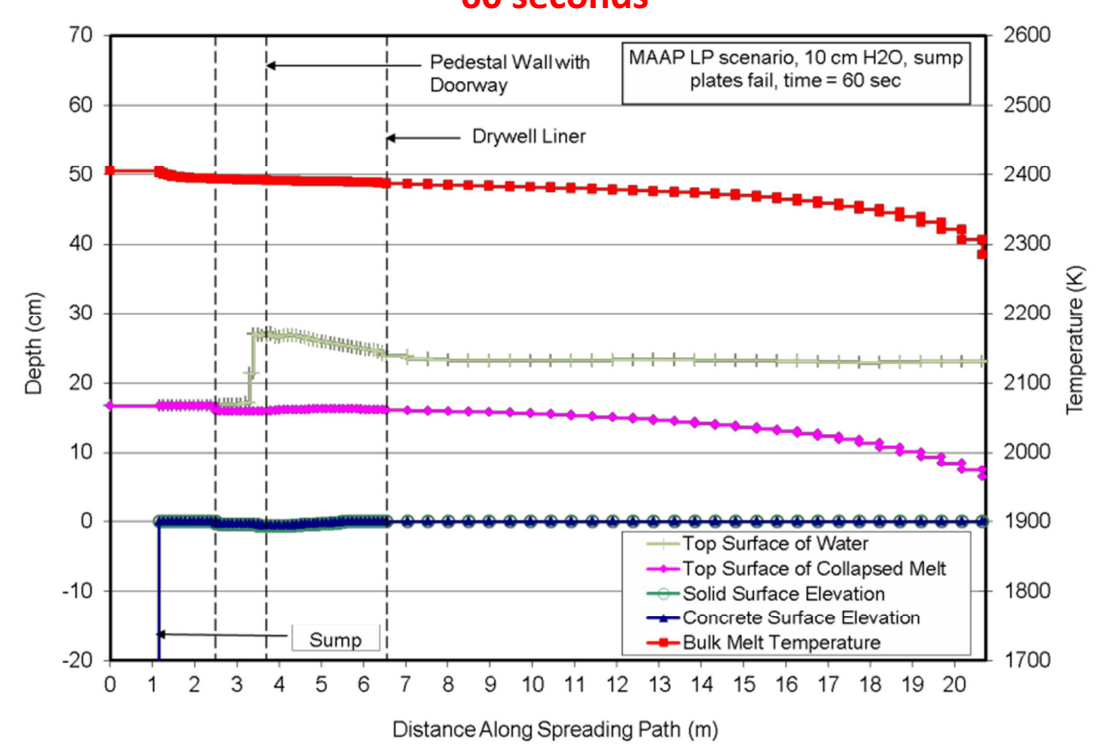

30 seconds

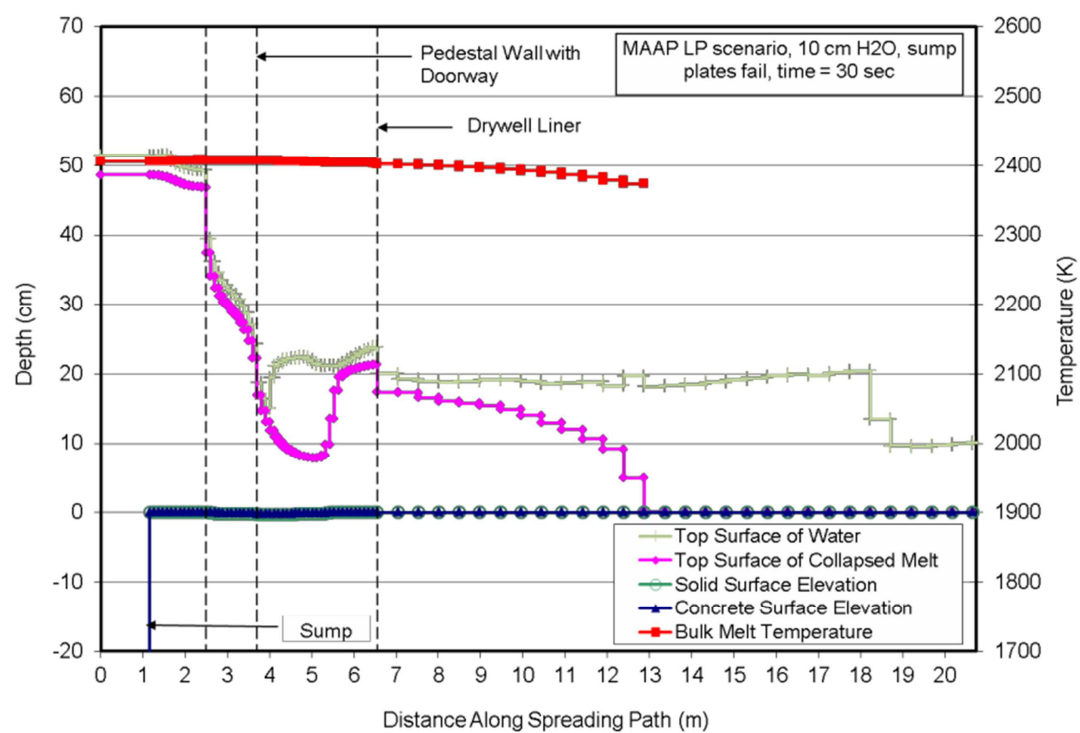

120 seconds

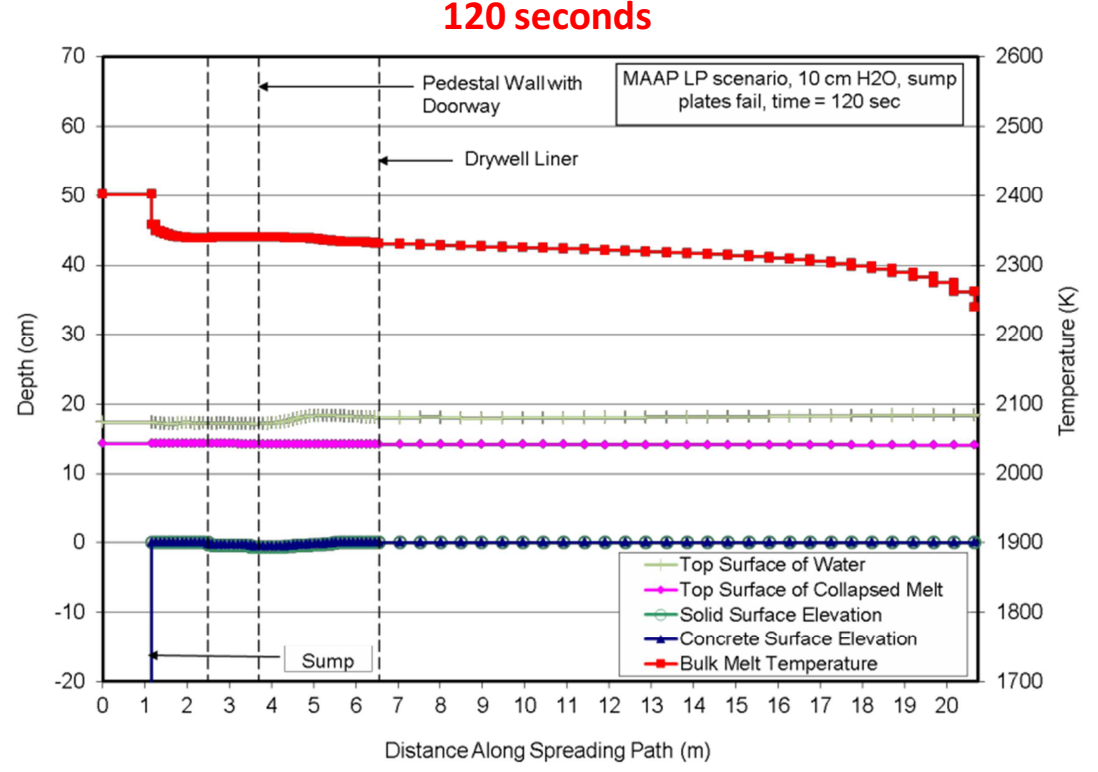

Figure 6-6 (contd.). Melt Temperature-Depth and Water profiles at Sequential Times for MAAP Scenario. 


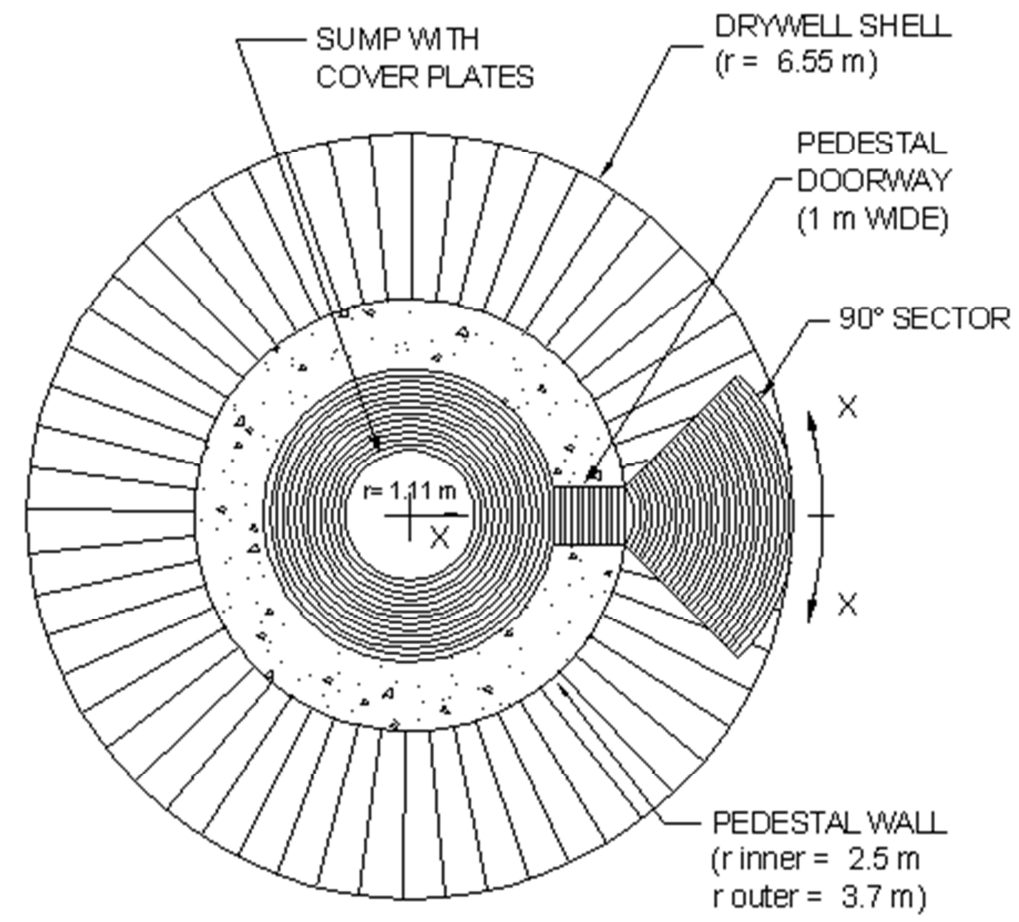

Figure 6-7. Fukushima Unit 1 Containment Nodalization Scheme.

As is evident from Figure 6-6, the sudden introduction of the core melt results in hydraulic forces that produce waves/sloshing behavior in the overlying water layer. The coupling of water displacement and boiloff in the sump region results in oscillations in water level that produce the oscillations in jet fragmentation fraction shown in Figure 6-2. As noted earlier, the downcomer spillover level was set to $60 \mathrm{~cm}$ in this analysis (same as Peach Bottom). As is evident from Figure 6-6, although there is sloshing, the water level does not locally reach the spillover height, and so there is no water loss into the downcomers for this particular case during the spreading transient.

In order to provide a basis for the long-term debris coolability analyses with CORQUENCH, the final core debris distributions at the end of the spreading phase for the MAAP and MELCOR pours are shown in Figure 6-8. For this particular MELCOR case, jet fragmentation was not modeled. This is due to the fact that CORQUENCH (as well as all other MCCI models known to the authors) is currently not able to analyze onset of MCCI under conditions in which the material distribution is dominated by a large particle bed. We hope to address this feature in future work.

Figure 6-8 allows post-spreading melt distributions with the enhanced water inventory model to be compared with results obtained previously [3] using a constant water height assumption. For the MAAP case, the fundamental prediction of uniform spreading has not changed. However, the model does predict dryout of the water inventory by $\sim 3$ minutes after pour inception, and so there is a period of dry cavity ablation prior to reflood that was initiated at 16.29 hours [22,23]; see Section 6.2. 

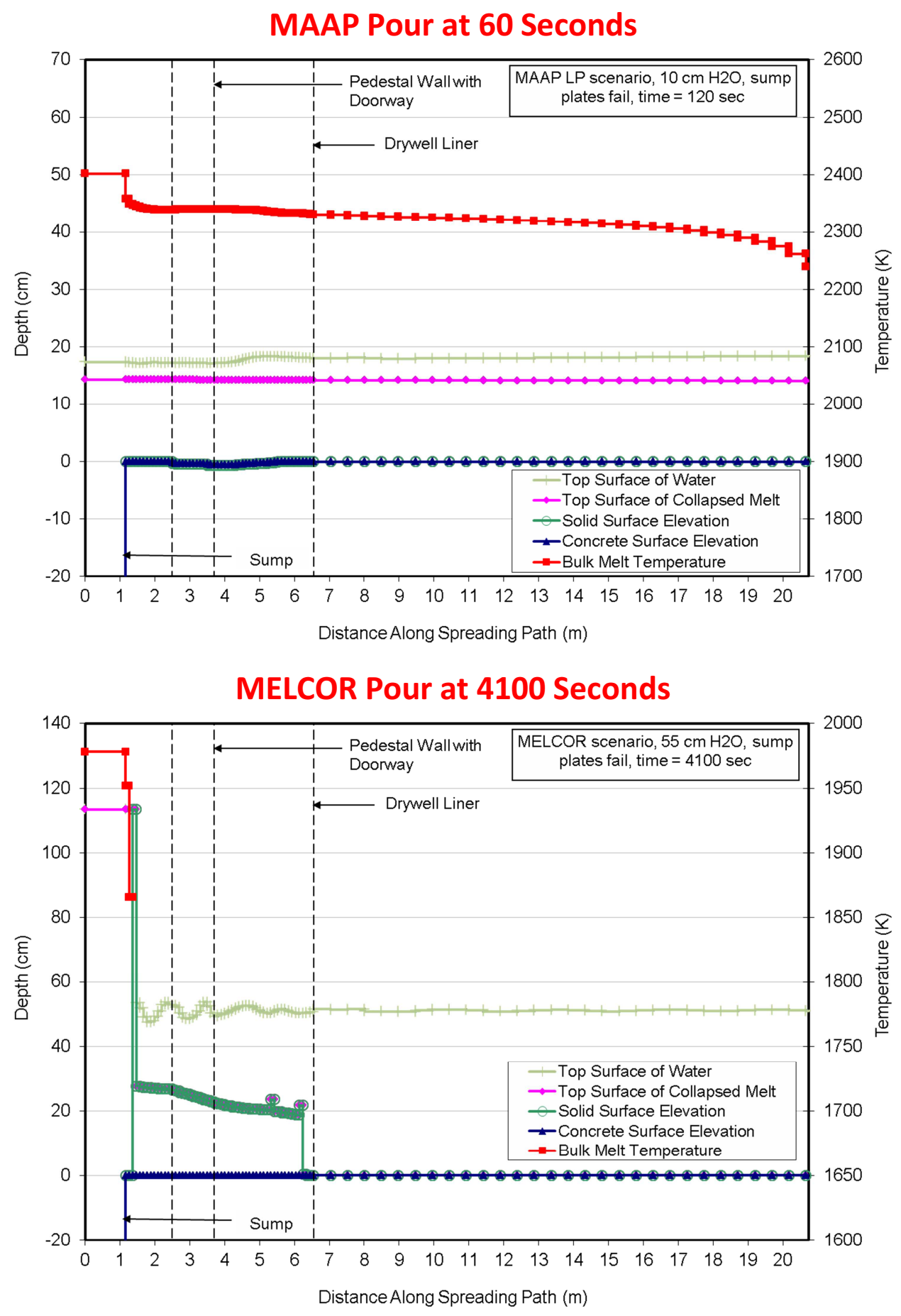

\section{Figure 6-8. Post-Spreading Melt Distributions for MAAP (top) and MELCOR (bottom) Pour Conditions.}

For the MELCOR case, there is a slight reduction in the extent of spreading which is principally due to enhanced cooling to subcooled water, as opposed to the assumption of a saturated water pool that was made in the previous work [3]. Although the reduction in spreading area is small, it is substantial in terms of potential impact on containment integrity. In 
particular, in the previous work [3] the melt was predicted to contact the liner outside the pedestal doorway, but spreading was very limited past that point. Due to contact with melt, shell heatup was substantial [3]. However, in this case, the melt is predicted to stop just short of the liner, and so thermal attack would be limited to radiation heat transfer from the melt to the liner before the cavity was flooded.

From the distributions shown in Figure 6-8, one additional insight related to accident management can be reinforced, and this relates to the location of water injection. In particular, due to the prediction of uniform melt spreading for the MAAP scenario, water injection either through the reactor vessel or by drywell sprays would be able to cover the core debris and cool the material as long as the injection flowrate was high enough. However, for the MELCOR case, if drywell sprays were used only the material that has spread out the doorway would be cooled, and the large accumulation of material in the pedestal would not be covered. This is due to the fact that the core debris depth in the pedestal is greater than the downcomer inlet height of 60 $\mathrm{cm}$. Thus, water injected in the drywell would gradually build up to the downcomer inlet and then spillover before being able to cover the material in the pedestal. In contrast, injection through the reactor vessel (i.e., through the hole in the bottom of the RPV) would offer the opportunity to cool the material in the pedestal before any water that was not boiled away would spill over into the drywell.

\subsection{CORQUENCH Results}

Results from the MELTSPREAD analyses of MAAP and MELCOR pours were used to define initial conditions for long-term debris coolability analysis with the upgraded multi-nodal version of CORQUENCH developed as part of this work. As noted earlier, a script was written that takes the MELTSPREAD output and prepares the CORQUENCH input given user-defined modeling choices that includes the desired nodal layout for the containment, and assumptions regarding the cavity ablation model to be used for each node. Specifically, the script takes the spatially dependent ablation depth data and melt/solidified debris distributions calculated by MELSTSPREAD and writes that information into a format that can be imported directly into the CORQUENCH input file. In the MELTSPREAD simulation, 84 nodes were used to discretize the containment (Figure 6-7). In the CORQUENCH analysis, the MELTSPREAD discretization was collapsed into twelve nodes as follows:

- The same sump model used in the MELTSPREAD analysis was repeated for CORQUENCH; i.e., the two sumps were mocked up as a single cylindrical node of equal volume; the 2-D (radial-axial) cylindrical cavity erosion model was used for this node.

- The balance of the pedestal floor outside the sump was modeled as a single node using the 2-D rectilinear cavity model with the side facing the sump treated as adiabatic (since lateral ablation at this interface is modeled in the sump simulation); ablation of the other wall was modeled, with this surface corresponding to the inner surface of the pedestal. 
- The pedestal doorway was modeled as a single node using the 2-D rectilinear cavity model with both sidewalls (corresponding to the inner surfaces of the pedestal doorway) undergoing ablation.

- The spreading area corresponding to the $90^{\circ}$ sector outside the pedestal doorway in the MELTSPREAD simulation (see Figure 6-7) was collapsed into a single node; the 2-D rectilinear cavity erosion model was used with the side facing the drywell liner treated as adiabatic, and the other side (that corresponds to the pedestal outer wall in the region of the doorway) treated as undergoing ablation.

- The balance of the drywell annulus was mocked up as a linear channel that was discretized into 8 nodes of uniform size. The width of these nodes was set equal to twice the drywell annular width as flow symmetry (with respect to the water inventory spreading model in CORQUENCH) is assumed. For the MAAP case in which these nodes were occupied by melt (see Figure 6-8), each node was modeled using the 2-D rectilinear cavity erosion model with the side facing the drywell liner treated as adiabatic, and the other side (that corresponds to the pedestal outer wall) treated as undergoing ablation. Every other node in the annulus was assumed to have a downcomer where spillover could occur to the torus if the water depth locally exceeded $60 \mathrm{~cm}$.

- For the MELCOR simulation in which melt only flowed part of the way out of the pedestal doorway, all the nodes in the drywell annulus past the doorway were treated as inactive, which means that water could collect and flow within these nodes (with the water inventory treated as adiabatic therein), but MCCI was not analyzed. The same assumption regarding the downcomers was made for these inactive nodes as was made for the MAAP case (see above bullet).

With respect to treating the liner as adiabatic for the MAAP case, this is admittedly a poor modeling assumption. However, CORQUENCH does not currently have the ability to evaluate heat transfer to the liner during MCCI. This is an upgrade that is outside the current scope of work.

Other information required to carry out the analysis includes cavity water flooding location, flooding rate, inlet temperature, and cavity pressure. TEPCO's best estimates of cavity flooding rate and pressure are shown in Figures 6-9 and 6-10, respectively [22,23]. Consistent with the TEPCO accident management procedure, water injection was through the RPV (i.e., onto the top of the core debris in the sump node); inlet water temperature was assumed to be 293 K. The plants at Daiichi were constructed using siliceous concrete; steel reinforcement was assumed to be present at a (typical) level of $6 \mathrm{wt} \%$; the exact level at these plants is not known. Modeling the reinforcement is important from the viewpoint of predicting long-term combustible gas production (viz. $\mathrm{H}_{2} / \mathrm{CO}$ ) from $\mathrm{MCCI}$ in the event that the core debris is not quenched. Finally, the cases were run with the CORQUENCH [17] melt eruption and water ingression models activated so that there is the possibility of quenching/stabilizing the core debris if sufficient water is injected. 
Key results from the MAAP simulation are provided in Figures 6-11 to 6-13 which show integral water inventory, power, debris mass distributions, noncondensable gas generation, and final debris configuration after the debris is predicted to be quenched after 107 hours of interaction.

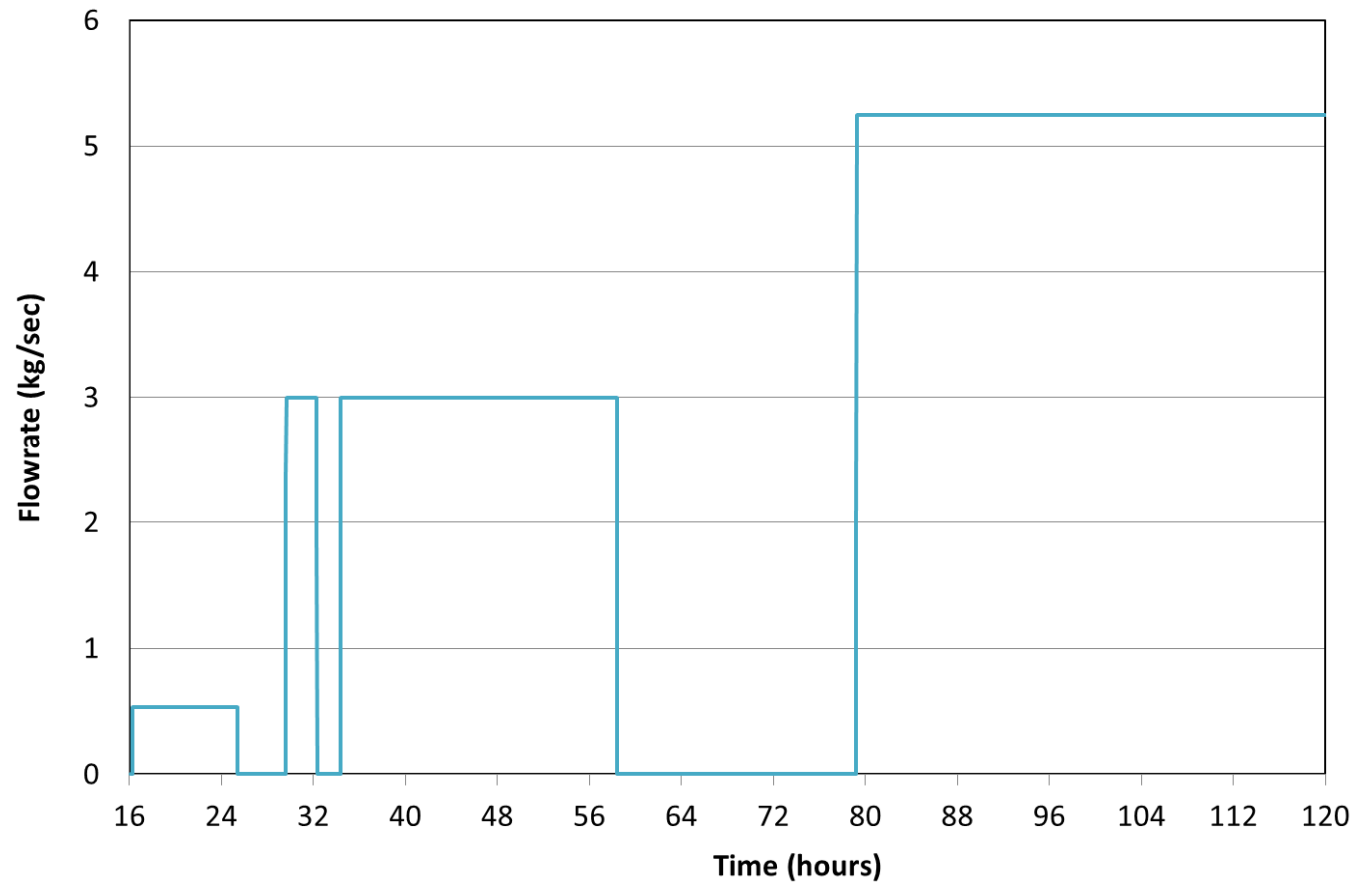

Figure 6-9. Best-Estimate of 1F1 RPV Flooding Rate (Courtesy of TEPCO [22,23]).

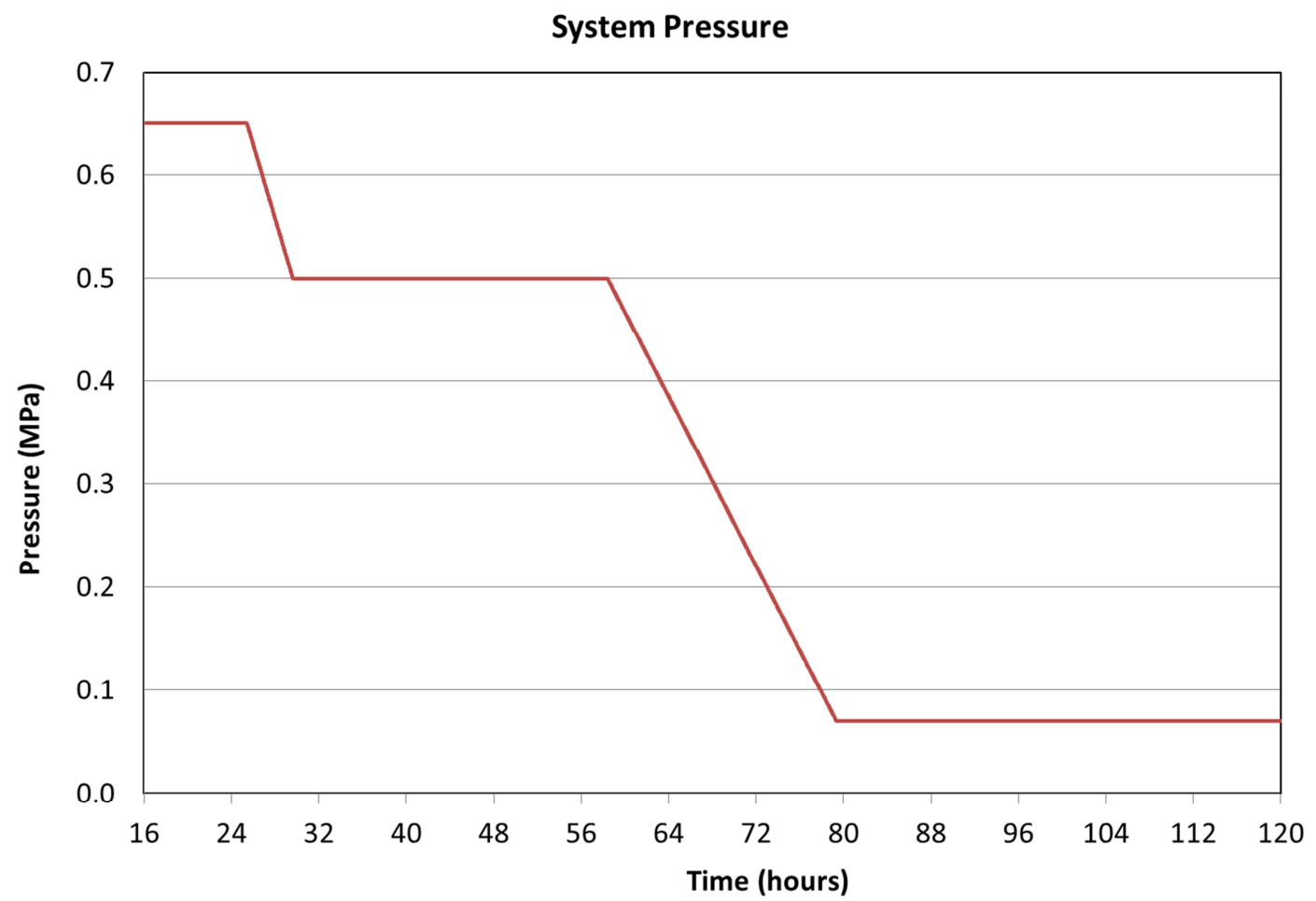

Figure 6-10. Best-Estimate of Containment Pressure Variation (Courtesy of TEPCO [22,23]). 


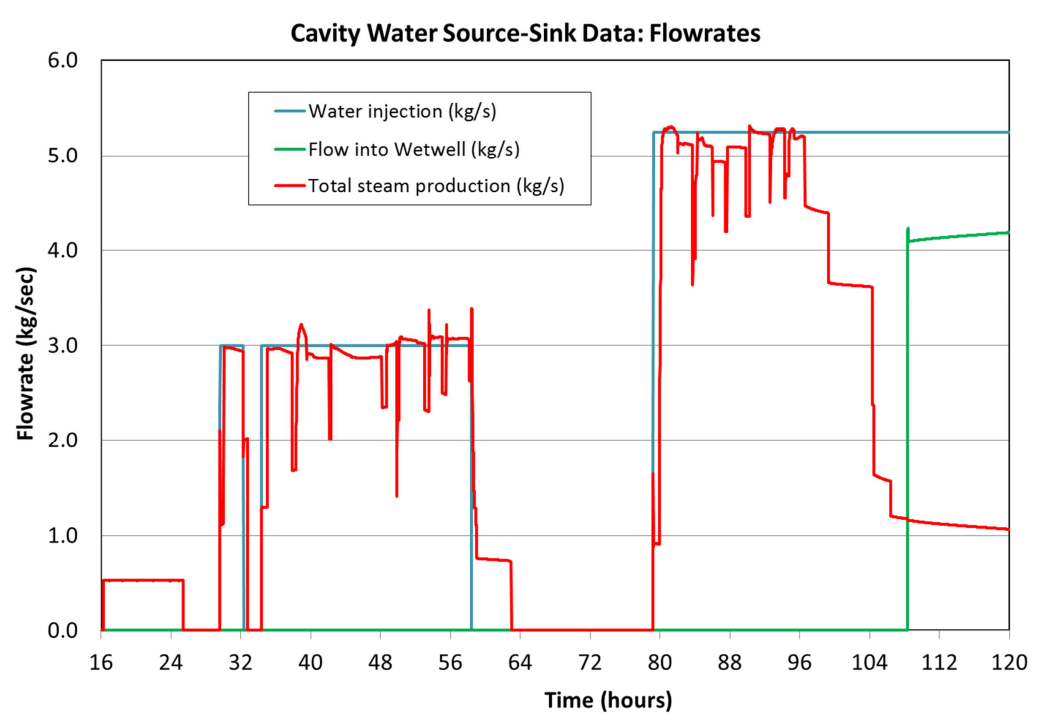

(a)

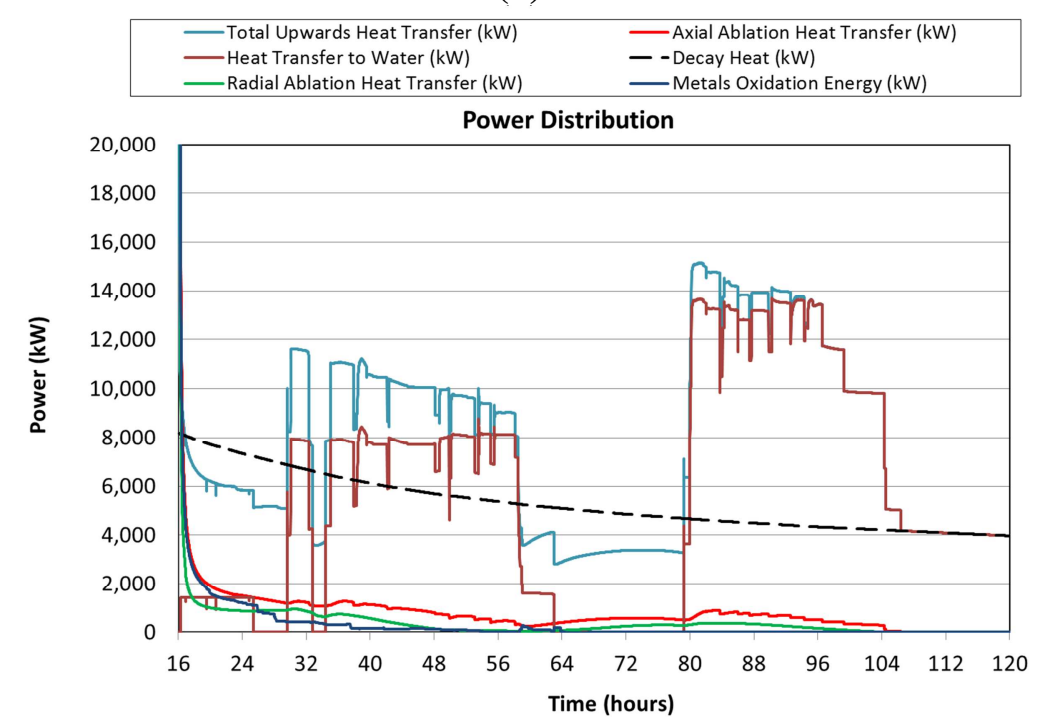

(c)

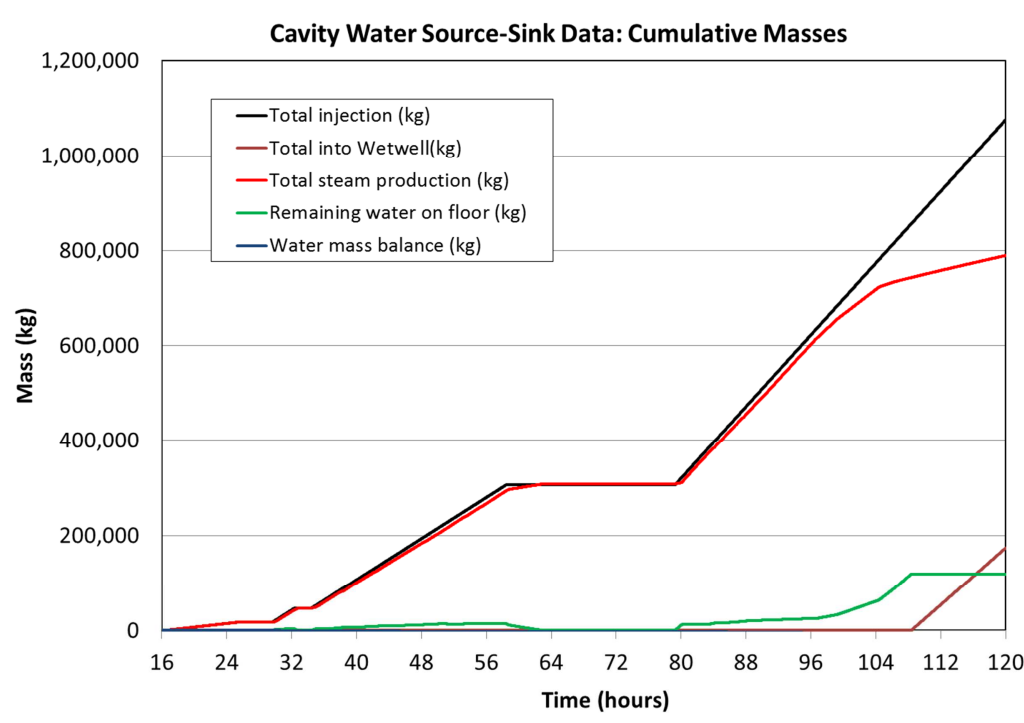

(b)

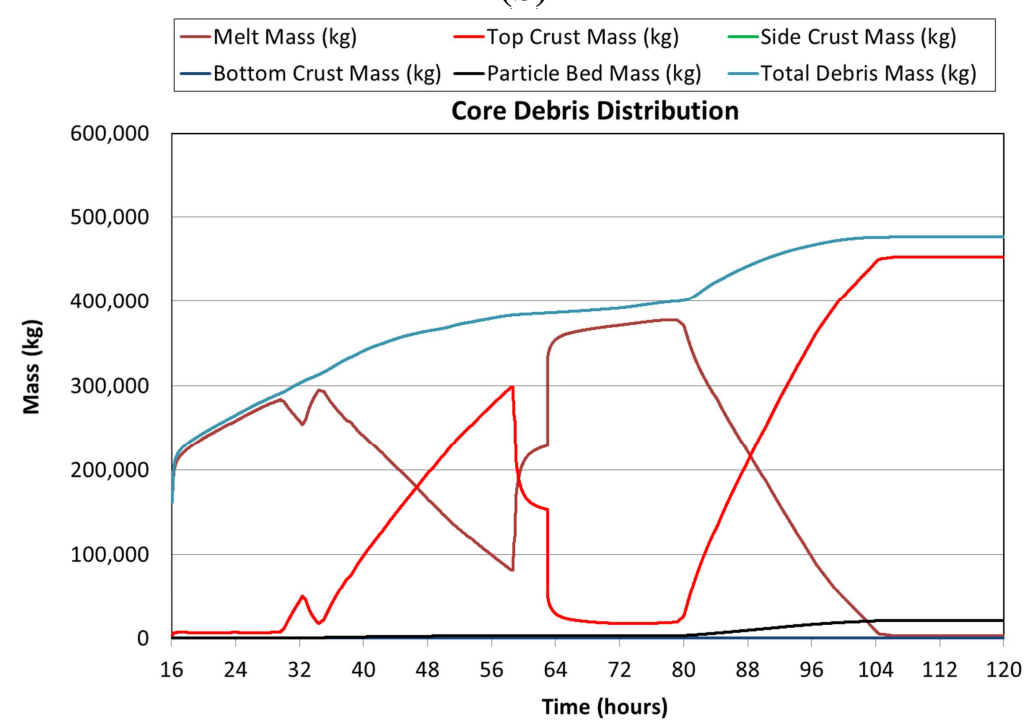

(d)

Figure 6-11. Principal Integral Results from MAAP Simulation: (a) Water-Steam Flowrates and (b) Masses; (c) Power Distribution, and (d) Core Debris Mass Distribution. 


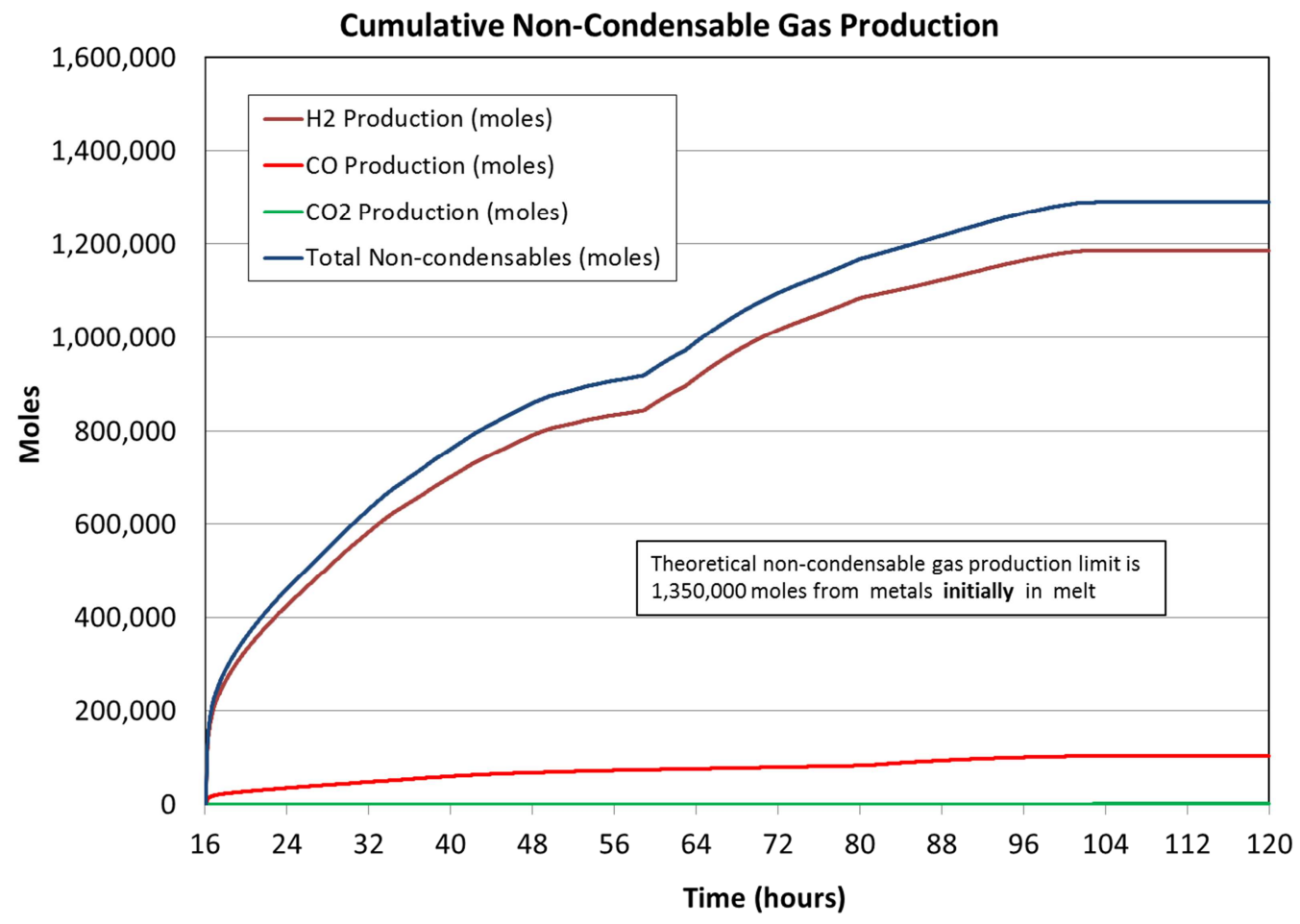

Figure 6-12. Cumulative Noncondensable Gas Production for MAAP Simulation.

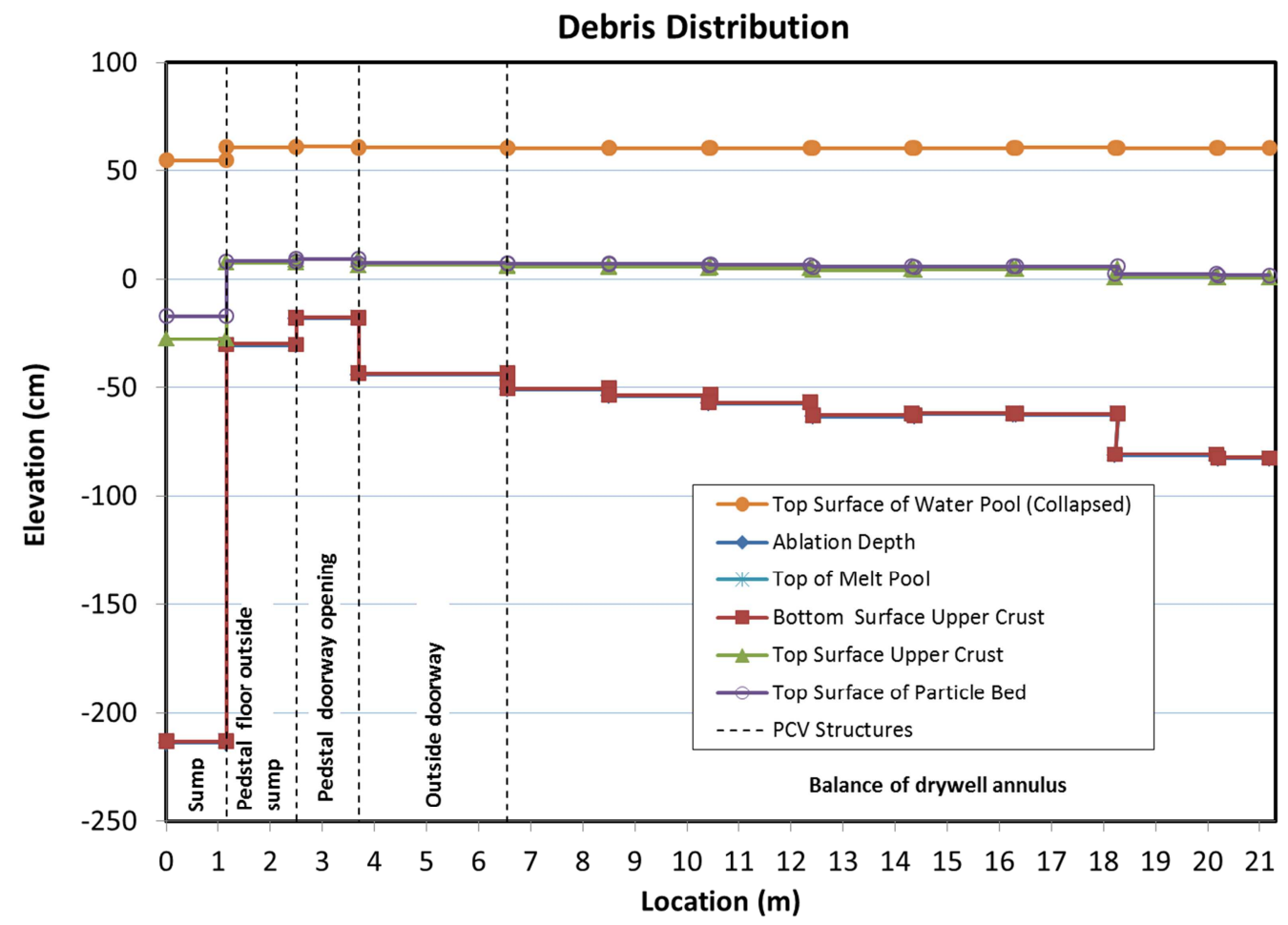

Figure 6-13. 1F1 Final Ex-Vessel Debris Configuration Based on MAAP Simulation: Quenched and Stabilized After 107 hours. 
Some general observations regarding predictions for this accident sequence are as follows. As is evident by comparing Figure 6-9 to Figures 6-11(a) and (b), the core debris cooling process was water-starved over the first 80 hours. As shown in Figures 6-11(c) and (d), the debris was almost quenched at 58 hours, but loss of water injection at that time lead to gradual boiloff of the water inventory, remelting of the core debris, and restart of MCCI. Finally, at 80 hours the operators were able to initiate substantial and sustained water injection, leading to gradual quench of the core debris over the course of the following day. Finally, at 107 hours, the core debris was predicted to be fully covered with water and quenched, thus terminating the exvessel phase of the accident sequence. Due to limited water injection and almost complete boiloff, the cavity is not flooded up to the downcomer inlets until $\sim 108$ hours after the accident was initiated (see Figure 6-11(b)).

The combustible gas generation due to MCCI follows the general trend one would expect from the quenching behavior (Figure 6-12). Note that the absence of combustible gases from MCCI was verified by TEPCO through analysis of PCV gas samples in August of 2011 [24].

The cavity axial erosion profile at termination of the accident (Figure 6-13) is reflective of the fact that the quenching process was water starved during much of the accident sequence. The axial erosion depth in the sump is noted to be $\sim 100 \mathrm{~cm}$ (note: original sump depth was 120 $\mathrm{cm}$ ). Somewhat surprisingly, a rather deep erosion depth of $\sim 80 \mathrm{~cm}$ is predicted in the drywell annulus diametrically opposite the pedestal doorway. This is due to the fact that water was boiled off as it flowed over the core debris out through the pedestal door and into the annulus, with insufficient flow to fully cover the debris clear to the back of the annulus during much of the accident (see Figures 6-11 (a) and (c)).

Not shown in Figure 6-13 is the extent of radial ablation predicted by this analysis. The cases presented herein were executed with a 3:1 radial-axial heat transfer coefficient multiplier, which is indicative of power split observed in MCCI tests with siliceous concrete [21]. On that basis, radial ablation is substantial, with nearly $200 \mathrm{~cm}$ of radial ablation predicted in the sump region, and $170 \mathrm{~cm}$ predicted in the pedestal wall at the back of the annulus. Thus, based on the results of this study, the pedestal would have been effectively undercut by the time the core debris was stabilized (see Figure 6-7; pedestal wall thickness is $1.2 \mathrm{~m}$ ). However, this prediction needs to be compared with actual plant observations [24] that indicate that the core debris was not able to spread to the back of the annulus. Furthermore, observations of the exterior of the pedestal wall $\sim 130^{\circ}$ from the pedestal doorway do not indicate any damage to the pedestal wall that one would expect if the wall was significantly attacked by core melt from the inside.

The analogous set of results from the MELCOR simulation are provided in Figures 6-14 to 6-16 which show integral water inventory, power, debris mass distributions, noncondensable gas generation, and final debris configuration after the debris is predicted to be quenched after 108 hours of interaction. Unlike the MAAP case, there was a significant water layer $\sim 0 \mathrm{~cm}$ deep at the start of the interaction; see Figure 6-8. As discussed in Section 6.2, the MELTSPREAD results indicated a substantial amount (i.e. $~ 60 \%$ ) of debris fragmentation due 


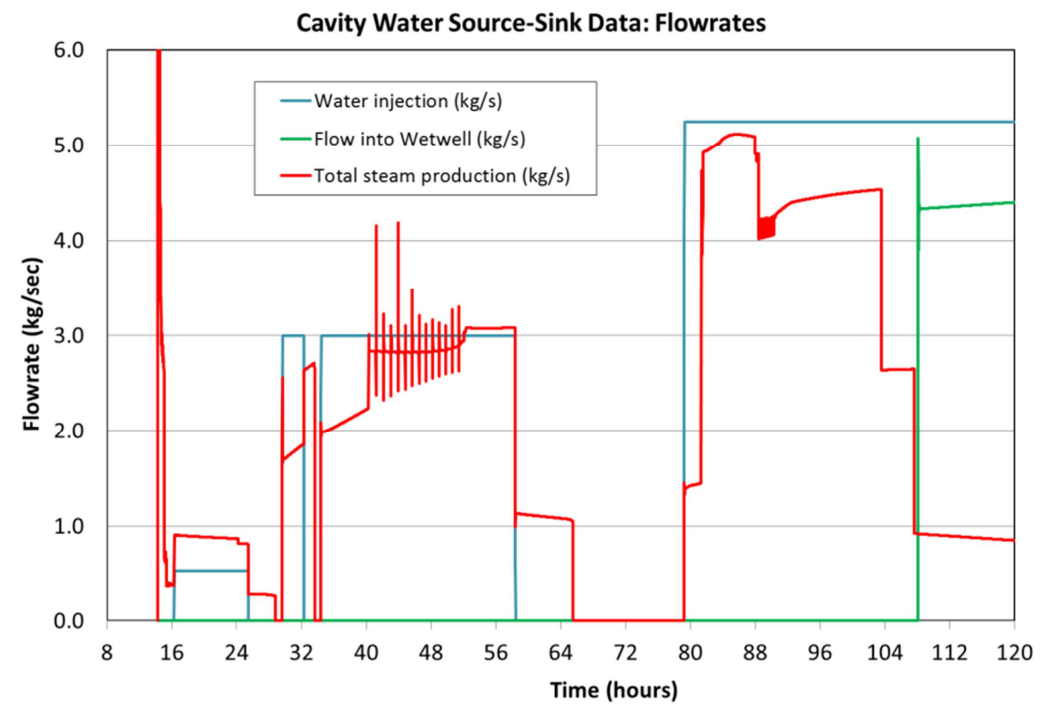

(a)

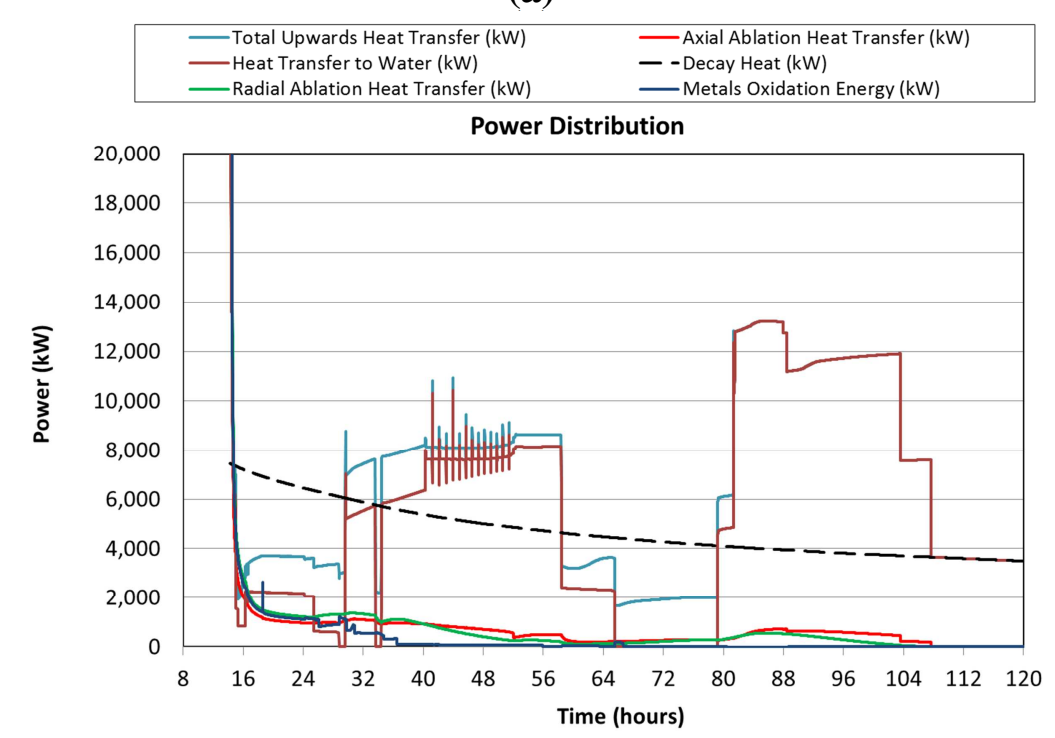

(c)

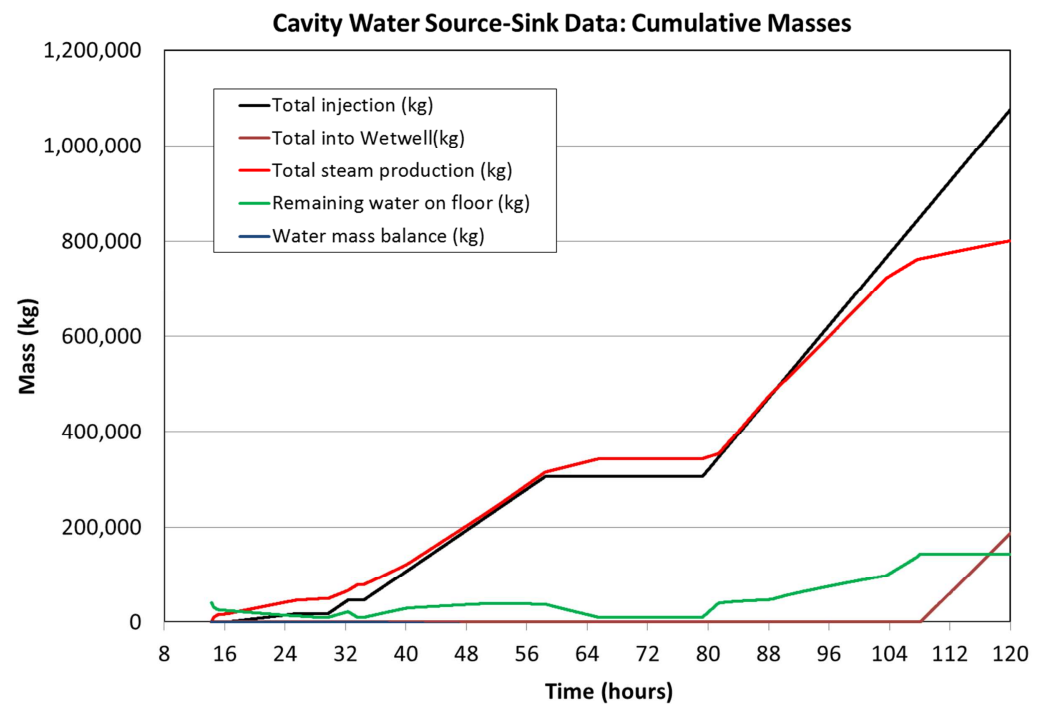

(b)

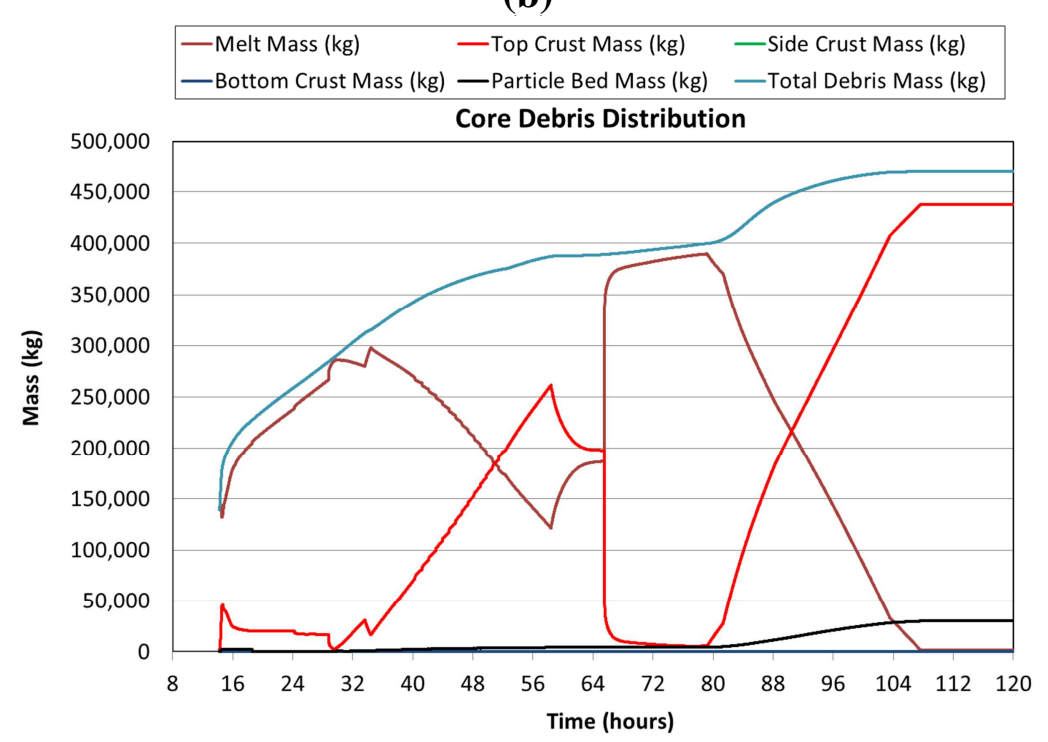

(d)

Figure 6-14. Principal Integral Results from MELCOR Simulation: (a) Water-Steam Flowrates and (b) Masses; (c) Power Distribution, and (d) Core Debris Mass Distribution. 


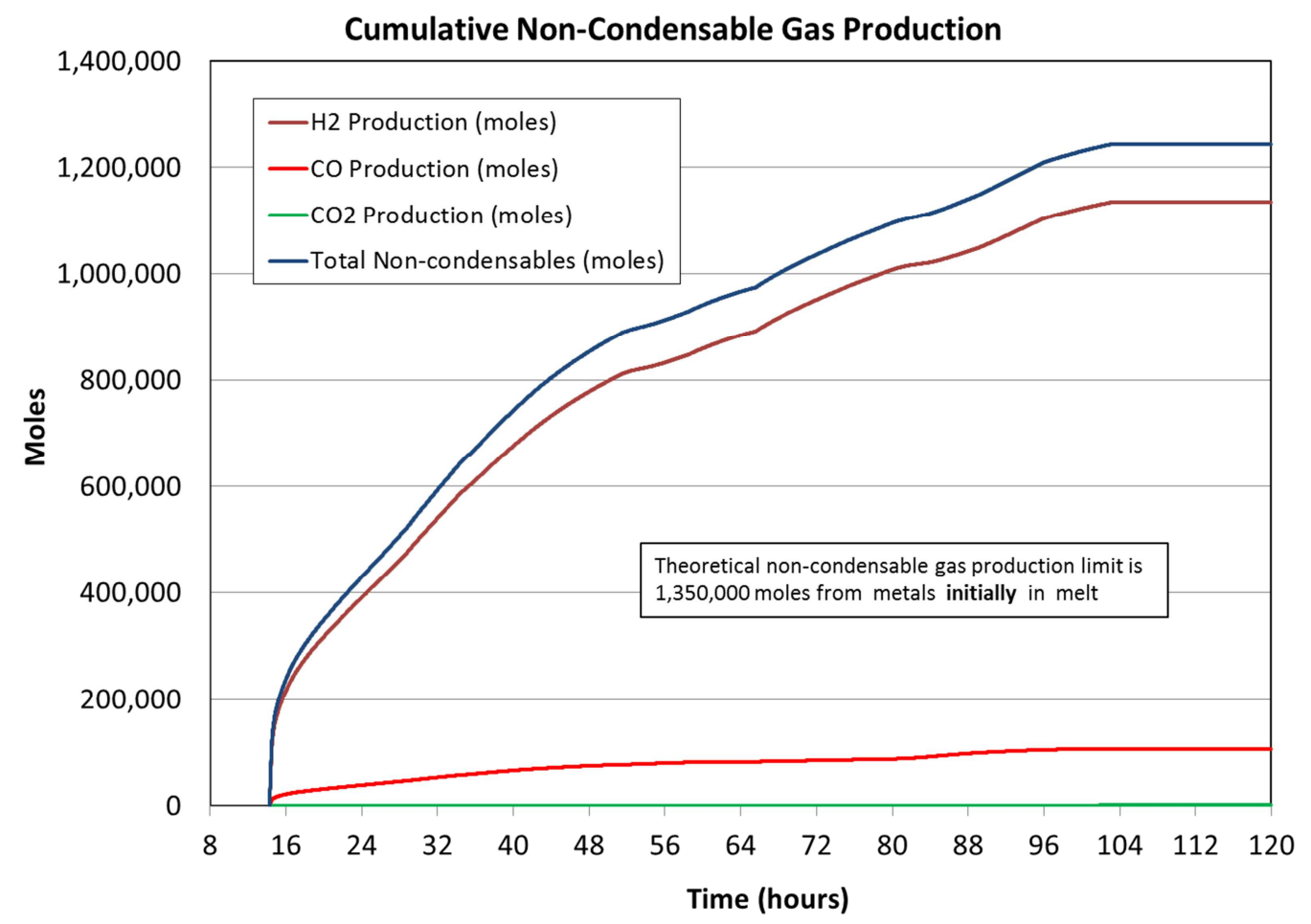

Figure 6-15. Cumulative Noncondensable Gas Production for MELCOR Simulation.

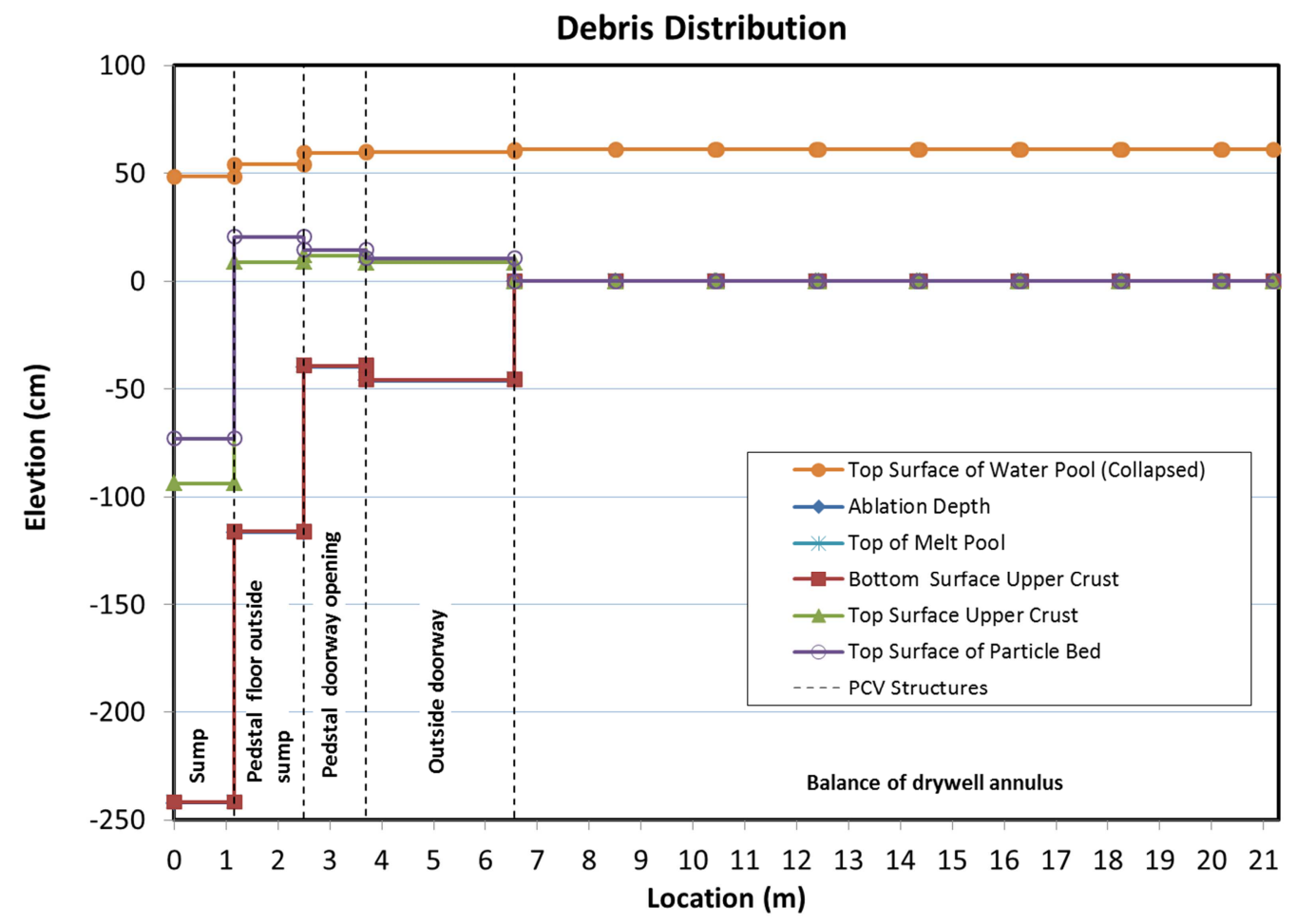

Figure 6-16. 1F1 Final Ex-Vessel Debris Configuration Based on MELCOR Simulation: Quenched and Stabilized after 108 hours. 
to melt stream breakup during the pour phase. This type of initial condition lies outside the scope of what CORQUENCH can currently model, and so this particular case was run using the initial conditions calculated when jet breakup is neglected.

The first observation is that despite the large differences in core debris distribution between MAAP and MELCOR, to first approximation the results are surprisingly similar. One difference is that due to the large accumulation of core debris in the sump for this case, axial ablation is increased to $\sim 120 \mathrm{~cm}$ before the debris is stabilized (Figure 6-16). As an additional byproduct of this deep accumulation, there is significant slumping (i.e. reduction of debris upper surface elevation) of the core debris in the sump over the course of the interaction due to three factors; i.e. : i) concrete densification upon melting (loss of mass due to off-gassing of concrete decomposition gases, as well as the fact that slag byproducts have a higher density than original concrete), ii) melt densification upon solidification (treated by the code), and finally iii) loss of melt mass to form a particle bed by the melt eruption mechanism; see Figure 6-14 (d). These factors lead to the formation of a depression in the sump region that acts as a bowl to collect water that drains from the RPV. As shown in Figure 6-14 (a), this limits the debris cooling rate due to the fact that water is collected in the depression, and the debris cooling rate therein is limited by the water ingression cooling rate over the reduced area covered by water. The upwards heat removal gradually increases due to rejection of decay heat from the crust to overlying water that continues to thicken by the water ingression cooling mechanism. This situation is illustrated in Figure 6-17 that shows the materials distribution at 38 hours. As is evident, the injected water is actively cooling the core debris in the sump, but the rim of corium at higher elevation on the pedestal floor as well as the material outside the pedestal doorway is not covered at this time. There is residual water on the floor in the drywell annulus that is not contributing to cooling as it is held back by the corium on the floor outside the doorway which effectively acts as a dam. The water level in the drywell was gradually boiled down to this point by cooling of the corium outside the doorway earlier in the transient. Naturally, there would be some (reduced) level of cooling where the water contacted the vertical surface of the corium dam, but since CORQUENCH treats the water cooling as 1-D from the top, this effect is not captured.

After water spillover begins from the depression in the sump region at $\sim 42$ hours, the overall core debris cooling behavior is noted to resemble that for the MAAP case (Figure 6-11). During the water addition phase beginning at $\sim 80$ hours, water was injected at a sufficient rate to fill the depression relatively rapidly, leading to a situation in which the core debris could be covered with water and begin to fill the drywell also. For this case, the ex-vessel core debris was predicted to be quenched and stabilized by 108 hours, which is close to the 107 hour prediction for the MAAP case. The time to stabilize is increased slightly for the MELCOR case due to the deeper melt accumulation in the sump region. 


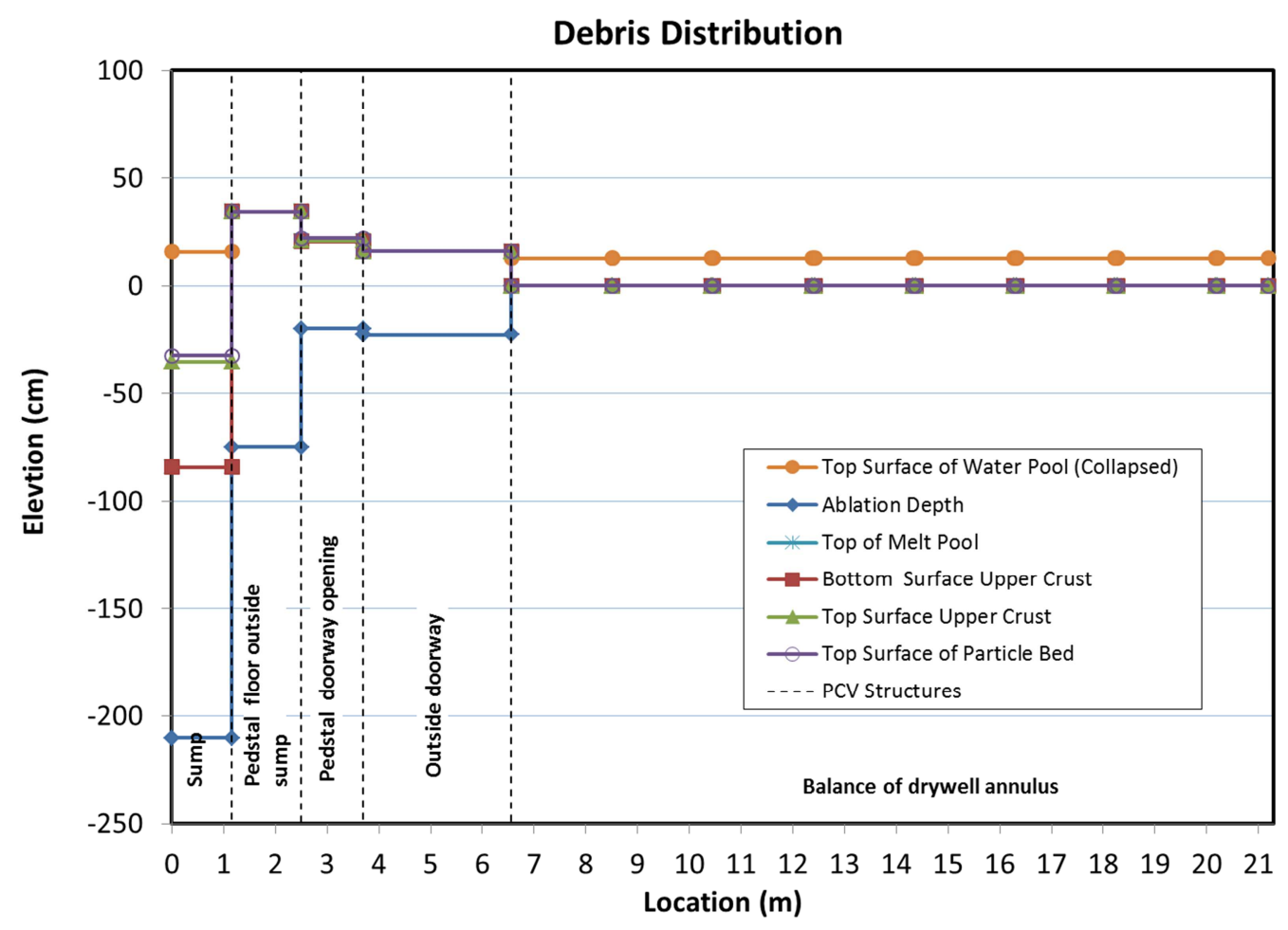

Figure 6-17. 1F1 Ex-Vessel Debris Configuration and Water Level at 38 Hours into the Accident Sequence Based on MELCOR Input.

As for the MAAP case, the combustible gas generation due to MCCI follows the general trend that one would expect from the quenching behavior (Figure 6-15). It is noted that the extent of gas generation based on the MELCOR simulation is slightly less than that predicted for MAAP (Figure 6-12). This is likely due to the decreased surface area of concrete in contact with the core debris for the MELCOR case; concrete decomposition gases drive the metals oxidation process that produces combustible gas.

Not shown in Figures 6-16 and 6-17 is the extent of radial ablation predicted by this analysis. Similar to the MAAP results, radial ablation is substantial, with $\sim 250 \mathrm{~cm}$ of radial ablation predicted in the sump region, and $\sim 240 \mathrm{~cm}$ predicted in the pedestal wall from the interior. This is noted to exceed the actual wall thickness (see Figure 6-7). However, as described previously, TEPCO examinations indicate no significant damage to the pedestal wall $\sim 130^{\circ}$ from the doorway. Thus, there are likely other factors to take into account, a few of which are discussed in Section 6.5.

\subsection{Insights from Updated Modeling}

During the course of this work, upgrades have been made to MELTSPREAD and CORQUENCH in order to provide a more realistic analysis framework for assessing SAWM strategies for BWRs. As a first step towards utilizing these new tools, a few scoping calculations have been carried out for the $1 \mathrm{~F} 1$ accident to determine if there are any new insights related to accident management over and above what was developed on the basis of earlier work [3]. These additional insights are outlined below. 
1) The current study has reinforced the previous observation that the location of water injection matters. The results of this work show that deep accumulations of core debris may develop in the pedestal for situations in which the core debris is released gradually from the reactor vessel and at low temperature. These accumulations are best cooled by water injection through the reactor vessel.

2) For situations in which the debris cooling rate is limited by the rate of water injection, non-uniform ablation patterns can develop in containment and the accident can progress such that only a portion of the core debris is covered with water. Substantial modeling efforts were made this year in order to capture this effect, and the results of these scoping calculations indicate that the upgraded codes are able to simulate this situation.

3) Regarding the effects of melt jet fragmentation, the results indicate that substantial fragmentation may occur for slow melt release rates, resulting in the formation of a large particle bed below the reactor vessel. This situation cannot currently be mocked up with most MCCI codes known to the authors, and that includes CORQUENCH.

4) Finally, preliminary analyses with an upgraded below vessel structure interaction model that includes an improved treatment of melt freezing and geometric effects (see Section 2.2) indicates that corium mass holdup in below vessel structure could be significantly higher than previously estimated [11]. Any debris that is held up in this structure would reduce the amount of cavity attack due to MCCI, particularly for cases in which the core debris is undercooled.

One interesting ancillary observation is drawn related to Point 3 above. For both the MAAP- and MELCOR-based simulations carried out within, extensive attack of the pedestal wall was predicted. This is predominately due to the significant reduction in the estimated water mass that was actually injected into the RPV during the accident [22,23]. One possible way that the current models could be made to better conform with plant observations that seem to indicate no significant attack of the pedestal wall (at least when viewed from the annulus [24]) is if a particle bed was formed during the melt relocation phase (as predicted in the MELCOR-based melt pour simulation), and if that bed could be effectively cooled by natural convection to the containment atmosphere during periods in which the cavity remained dry. Given the current state of modeling in CORQUENCH, we are not able to provide answers to this question.

\subsection{Additional Modeling Needs}

In terms of insights related to modeling of these long-term, water limited accident scenarios, we found that it is critical to be able to calculate local core debris quench, dryout, reheating, and transition back into MCCI in order to reasonably mock up these scenarios. A first order method was developed and implemented as part of this work, the results of which are illustrated in Figures 6-11(d) and 6-14(d). This approach basically treats crust remelting using a quasi-steady heat transfer approach, but as is evident from these figures, this approach leads to unrealistically fast remelting rates. To illustrate this, note that based on an adiabatic heat transfer analysis, the internal heating rate of core debris a few days after accident initiation is estimated to be of the order of $5 \mathrm{~K} /$ minute. On this basis, for debris that was previously quenched to water 
saturation temperature, it would take several hours for core debris to reheat to the melting point. Thus, for this type of scenario involving reheating of deep accumulations of previously quenched debris, sensible heat (i.e. heat capacity) effects needs to be modeled in the remelting material.

Another modeling need that was identified as work progressed is the ability to analyze heat transfer from particle beds after they have completely dried out. In order to move forward with the overall modeling goals, the beds are currently treated as adequately cooled as long as there is some degree of water left in the bottom of the bed. However, after the bed dries out the decay heat in the bed will offset, or possibly lead to heating, of the crust upper surface, thereby increasing the crust melting rate. For sufficiently deep beds, the beds themselves may reheat and melt. This is likely not a major factor for the current study as the amount of material rendered into the form of a bed by melt eruptions was relatively small (due to the low gas content of siliceous concrete). However, this could become a significant distortion for high gas concretes like limestone/common sand or limestone/limestone in which the extent of eruptions are substantial [21]. Related to this area (and discussed in Section 6.4), for low pour rate vessel failure scenarios, significant debris fragmentation is predicted if water is present on the cavity floor. This could be viewed as an initial condition for the MCCI analysis, and is currently not treated in CORQUENCH and most other MCCI codes.

Another point not fully appreciated at the start of this work was the extent that lateral ablation can alter the original cavity configuration that we have attempted to model using a fixed mesh approach. For example, in the MAAP analysis the cavity floor area is predicted to increase from $113 \mathrm{~m}^{2}$ to $181 \mathrm{~m}^{2}$ over the 107 hours of interaction, which amounts to a $60 \%$ increase. Currently, the water spreading model treats node spacing and flow arc lengths as constant, with the node surface area increased to account for lateral ablation. Thus, the meshing treatment needs to be improved. However, there is a larger distortion that is due to the fact that the nodes are treated as isolated and so there is no interaction. This approach needs to be improved particularly in the pedestal region where the sump node can grow to overtake the radial ring between the sump and pedestal wall. Thus, the nodes need to communicate and the meshing adjusted to provide a more realistic treatment when 2-D ablation is modeled at the interface between adjacent nodes.

With respect to the below vessel structure interaction model, potential areas of improvement were outlined in Section 2.2 and are reiterated here. The model is noted to be rather simplistic, and does not account for:

1) time (depth) depended properties of the frozen debris,

2) internal heat generation in the debris,

3) the finite size of the structures, and

4) the enhanced heat transfer due to the flowing melt. 
Addressing the first of these simplifications would provide for a more refined answer in the case of a pour with time dependent melt properties (i.e. an initial metallic pour followed by an oxidic pour). Addressing the second through fourth areas would likely lead to a reduction in the predicted melt mass freezing onto the structures. The splash model assumes all melt contacting horizontal members is 'splashed'. In reality, the amount of melt splashed depends on the velocity of the melt and as well as melt thermophysical properties (i.e. surface tension). Future versions of this model should account for these affects.

Going forward, this model will be integrated into the MELTSPREAD code and exercised for a range of melt pour conditions. A few of the modeling refinements noted above will likely be incorporated as the work progresses. 


\subsection{PLANNED FISCAL YEAR 2017 ACTIVITIES}

In FY17, the focus will be on validating the upgraded models against available data as well as data from new debris coolabilty tests underway at Argonne. In addition, it is planned to complete the documentation for these two codes to a level that the codes can be released for use by industry and R\&D organizations. Finally, we also plan to continue working with industry by carrying out analyses with these upgraded models aimed at supporting the development of optimized water throttling strategies for BWRs.

As noted in Section 6.5, several additional model improvements were identified as this work moved forward and the models were applied to the 1F1 accident scenario. These improvements will be pursued as funding allows. 


\subsection{REFERENCES}

1. Nuclear Energy Institute, "Industry Guidance for Compliance with Order EA-13-109," NEI 13-02, Rev. 2, December 2014 (ADAMS Accession No. ML13316A853).

2. E.J. Leeds, EA-13-109, "Issuance of Order to Modify Licenses with Regard to Reliable Hardened Containment Vents Capable of Operation under Severe Accident Conditions," USNRC, June 6, 2013.

3. K. R. Robb, M. W. Francis, and M. T. Farmer, "Enhanced Ex-Vessel Analysis for Fukushima Daiichi Unit 1: Melt Spreading and Core-Concrete Interaction Analyses with MELTSPREAD and CORQUENCH," ORNL/TM-2012/455 (2013).

4. M. T. Famer (editor), R. Bunt, M. Corradini, P. Ellison, M. Francis, J. Gabor, R. Gauntt, C. Henry, R. Linthicum, W. Luangdilok, R. Lutz, C. Paik, M. Plys, C. Rabiti, J. Rempe, K. Robb, and R. Wachowiak, "Reactor Safety Gap Evaluation of Accident Tolerant Components and Severe Accident Analysis,” ANL/NE-15/4, March 2015.

5. N. Yamano, Y. Maruyama, K. Moriyama, and J. Sugimoto, "Technical Note on ExVessel Core Melt Debris Coolability and Steam Explosions," NEA/CSNI/R(96)24, December 1996.

6. M. Saito et al., "Experimental Study on Penetration Behaviors of Water Jet into Freon-11 and Liquid Nitrogen," ANS Proc., National Heat Transfer Conference, pp. 173-183, Houston (1988)

7. M. Epstein and H. K. Fauske, "Steam Film Instability and the Mixing of Core-Melt Jets and Water," ANS Proc. National Heat Transfer Conference, Denver (1985).

8. B. W. Spencer. S. K. Wang, C. A. Blomquist, L. M. McUmber, and J. P. Schneider, "Fragmentation and Quench Behavior of Corium Me1t Streams in Water," NUREG/CR6133, ANL-93/32 (February 1994).

9. D. Magallon, I. Huhtiniemi, and H. Hohmann, "Lessons Learnt from FARO/TERMOS Corium Melt Quenching Experiments," OECD/CSNI Specialist Meeting on Fuel Coolant Interactions, NEA/CSNI/R(97)26, JAERI-Tokai-Mura, Japan, 19-21 May 1997.

10. T. G. Theofanous et al., "The Probability of Liner Failure in a Mark-I Containment," NUREG/CR-5423, 1991.

11. C. C. Chu, J. J. Sienicki, and B. W. Spencer, "The Effects of Below-Vessel Structure and Water on Ex-Vessel Melt Arrival Conditions in a Mark I Containment," NURETH-5, Salt Lake City, Utah (1992).

12. F. Incropera and D DeWitt, Fundamentals of Heat and Mass Transfer, J. Wiley and Sons, $5^{\text {th }}$ Edition (2002). 
13. K. Sato, et al., ““'Melting Attack of Solid Plates by a High Temperature Liquid Jet Erosion behavior by a molten metal jet," Nuclear Engineering and Design, Vol 132, pp 171-186, 1991

14. M. Saito, et al., "Melting Attack of Solid Plates by a High Temperature Liquid Jet Effect of Crust Formation," Nuclear Engineering and Design, Vol 121, pp 11-23, 1990.

15. M. T. Farmer, J. J. Sienicki and B. W. Spencer, "The MELTSPREAD-1 Computer Code for the Analysis of Transient Spreading in Containments," ANS Winter Meeting Session on Thermal Hydraulics of Severe Accidents, Washington, DC, November 11-15, 1990.

16. M. T. Farmer, "Modeling of Ex-Vessel Corium Coolability with the CORQUENCH Code," Proceedings 9th Int. Conf. on Nucl. Eng., ICONE-9696, April 8-12, 2001.

17. M. T. Farmer, "The CORQUENCH Code for Modeling of Ex-Vessel Corium Coolability under Top Flooding Conditions, Code Manual - Version3.03," OECD/MCCI-2010TR03, March 2010.

18. M. L. Corradini et al., "Reactor Safety Technologies Pathway Technical Program Plan," INL/EXT-15-35976, Revision 1, June 2016.

19. S. Lomperski and M. T. Farmer, "Experimental Evaluation of the Water Ingression Mechanism for Corium Cooling," Nuclear Eng. Design, Vol. 237, pp. 905-917, August 2006.

20. S. Lomperski, M. T. Farmer, and S. Basu, "Experimental Investigation of Corium Quenching at Elevated Pressure,” Nuclear Eng. Design, Vol. 236, pp. 2271-2280, 2006.

21. M. T. Farmer, S. Lomperski, D. J. Kilsdonk, and R. W. Aeschlimann, “OECD MCCI-2 Project Final Report," OECD/MCCI-2010-TR07, November 2010.

22. Tokyo Electric Power Company, Inc., "The 4th Progress Report on the Investigation and Examination of Unconfirmed and Unresolved Issues on the Development Mechanism of the Fukushima Daiichi Nuclear Accident," December 17, 2015. See: http://www.tepco.co.jp/en/press/corp-com/release/betu15_e/images/151217e0101.pdf

23. Tokyo Electric Power Company, Inc., "Evaluation into the Amounts of Water Injected to Unit 1 by Fire Engines," See: http://www.tepco.co.jp/en/press/corpcom/release/betu15_e/images/151217e0112.pdf

24. J. Rempe et al., "US Efforts in Support of Examinations at Fukushima Daiichi - 2016 Evaluations," ANL/LWRS/16-02, August 2016. 


\section{Argonne}

\section{NE Division}

Argonne National Laboratory

9700 South Cass Avenue, Bldg. \#208

Argonne, IL 60439

www.anl.gov 